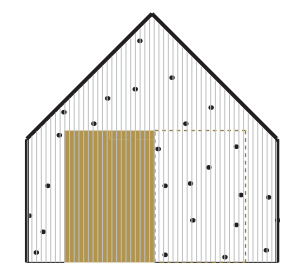

\title{
A HOUSE THAT GROWS ON THE INSIDE
}

By Amy Lane

A thesis submitted to the Victoria University of Wellington in partial fulfilment of the requirements for the degree of Master of Architecture (Professional)

Victoria University of Wellington

2018 
This page is intentionally left blank. 
With house prices rising so rapidly, many New Zealand families find the stretch to homeownership beyond them. It is now customary to hear of people unable to purchase a property for their needs, in relation to the size of the house, its location or both and the idea of homeownership is fast becoming a pipeline dream for most people. With large upfront costs and large mortgage repayments, the cost of purchasing or building a house is unaffordable for a growing number of the population (Aravena \& Lacobelli, 2012; Michael Bassett, 2013). Affordability is a broad notion but in essence, this research portfolio addresses it as the concern for accessibility of New Zealanders to put a roof over their heads. The crux of this issue is the relatively high cost to purchase a place to call home, making housing a commodity to enrich a few. An alternative solution to building and financing a home is needed.

This research portfolio questions how flexible design and incremental construction approaches can be applied to a range of sites typical to the New Zealand context, providing an alternative housing solution that addresses housing affordability. This alternative housing solution demonstrates flexible design and incremental construction tactics derived from the comparative and critical analysis of literature and precedence. These tactics are demonstrated through the design of four typologies that accommodate the users changing needs and financial circumstances. Housing affordability has been addressed by the consideration of these flexible design and incremental construction tactics to allow for incremental investment. As the users, financial circumstances increase or change, the design and construction of their dwelling allows them to make changes easily. This reduces the need for major construction work in order to change the layout and use and it easily allows for the opportunity to expand when the money becomes available. It also averts the necessity to move which in the current property market is costly in terms of finances and time.

To address the aims of this research portfolio, this alternative housing solution inverts the typical process of building and financing a home. It responds effortlessly to the occupant's requirements, however varied. Incorporating flexible design and incremental construction tactics allows for incremental change and incremental investment over the lifetime of the building. At times when a lack of supply has resulted in rampant price increases, we need to question why, would one build a house that takes a great amount of time, money and effort to construct but so quickly becomes redundant? A dwelling, therefore, shouldn't be a product. A dwelling should be an ongoing process. 
"A house should'nt be a product, it should be an ongoing process."

- Amy Lane 
I'm writing this from my shoebox of a room in an overpriced rental property that has no heating.

I couldn't tell you how many times I have dreamed about purchasing one of the houses advertised in those glossy property magazines and every time it takes roughly 9 seconds before I am hit with a massive reality check. The house "ideal for first home buyers" with an asking price of $\$ 750,000$ is a complete joke.

Let's face it I am part of generation rent and may need to be supported by the "bank of mum and dad."

I have a strong believe the housing market is "broken" and the motives for this research portfolio really stems from the fact I want to suggest a way of mending it.

I remember at the start of the year my supervisor asked me... do you want to build your own house one day? I quickly responded YES one day... One day I hope to build a house that grows on the inside. A house that is designed and built in a way that I could add to it as I please and my finances allowed me.

Watch this space. 
ABSTRACT III

PREFACE

INTRODUCTION

The question

02

Terminology

03

Aims and Objectives $\quad 04$

Methodology 05

Thesis Structure $\quad 07$

My House my Castle $\quad 13$

Priced Out and Locked out $\quad 15$

Bigger is Better. $\quad 16$

Musical Houses $\quad 17$

3.0 DESIGN PHASE 1
Core + Module

Core + Module

Core + Module Exploration $\quad 22$

Core + Backbone + Module Exploration $\quad 24$

4.0 LITERATURE
A Flexible Approach to Design

A Case for Incremental Housing 33

Building in Layers $\quad 36$

5.0 DESIGN PHASE 2
Core + Incremental Module Exploration

Core + Incremental Module Exploration 41

Analysis $\quad 47$

Naked House $\quad 48$

System $3 \quad 50$

Villa Verde $\quad 52$

Module $1.2 \quad 54$

Low Cost House $\quad 56$

Garden House $\quad 58$

Knowledge transfer $\quad 62$

8.0 DESIGN PHASE 3
The Final Idea

Frame and Generic Space $\quad 71$

Creating the Shell 73

Growth on the Inside $\quad 76$

SIP's VS Sticks $\quad 78$

Affordable Building $\quad 80$ 


\begin{tabular}{|c|c|c|}
\hline & The Test Sites & 82 \\
\hline & The Narrow Site & 83 \\
\hline & The Wide Site & 117 \\
\hline & The Un-Used Back Yard Site & 119 \\
\hline \multirow[t]{4}{*}{10.0} & CONCLUSION & \\
\hline & Research Importance & 132 \\
\hline & Research Conclusions & 133 \\
\hline & Further Developments & 134 \\
\hline \multirow[t]{2}{*}{11.0} & BIB LIOGRAPHY & 138 \\
\hline & FIGURE LIST & 139 \\
\hline
\end{tabular}




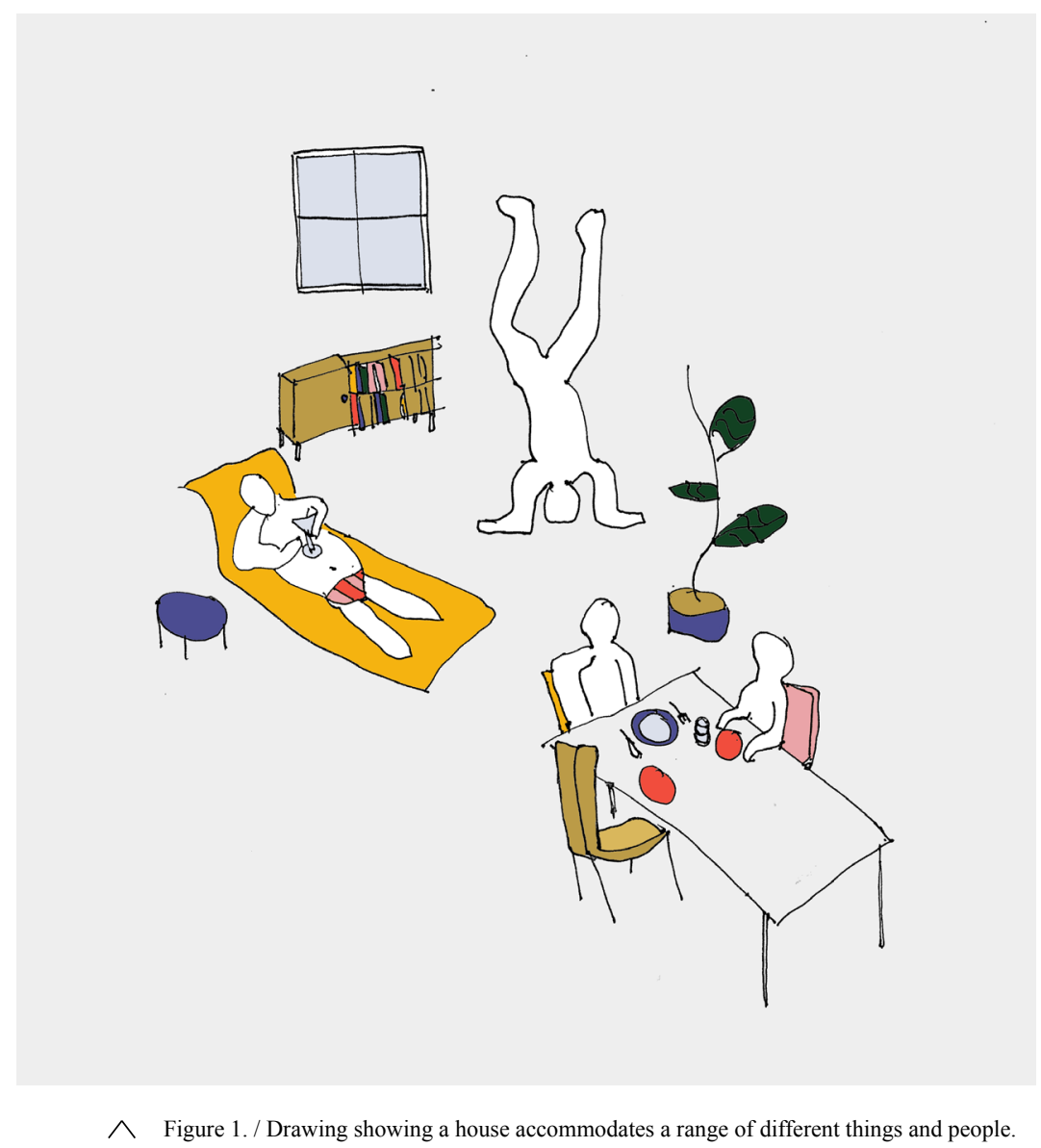




\subsection{INTRODUCTION.}


How can flexible design and incremental construction approaches be applied to a range of sites typical to the New Zealand context, providing an alternative housing solution that addresses housing affordability? 
In order to facilitate a clearer understanding throughout this research portfolio, and to create a degree of familiarity throughout the document, a general definition of these terms has been listed below:

Flexible / Flexibility

Throughout this research portfolio flexibility, in an architectural sense, is the ability to adapt to the changing needs and circumstances of users. The term, adapt also means relates to the term flexible. In essence, flexibility has been used as a tool to create housing that can respond to the volatility of dwelling.

Incremental / Incrementally

The term incremental in this research portfolio relates specifically to a step by step process to the design and construction of housing. It refers to the concept whereby components are added or altered as money, time, or materials become available.

Affordable / Affordability

Affordability is a broad notion but in essence, this research portfolio addresses it as the concern for accessibility of New Zealanders to put a roof over their heads. The crux of this issue is the relatively high cost to purchase a place to call home.

\section{Tactics / Techniques}

Both of these terms have the same meaning in this research portfolio and both refer to ways in which a particular thing can be achieved.

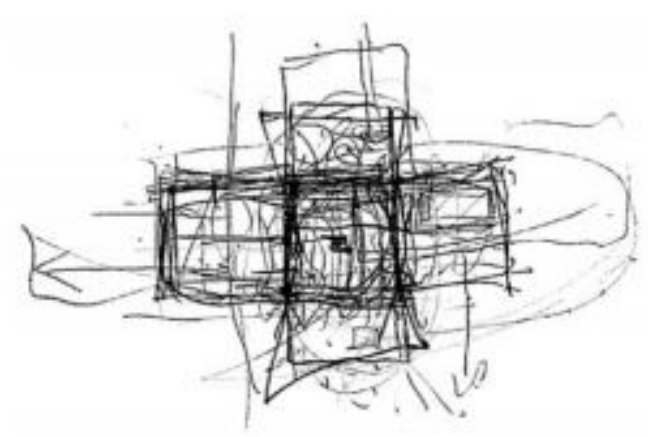

Figure 2. / Sketch to describe flexible design and its everchanging form. 


\begin{abstract}
Aims:
To demonstrate how flexible design and incremental construction approaches can be used to create a series of housing typologies for a range of different sites to respond to the users changing needs and financial circumstances.
\end{abstract}

To provide an alternative housing solution in response to New Zealand's housing affordability issues.

To explore the opportunity of flexible design and incremental construction in the New Zealand context.

\title{
Objectives:
}

To analysis and critique existing flexible design and incremental construction approaches seen in a range of different precedents.

To provide a series of tactics that act as a summary of the key research findings from the literature, precedents and initial design phases and form the knowledge transfer applicable for future developments.

\section{Scope:}

Site-specific - It doesn't have existing sites. The sites used are only test sites and have varying characteristics based on typical sites in New Zealand. The intention is that the design outcomes could be applied to a varied range of sites and locations in New Zealand and are not limited to sites that are exactly same.

A medium density development - It works within a single dwelling scale, however, research outcomes and the tactics that have been suggested could be applied at a larger scale and likewise a smaller scale such as an apartment.

A building that has been priced by a QS and ready for consent - It is about the idea and how flexible design and incremental tactics could be applied to suggest a more affordable housing solution. 
This is a design-led research portfolio iteratively developed in pursuit of a rigorous design outcome. It carries out design-led research through both research for design and research through design. Firstly, research for design is exercised to support the process of designing (Downtown 2003). Research for design has been carried out to provide a theoretical understanding and case study analysis for the terms flexible and incremental housing. This was done in order to understand existing contexts, precedents, situations, issues and opportunities, as well as to determine an approach to design which provides a set of tactics for flexible design and incremental construction applicable for future projects. This foundation is extended in the following chapters which employ research through design. As Peter Downtown mentions in his book Design Research,

"Design is a way of inquiring, a way of producing knowing and knowledge; this means it is a way of researching." (Downtown, 2003, p.2)

Each design outcome has been reflected on before progressing to the next design allowing for the critical development of ideas. This follows Peter Downton's method of testing, where "constant judgements are made about the degree of success of each proposition of whatever scope or scale and can only utilize the designers existing knowing or knowledge." (Downtown, 2003, p.100)

As such, the configuration of this research portfolio works through a series of design iterations and outcomes that eventually lead to a final design which most effectively applies flexible design and incremental construction approaches. Though the final design outcomes are by far the most significant and valuable in terms of the research question, it is important that the previous iterations are included sequentially in order to understand the evolution of this research and design outcome.

The underlying argument contributing to individual knowing and disciplinary knowledge is that these tactics can be used to create a dwelling that inverts the typical process of building and financing a home allowing for incremental change and incremental investment over the lifetime of the building. 


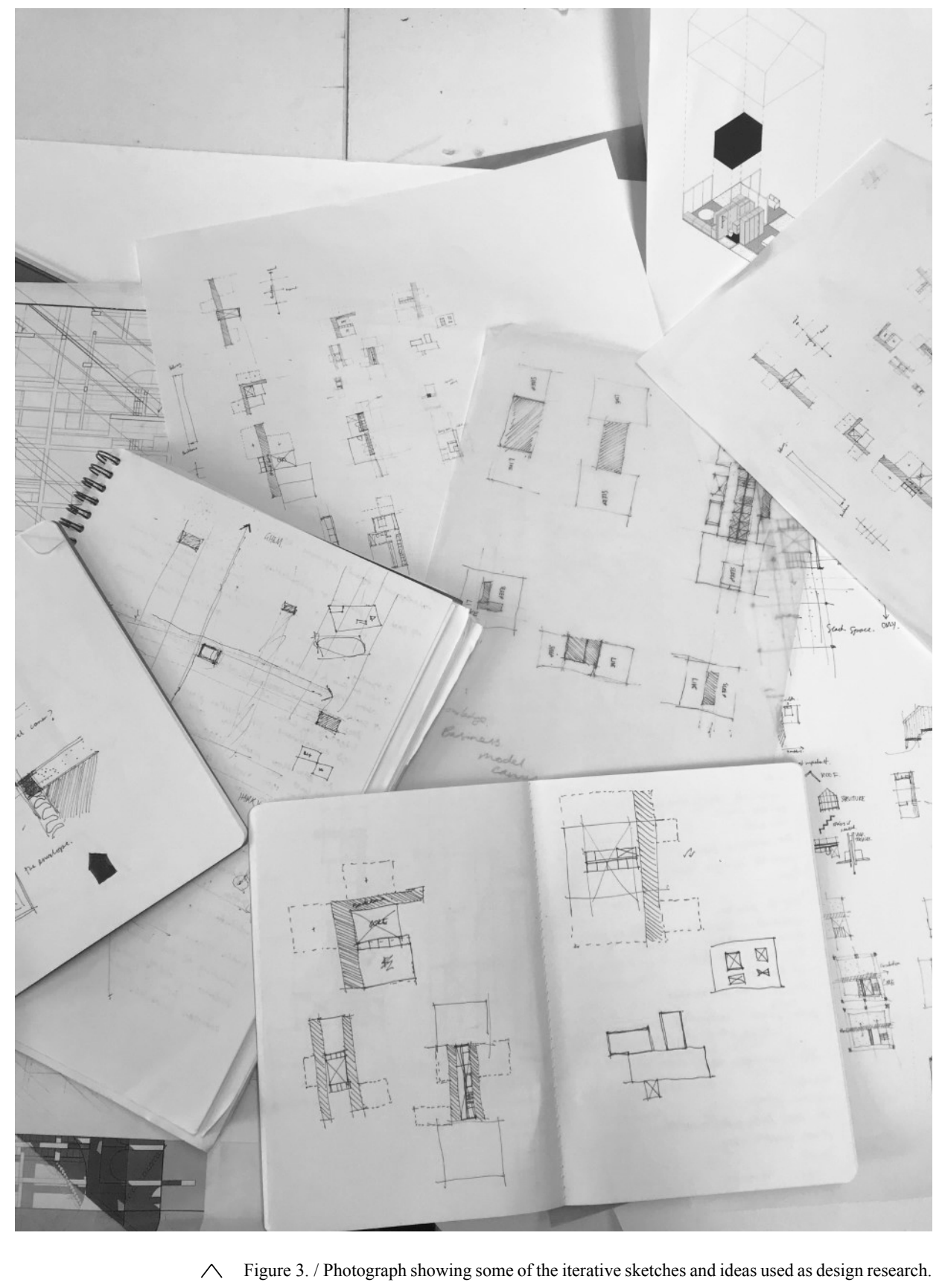




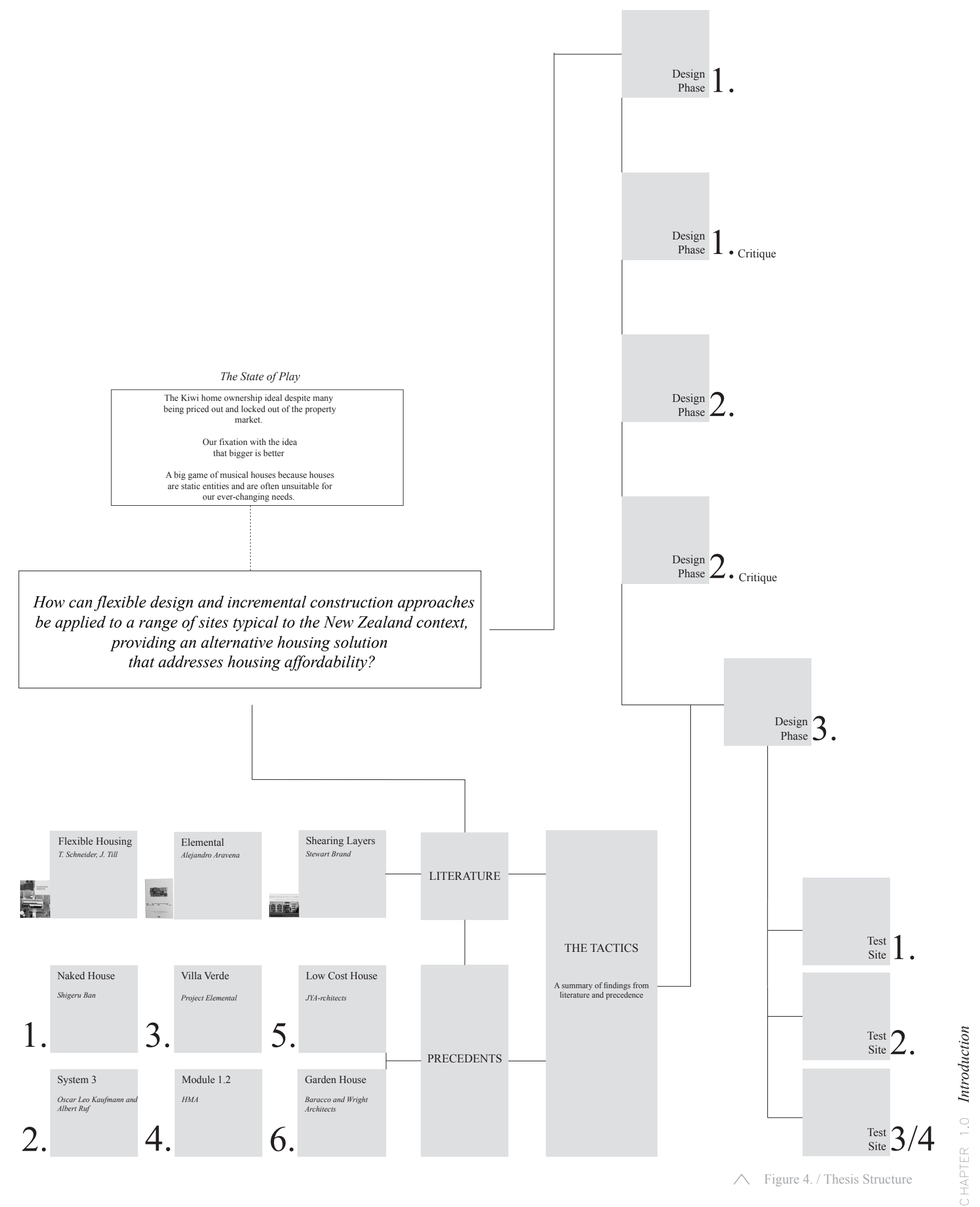




\subsection{Introduction}

This research portfolio is composed of eleven chapters. The introduction establishes the scope of this research portfolio as well as its research aims and objectives. It essentially structures the approach to providing an alternative housing solution that demonstrates incremental construction and flexible design tactics used to address housing affordability.

\subsection{The State of Play}

This chapter explains the current situation, the state of play, our homeownership ideal despite the reality for many young kiwis being priced out and locked out of the current property market. It expresses the need for everyone to have access to a decent home at a price they can afford. Understanding these issues was necessary to begin a design response which ultimately answers the research aims.

\subsection{Design Phase 1}

This phase focusses on translating research from the previous chapter into design. The need for a more affordable solution in terms of building method and the opportunity for a more flexible approach to design has been explored to allow for future change and expansion. This design phase explores the idea of creating a core plus module. The arrangement of modules and core was iteratively explored to determine the appropriate relationship and arrangement between the two. A critical reflection encouraged a move towards an exploration of how the modules could be added incrementally.

\subsection{Literature}

Literature was reviewed in this chapter to posit theoretical approaches to resolving the design issues raised in the research so far. Critical reflection of the literature outlined how we can attempt to solve issues surrounding housing inflexibility and affordability by reapplying these key theories with an understanding of the New Zealand context. Used to locate the research problem within a theoretical framework, these key texts review underlying theory and ideas relevant to this area of research and help establish a design response that ultimately answers the research question.

\subsection{Design Phase 2}

This phase expands on and develops the lessons learned in the first design phase. With the added knowledge of key literature, this phase explores not only flexible design principles, but the idea of half a good house, and the idea that the users could add modules incrementally as their finances allowed them. 


\subsection{Precedents}

The previous chapters addressed the research question explaining the 'what' and 'whys' of flexible design and incremental construction. This chapter explains through the analysis of precedents, how flexible design and incremental construction has been and may be achieved. It explores through existing precedence the issues of use and plan and then the issues of structure and construct. Precedent analysis has provided a means of evaluation and critique in order to understand important design and construction techniques necessary for the design response.

\subsection{The Tactics}

This chapter summarises the knowledge that will be passed on to the architecture profession. A series of tactics to design flexibly and construct incrementally have been created, summarising the knowledge of both the literature and precedents and are used to demonstrate a way of achieving the aims of this research portfolio.

\subsection{Design Phase 3}

This phase explains through both research and design, the final idea. It reviews previous design outcomes as well as the tactics that concluded the literature and precedents. It presents the idea of a house within a house and the idea that a shedlike frame could create a waterproof shell in which changes could be made on the inside. It explains these components and the tactics needed for the flexible design and incremental construction of a more affordable, alternative housing solution.

\subsection{The Final Designs}

This chapter presents a series of housing typologies suited to a range of sites typical to the New Zealand context. Four sites have been used to test how these tactics could be applied to a range of different sites with varying typologies and sizes. Each typology has incorporated the flexible design and incremental construction tactics outlined in this research, allowing the users to incrementally add depending on their changing needs and financial circumstances.

\subsection{Conclusion}

The conclusion provides a critical discussion on the research importance and research conclusion. It summarises the research problem and its importance and then concludes the research finding of this portfolio. It also suggests further development. 


\section{THE PROBLEMS}

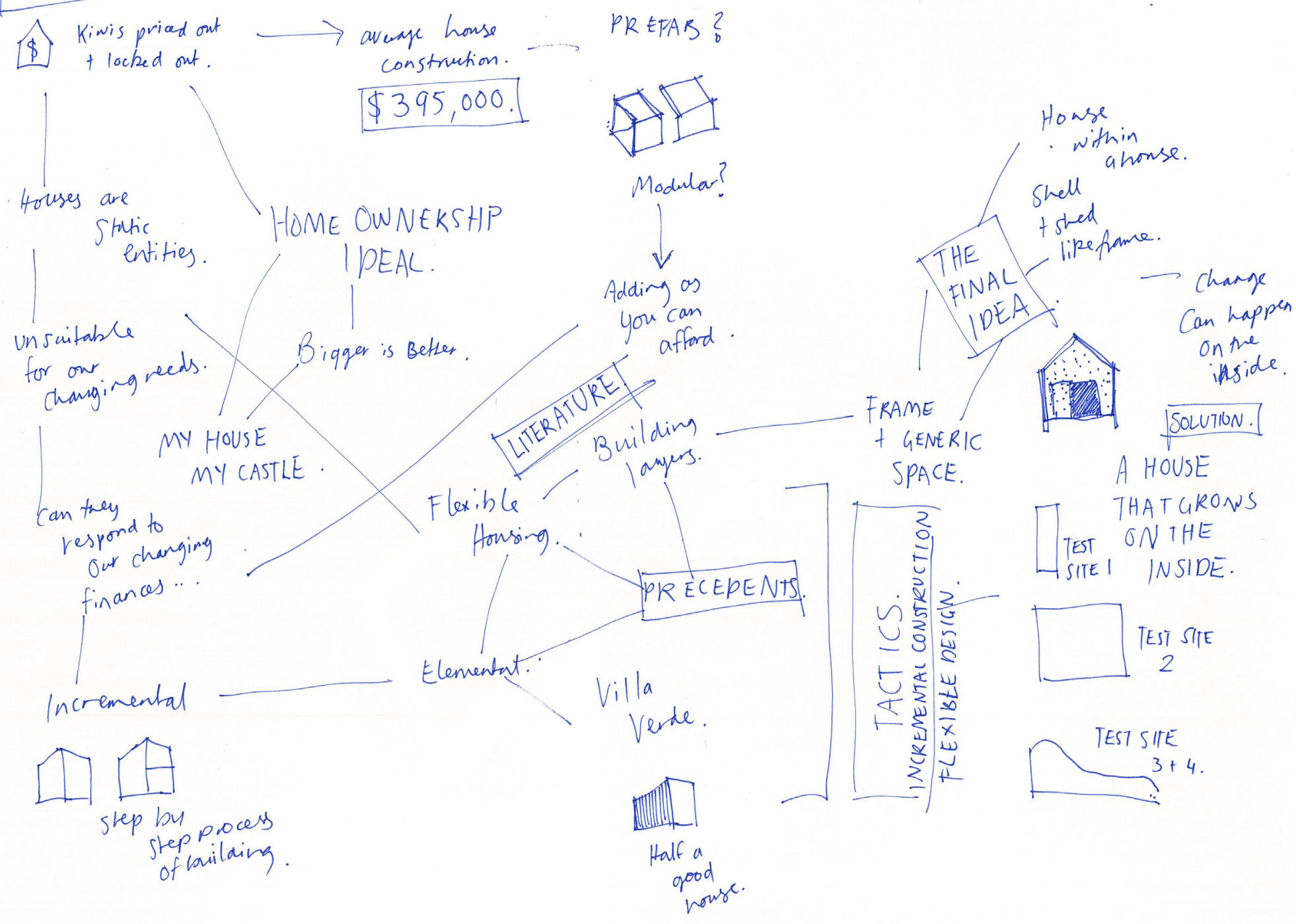


2.0 THE STATE OF PLAY. 
Everyone agrees that there is such a thing as a housing problem, and a concern for accessibility of New Zealanders to put a roof over their heads. It is not easy to put into a few words what the problem is, it is a combination of things outlined in this chapter. This chapter explains the current situation, our homeownership ideal despite the reality for many young kiwis being priced out and locked out of the current property market. It will discuss our fixation with the idea that bigger is better, and the idea that people are just playing musical houses because houses are static entities and are often unsuitable for our ever-changing needs. This chapter summarises the need for everyone to have access to a decent home at a price they can afford.

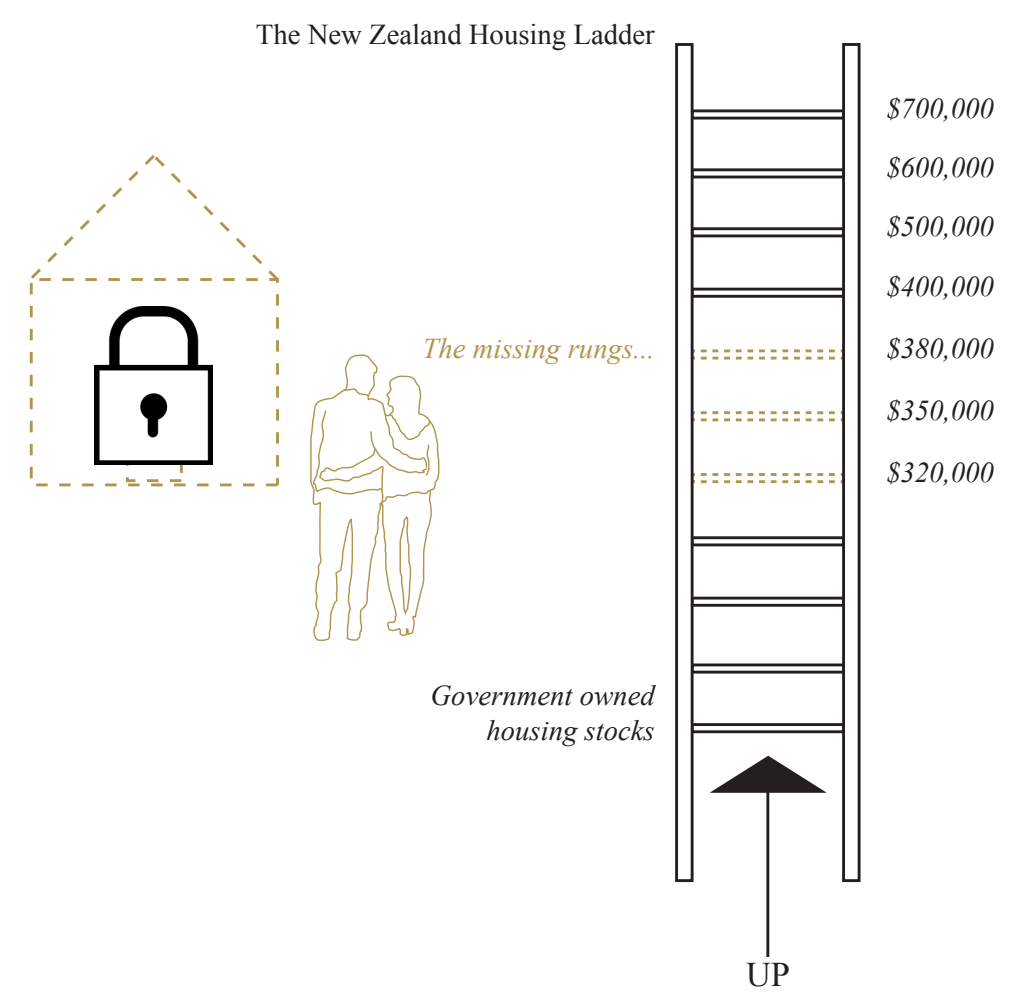

Figure 6. / The missing rungs in the current NZ Housing Ladder. 
Owning your own house is the quintessential Kiwi dream. We're told there's nothing we would like more than to have our names on the mortgage that paid for the roof over our heads. New Zealanders prefer to live in a detached dwelling they own, as it offers greater security of tenure and stability (Schrader, 2012). Housing preferences are also influenced by a shared desire for the authentic home which usually meant a detached dwelling on a piece of land. The owner-occupied dwelling is a private space, a 'castle'. The issue these days being, you can't claim your house is your castle when in the current housing market all you can afford is a rental property.

The home-owning, two-parent family on the cover of this States Advances Corporation brochure represents the ideal post-war family. Men mowed lawns, women wore aprons and focused on household tasks while children played happily on their quarter acre section. These ideals are very farfetched in today's housing market.

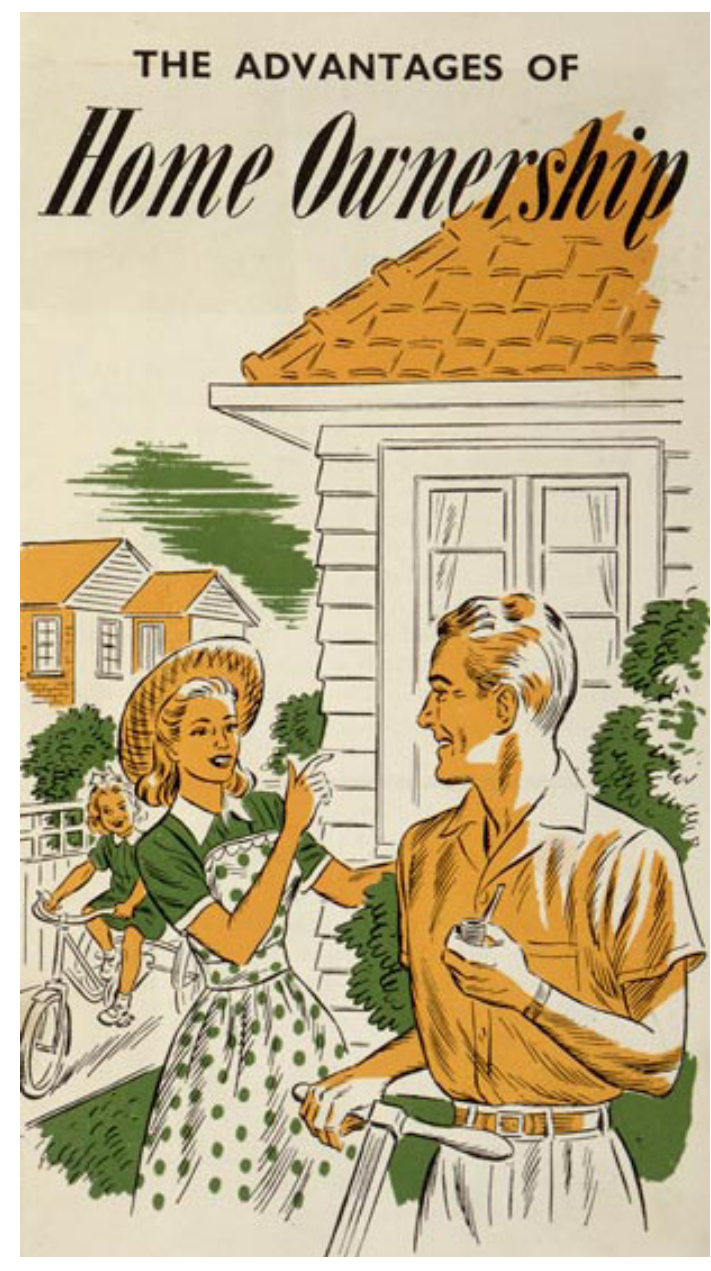

$\wedge$ Figure 7./ State Advances Corporation brochure repesents the ideal post-war family. Alexander Turnball Library 1950. 
The average construction cost of an 'average house' has risen $28 \%$ over the past five years and by $180 \%$ over the past 20 years. In late 2017 , this average cost, New Zealand wide, was 
Despite New Zealanders having a preference to own their own home, home ownership has fallen and is falling still, as houses become more expensive (Eaqub \& Eaqub, 2015). According to the Statistics New Zealand Dwelling and Household estimates in January 2017, homeownership rates are the lowest in 66 years (Miller, 2017). In 1986 the percentage was above $73 \%$ and has since been falling. Nationwide 63.2 per cent of people today live in their own home (Statistics NZ, 2017). More and more Kiwis are being locked out of owning their own home and are forced to rent.

As mentioned above, New Zealanders still have a preference to own their own home. One of the predominant reasons for the preference of individual property ownership is territory - security through the physical ownership of the land underfoot and under the dwelling (Eaqub \& Eaqub, 2015). But with the average age of a first home buyer drifting up to 36 years of age, many New Zealanders have given up on this kiwi dream of homeownership (Interest New Zealand, 2016). Combined with the average time required to save a deposit being 8 years, the acceptance of many New Zealanders to rent for life has lowered the aspiration of homeownership. New Zealand is entering the first generation of lifetime renters who have either no ability to own or no desire to own their own home.

One of the barriers for young kiwi buyers is collating funds for a deposit. You may think spending money on flat whites and smashed avocado is the crux of this issue, but the real issue is household incomes have reduced over the past 3 years in comparison to the cost of living. Yes, you can always go out for brunch less often, but house prices in New Zealand are still extremely high in relation to incomes. In the first quarter of 2012 , the median house price was $\$ 370,000-7.16$ times the average ordinary time annual wage (New Zealand Productivity Commission, 2012). Back in 1990, the ratio of wages was around 4.4 (2012). Young kiwis are therefore caught in a trap where a disproportionate amount of income from their labour is required to access housing.

Another barrier is finding a house in the lower spectrum of the housing ladder. There should be a focus towards developers constructing affordable housing in this lower spectrum. The residential building industry needs stimulating in a controlled direction to assist with building in affordability. If the largest amount of new homes that were available to the market were affordable, then by default, the market would become more affordable. We need to incentivize the construction of smaller homes and smaller homes will be built. We need to incentivize affordable homes and affordable homes will be constructed. 
Even with the constant clamor about rising house prices making homeownership elusive for young kiwi's we are still building expensive unnecessarily big houses. It's not just the prices that are out of control. Over the past half-century, New Zealanders' expectations for their house have ballooned - we are addicted to square meters, and each decade our appetite grows. In 1976, the average new house in New Zealand had a floor area of $121 \mathrm{~m} 2$, by 2011 it was $209 \mathrm{~m} 2$ (Marriage, 2010). Never mind the fact that the average household size is predicted to fall to 2.4 people by 2031 , we still want more and more rooms for fewer and fewer people (Statistics NZ, 2016).
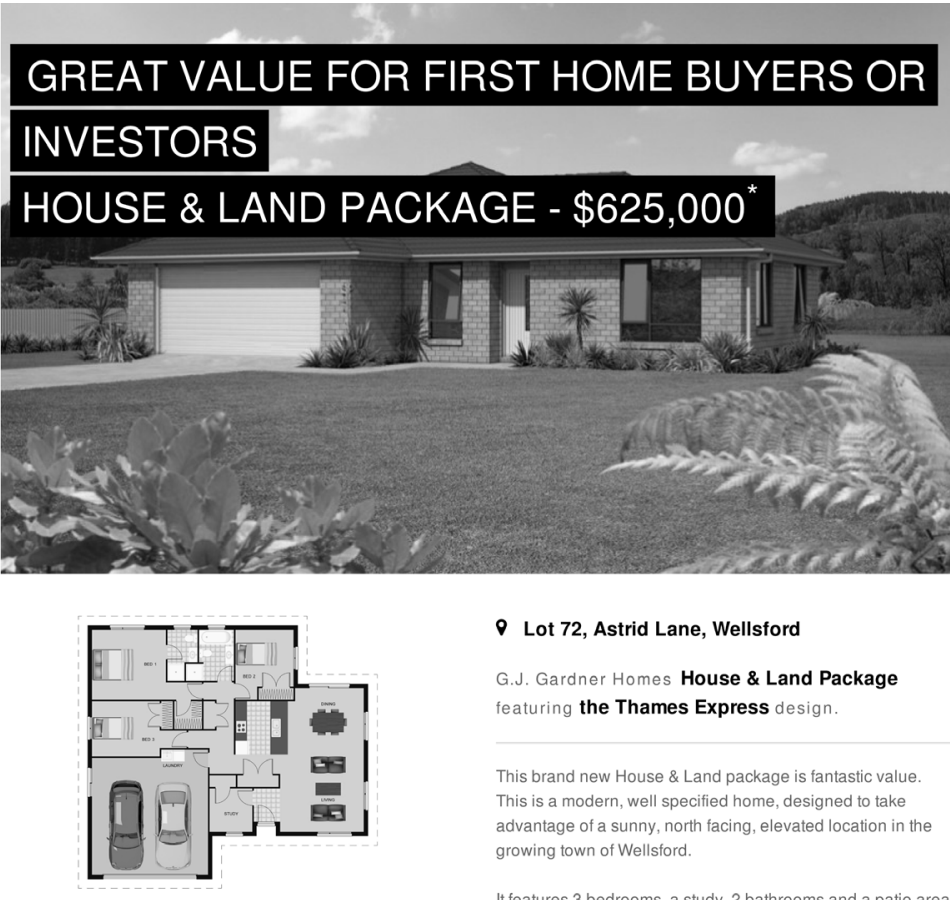

- Lot 72, Astrid Lane, Wellsford

G.J. Gardner Homes House \& Land Package featuring the Thames Express design.

This brand new House \& Land package is fantastic value This is a modern, well specified home, designed to take advantage of a sunny, north facing, elevated location in the growing town of Wellsford.

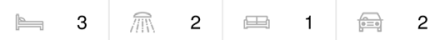

Ifeatures 3 bedrooms, a study, 2 bathrooms and a patio area - sited on a level $653 \mathrm{~m} 2$ easy care section.

Floor Area: $158.4 \mathrm{~m}^{2} \quad$ Land Area: $653 \mathrm{~m}^{2}$ - The price is an indication of the build cost only and includes land. It should be used as a rough guide. Refer to our About Pricing page for

G.J. Gardner Homes Listing No. RN-4538 more information. Images are artist's impression only.

Orewa Office:

Tamariki Plaza, Unit A, 20 Tamariki Avenue, Orewa, Auckland, 09427 9231, rodney@gigardner.co.nz

Mangawhai Office:

6 CONTACT: PATRICK TAUNT - 021989328

Unit 5, The Hub, 6 Molesworth Drive, Mangawhai, 09423

1020, rodney@gjgardner.co.nz

Copyright: These designs and illustrations remain the propery of G.J.G Gardner Homes and may not be used or reproduced in whole or in part without wititern
consent. Please note: Rogional varatio ons in productis and buliding roquirements 
It is evident that when entering the property market there a high cost to purchase a new home. However, purchasing a home or building often doesn't respond to our changing needs. Why just why, would one build a house that takes a great amount of time, money and effort to construct or even to buy but so quickly becomes redundant?

A Statistics NZ study explored reasons people moved from their previous residence stating that housing was the second reason for moving with economic being the first (Statistics NZ, 2007). Housing reasons were nearly always characterised by the previous dwelling being too small and the layout being unsatisfactory for their needs at a particular time (2007). These present forms of housing are unable to respond to the users' domestic needs; the effect is that large numbers of houses are occupied by miss-matched families. With alterations being hugely expensive and timely, people often move from house to house to suit their changing needs. Real estate fees and moving costs in the current property are also costly in terms of finances and time. Real estate fees and commissions have an increased effect on sale price as the vendors generally include these fee and commissions into the asking price. As the market price has increased affordability has decreased.

Housing design based on predetermined ideas imposed by the architect often generates housing that is static and will not grow and change with its users. Developers, mostly they repeat the same identical cookie cutter house type, preferring to market their homes to the idealised version of the 'conventional' family. Developers also persist in treating the 'family' as a static entity. This approach to building becomes unsuitable for the occupants changing needs and results in occupants having to move which is often costly in terms of time and money. N. John Habraken, in his text, Supports: An Alternative to Mass Housing, describes this process as a 'game of musical chairs' (Habraken, 1972, p. 36). But instead of chairs, we are playing a game of musical houses. 


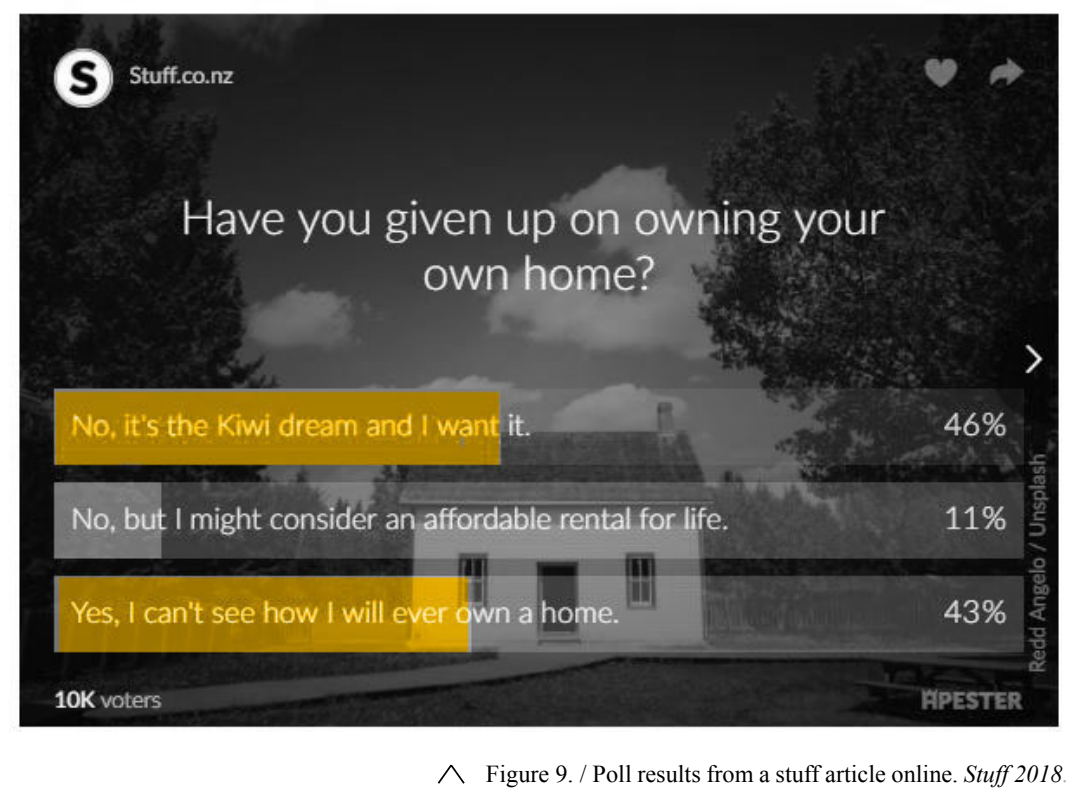


3.0 DESIGN PHASE 1. 
This phase focusses on translating research from the previous chapter into a design. The research outlined in the previous chapter highlighted a need for a more affordable solution in terms of building method. It also highlighted an opportunity for future building to apply a more flexible approach to design to allow for future change and expansion. This design phase explores the idea of creating a core plus module. Existing types of prefabrication have been analysed to determine an appropriate method of construction. The arrangement of modules and core was iteratively explored to determine the appropriate relationship and arrangement between the two.

The use of prefabricated materials has been explored as an alternative construction method, one that could potentially address the aims of this research portfolio to provide an alternative housing solution that addresses housing affordability. A Prefab NZ report published earlier this year suggests prefab houses cost on average $\$ 47,000$ less to build than their built-on-site equivalent and can cut as much as $50 \%$ off construction time (Bell 2010). They also produce less waste and result in a higher quality product. Pamela Bell, Prefab New Zealand Executive mentions in her thesis, Kiwi Prefab, up to $15 \%$ of total construction costs can be reduced using a prefabricated material. That can amount to a $\$ 32,000$ saving on a $157 \mathrm{sq}$ m house (Bell 2009).
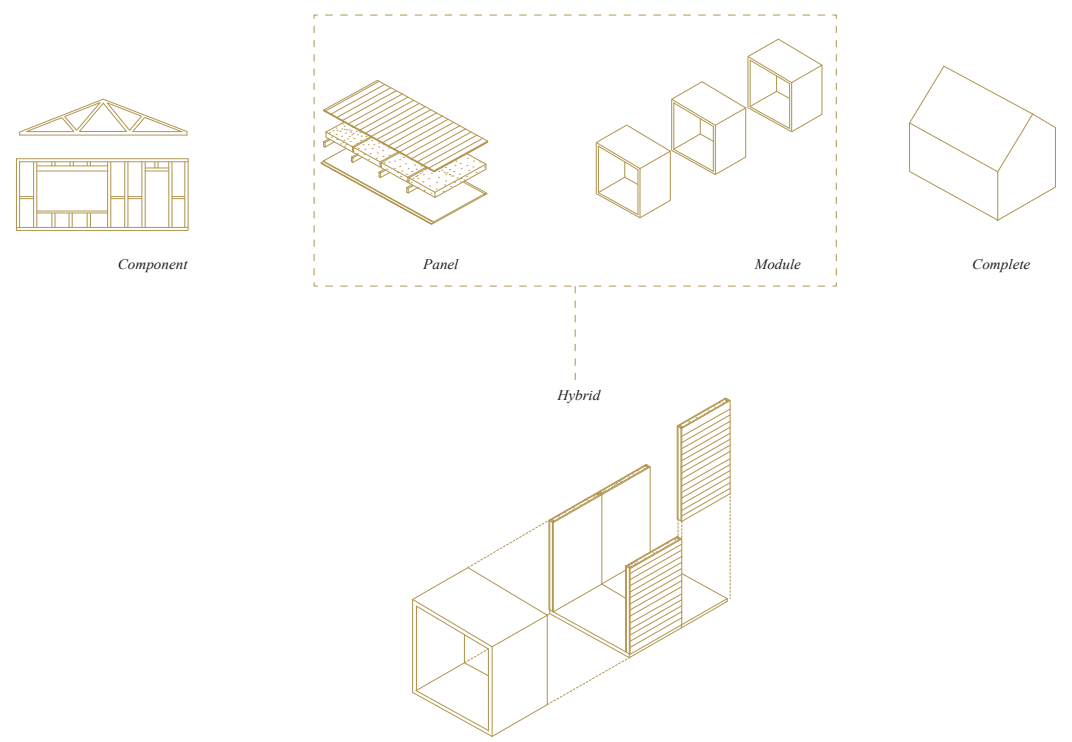

Figure 10. / Diagram showing the type of prefabrication this research portfolio explores. 
First Light Studio's award-winning UniPod design became an important precedent. Their design won PrefabNZ's UniPod design competition. As an open-source universally accessible bathroom, the UniPod design "cleverly combines all of the necessary functional requirements in a smart wall services core that is highly space efficient. Its small space means a high degree of usability for different building types" according to Prefab NZ Board Chair and Judge Damien Otto (Bell 2016). UniPod is a one-piece bathroom, kitchen, services, and utilities. The bathroom and kitchen pod is essentially brought to site as one giant piece of Lego.

Expanding on the design of the UniPod, the idea that the core would act as the nervefunctioning center of the home, housing all the key services for daily life began to be explored. It was important to explore the idea of the core where the kitchen and bath are shipped as a three-dimensional unit, whereas the living spaces, which are less prescribed, are panellised and potentially assembled on site.
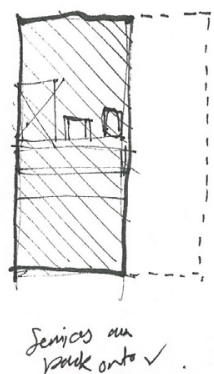
each ofter.

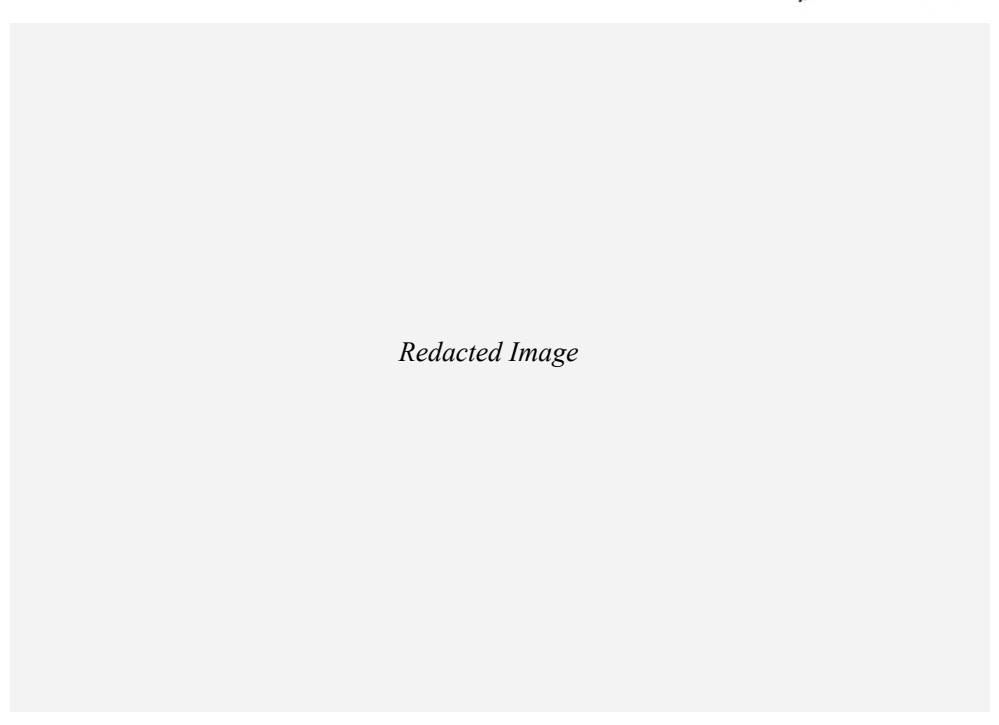

$\wedge$ Figure 11./ Diagram explaining the service core Figure 12. / The Uni Pod Design. Prefab NZ 2016 

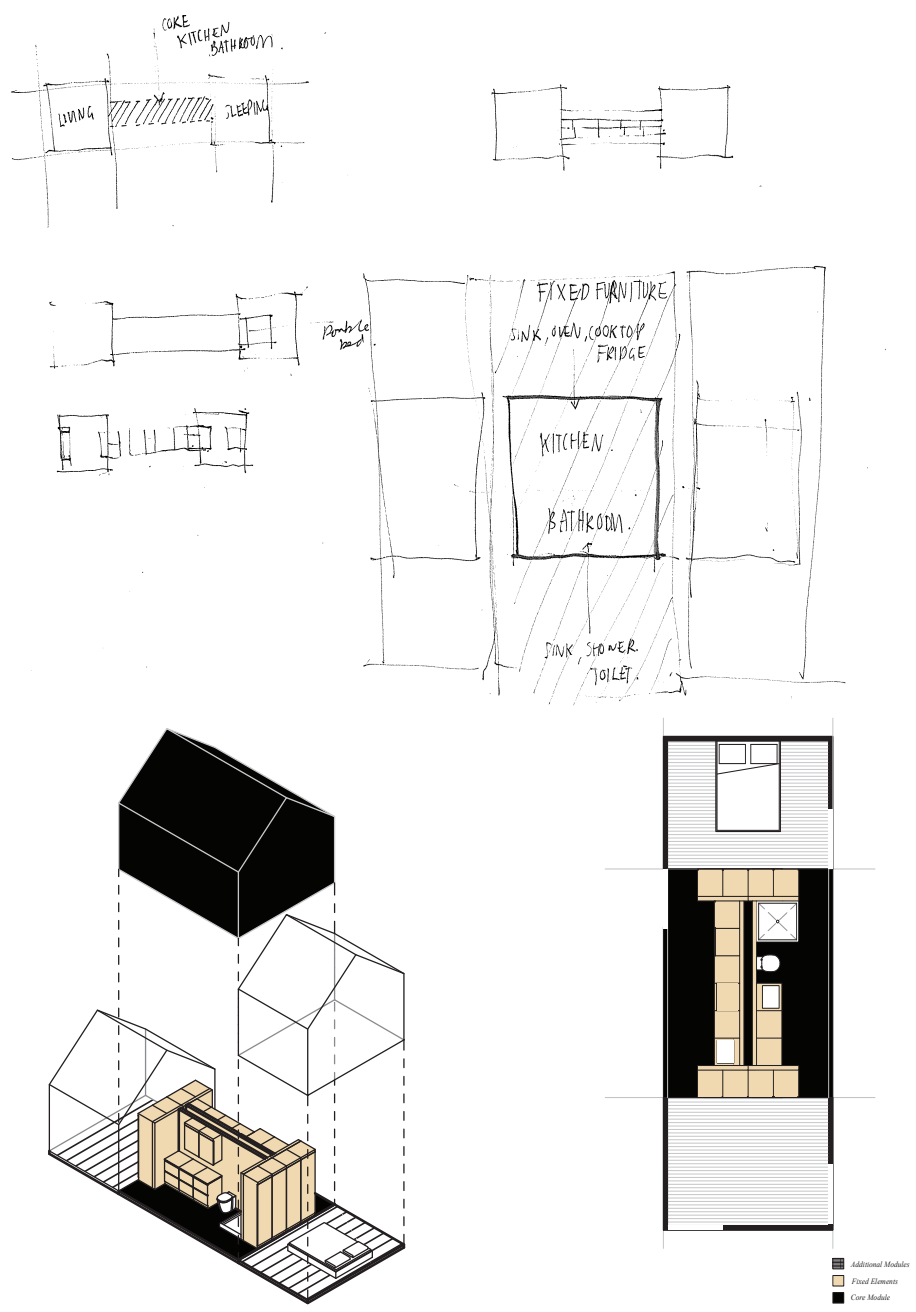

$\wedge$ Figure 13. / Design Exploration 1.

The aim of this exploration was to explore the relationship between the core and the module in plan and how they could be arranged to allow for additional modules to be connected possibly at a later stage. This first iteration explores how the core can become the central functioning center of the dwelling. This particular layout allows for modules to be extended both ends and the core acts as a halfway divide between sleeping and living areas.

Critical Reflection:

Access to each area, living, and sleeping should not be through the kitchen or bathroom. These spaces are not designed as a thoroughfare. 
Design Exploration

Core + Module
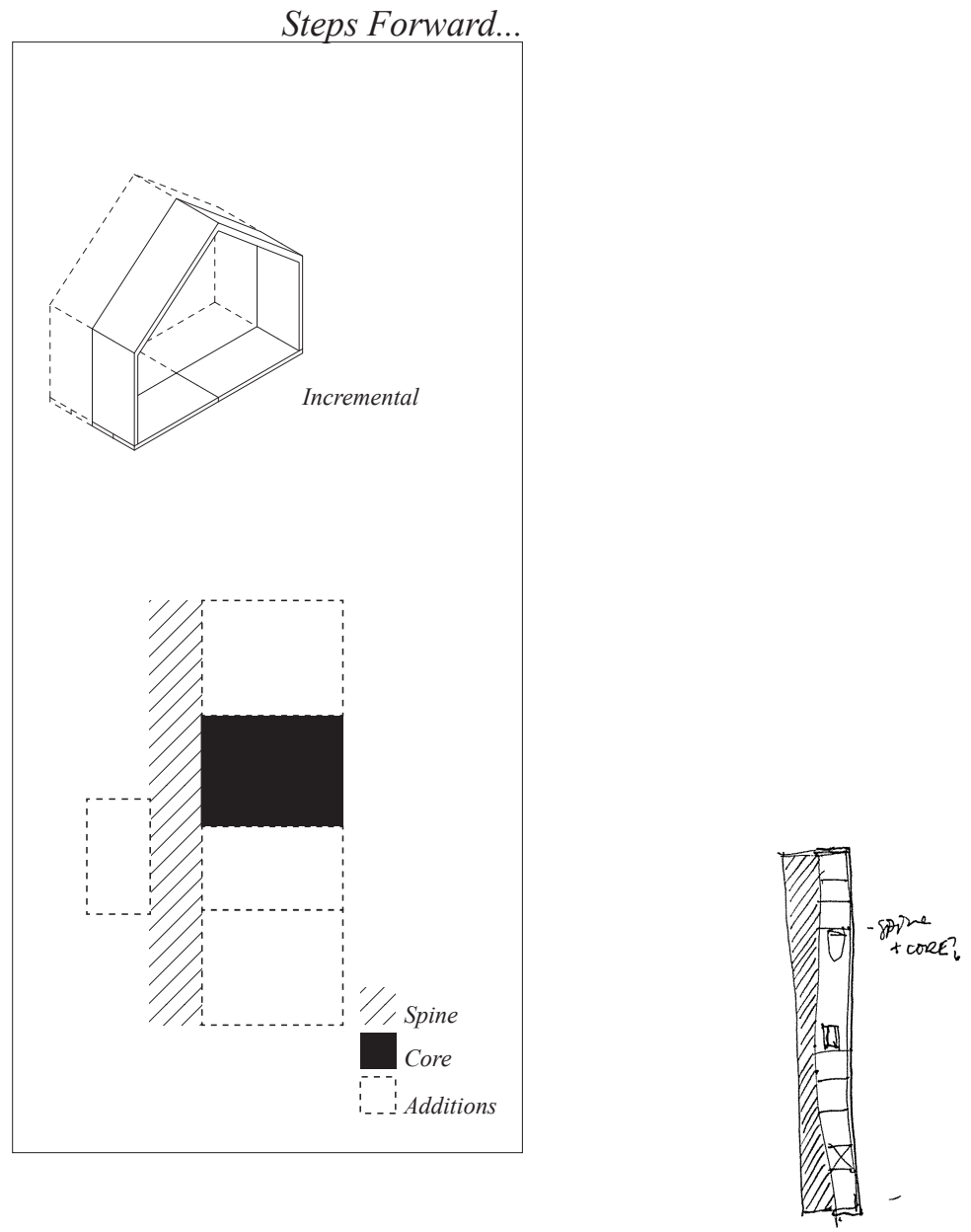

Figure 14. / Critique of Design Exploration $1 \wedge$

Figure 15. / Sketch exploring the potential of a backbone that is attached to the core.

$\wedge$

Whilst carrying out this exploration, a connecting space or space coined in this research portfolio as the backbone and spine also became necessary. A critique of the previous design exploration was that the core shouldn't act as a thoroughfare. As the core acts as the nerve or functioning center, it was necessary to have a connecting space that became the backbone. 

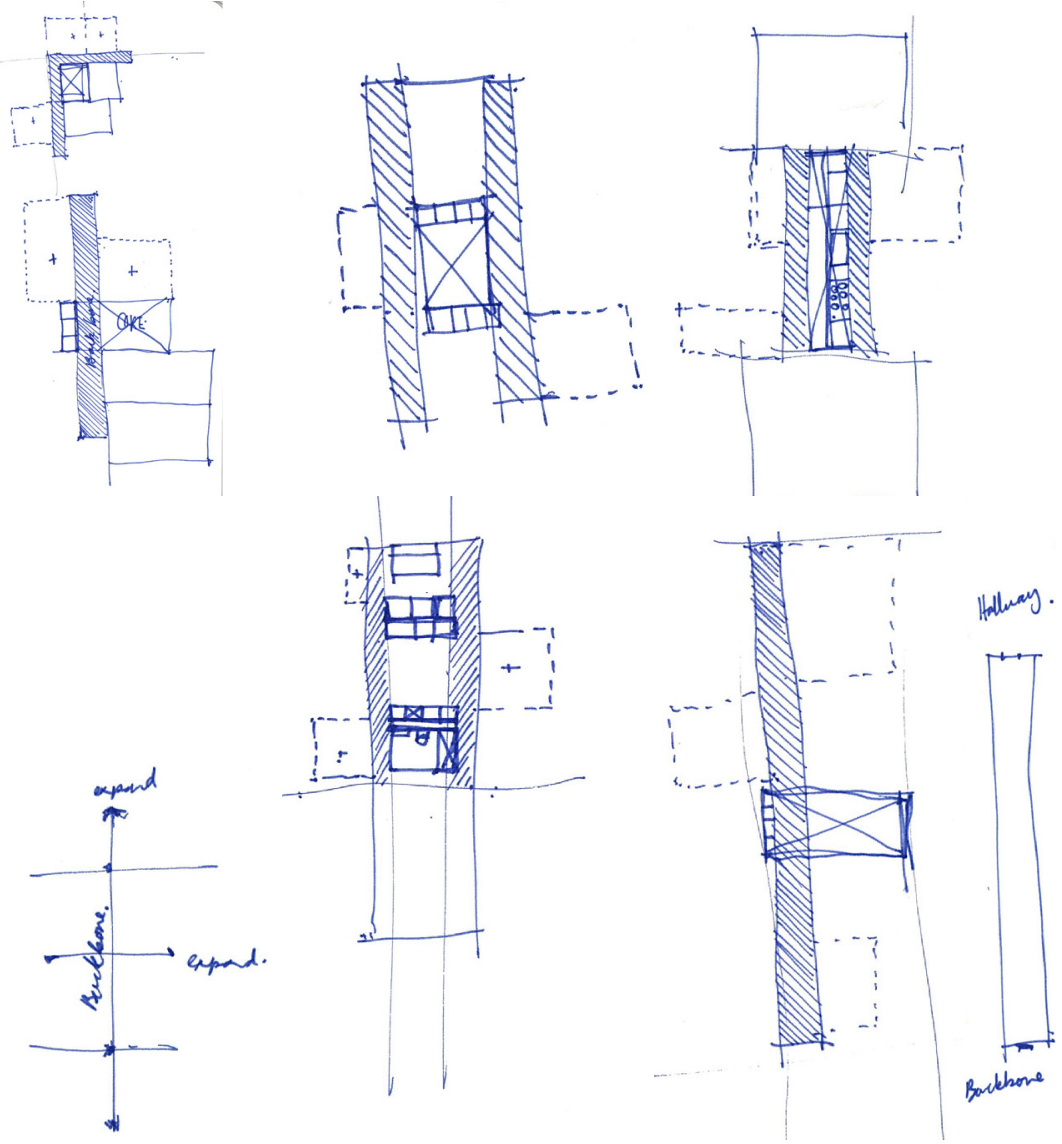

Figure 16. / Planning Exploration showing the possible arrangements of the modules and the core + backbone

These sketches explore the arrangement of the core and how the connecting area, coined the term backbone or spine, could allow for additional modules to easily be added. They show the multiple combinations applying this idea of having a core and backbone in which the modules can be 'plugged in'.

\section{Critical Reflection:}

The placement of the core towards the center of the plan works best as it forms the heart of the home. When placed towards the end it does not have the same function and is quite removed.

The connecting space or backbone needs to run the length of the building to allow for the modules to be connected.

Similarly sized modules should be used as this allows for repetition during construction off-site. 


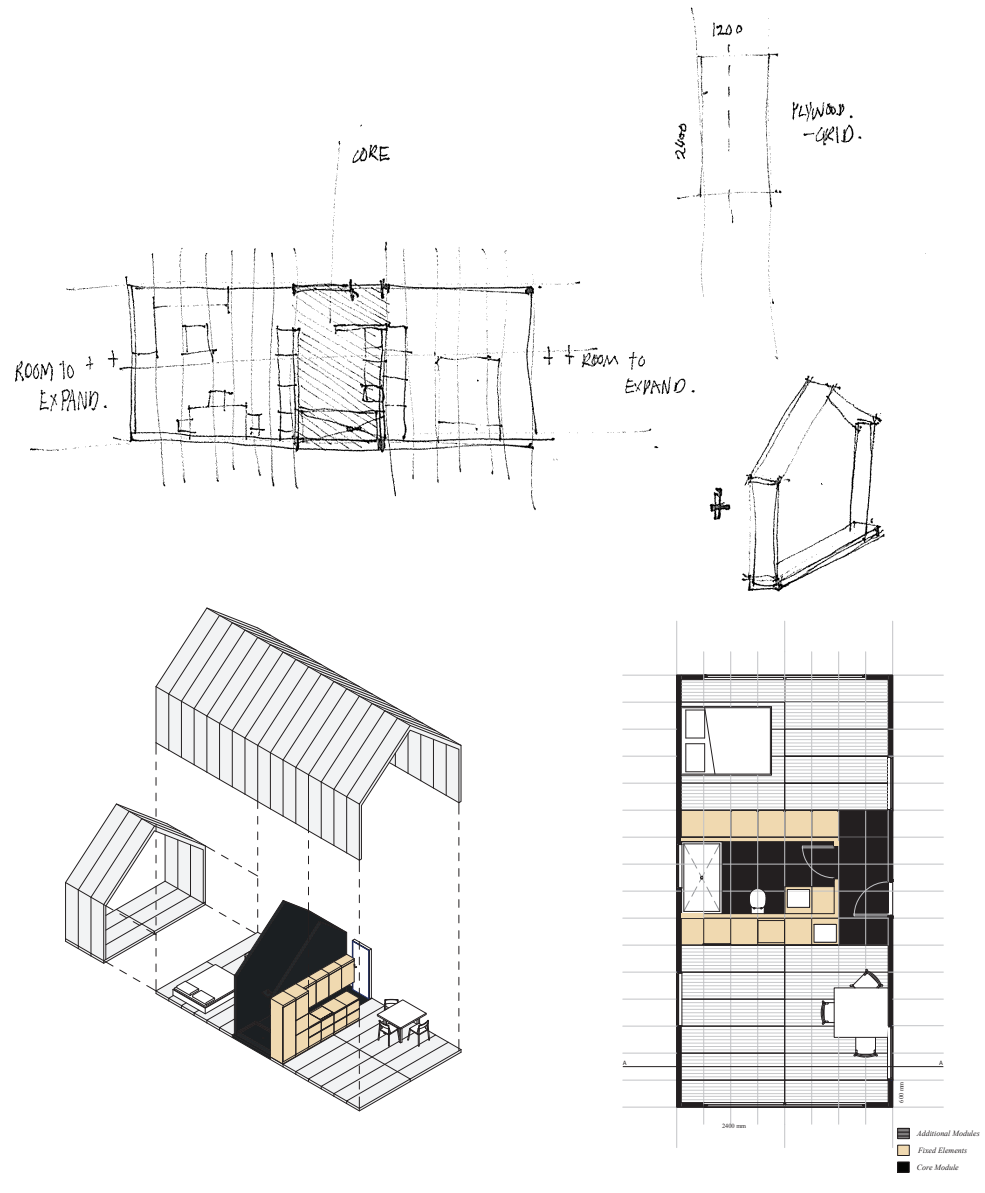

Figure 17./ Design Exploration 2.

This second design exploration expands on the first by considering the incremental addition of modules. Similar to the first iteration, the core separates the living and sleeping areas but it presents a solution to the thoroughfare issue connecting these spaces. By allowing space to the side of the core that runs the length of the building, additional modules can be placed either end and the backbone can act as a connecting space between each area.

\section{Critical Reflection:}

The grid and size of the modules became a key part of this design as it dictated the planning arrangement.

The module size and therefore grid layout could be made wider. This would mean fewer modules would need to be connected together.

The core containing all fixed furniture and elements allows the living and sleeping spaces to be less prescribed and allows them to have varying functions. 
Design Exploration

Core + Backbone + Module

Steps Forward...

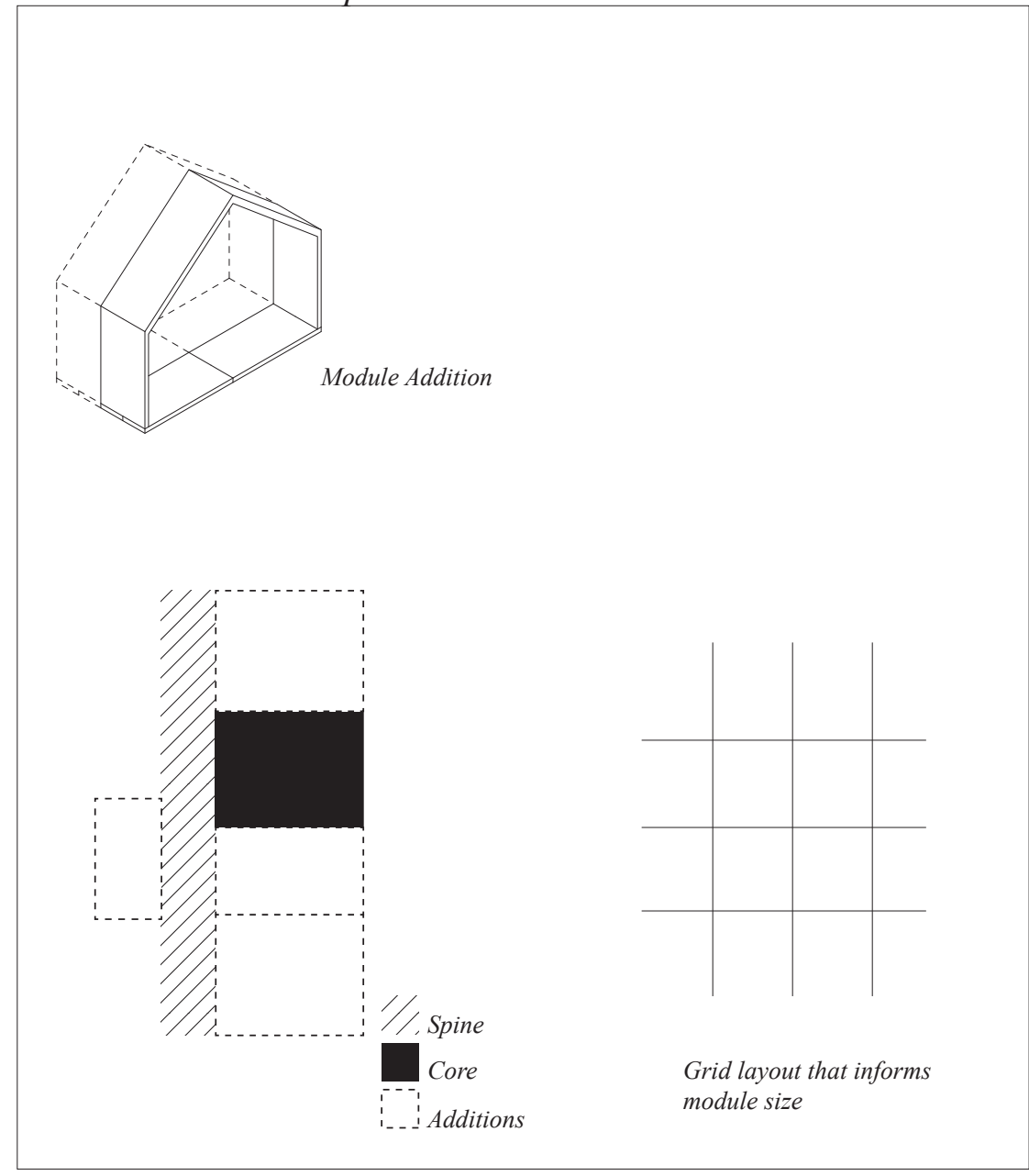

$\wedge$ Figure 18. / Critique of Design Exploration 2 


\subsection{LITERATURE.}


"We shall need more daring, more cool, understanding than that we are displaying at present. We live in our homes badly; we have built them in culpable innocence and now fret helplessly in a synthetic wilderness of our own construction. We need - more urgently than architectural utopia's, ingenious traffic systems, or ecological programmes - to comprehend the nature of citizenship, to make a serious imaginative assessment of that special relationship between the self and the home, its unique plasticity, its privacy and freedom."

- Jonathan Raban, Soft City p.12 
It is clear that housing has become a commodity to enrich only a few. This is the problem that needs to be addressed by design research to find an alternative solution to building and financing a home. As a solution to this problem, we don't just want to build the norm that so quickly become obsolete. New housing should respond to change whether it be, evolving definitions of family, demographics, financial circumstances or living patterns. Houses need to be more affordable, more flexible and responsive to a family's changing needs and financial circumstances.

This chapter, therefore, posits theoretical approaches to resolving these problems. It outlines how through a critical reflection of literature, we can attempt to solve the issues surrounding housing inflexibility and affordability by reapplying these key theories with an understanding of the New Zealand context. The review of three key texts will provide a critical response that addresses the research question aims and objectives. The first is Jeremey Till and Tatjana Schneider's Flexible Housing that was used to define the term flexibility and how it relates to design and construction (Schneider \& Till, 2007). The second is Elemental, offering an Incremental Housing Guide by Alejandro Aravena (Alejandro Aravena, 2012). The third is Steward Brand's theory a building is made up of several layers of change (Brand, 1994). Used to locate the research problem within a theoretical framework, these key texts review underlying theory and ideas relevant to this area of research. They will help establish a strategic set of design principles for flexible design and incremental construction that can be incorporated into the following design exploration.

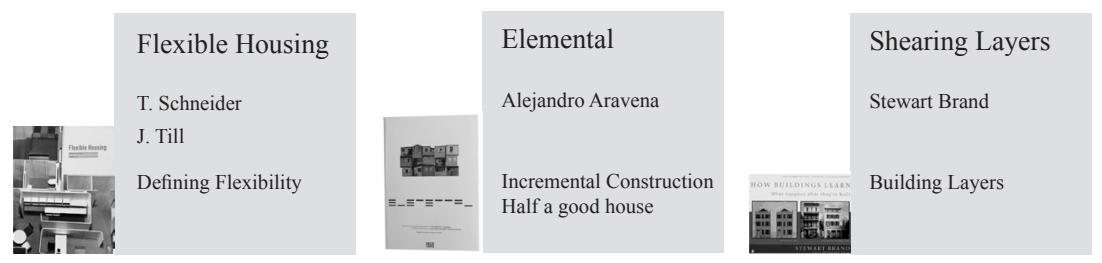


A detailed argument explaining flexibility in a what, why, how format is presented in Jeremy Till and Tatjana Schneider's book, Flexible Housing. This particular section critically responds to their definition of flexibility in housing and why it should be applied to design.

To introduce the term flexible housing, Till and Schneider define flexible housing as; "housing that can adjust to changing needs and patterns, both social and technological." (Schneider \& Till, 2007, p. 4) Essentially flexible housing is housing that can adapt to the changing needs of the users, the ability to adjust one's housing over time. It includes the potential to incorporate additions over time, to adjust to changing demographics, or even to completely change the use of the building. At its core, therefore, flexible housing is housing that can respond to the volatility of dwelling (Schneider \& Till, 2007). The notion of flexibility responds to future uncertainty in a built or natural environment that can neither environmentally nor socially afford to construct buildings as disposable commodities.

Till and Schneider imply that for design to be flexible a number of principles need to be applied (Schneider \& Till, 2007). They use an analogy soft/hard to define two different types of flexibility. Soft refers to tactics which allow certain indeterminacy. Indeterminacy meaning not definitely or precisely determined or fixed. Soft use allows the users to adapt the plan according to their needs. Hard refers to elements that more specifically determine the way that the design may be used. These are elements that are static, fixed and more determinate (Schneider \& Till, 2007). Hard could be allied with construction as elements such as the structure or frame which are more permanent. These elements have to be considered in order to achieve flexibility. Soft could design elements that are not permanent such as functionally neutral space. It is space that could be made and remade by human activity, through everyday interactions with the space.

A definition between the terms hard and soft can be seen in Le Corbusier's Domino system. Stripped of architecture, the Dom-ino is a pure system. It invites use to complete it and inhabit it however we desire. No walls, no rooms, just a skeleton. Arguably the first case in architectural history of a house designed as an open system, the Dom-ino standardised construction system allows for the residents to complete as they sit fit by (McGuirk, 2014). The structural frame could be described as a hard element, fixed and the most permanent. In the Dom-ino the hard element is the structural frame. The soft elements refer to the space that is remade by human activity, the space left raw to allow the users. His idea, however, was abandoned as it had its flaws such as the structure being too slender to support the slabs and addition loading that would come as the users adapted the interior space to suit their needs (Iskenderoglu, 2009). This highlights the importance of the relationship between construction system and design. The construction system needs to respond to the variety of designs possible. 


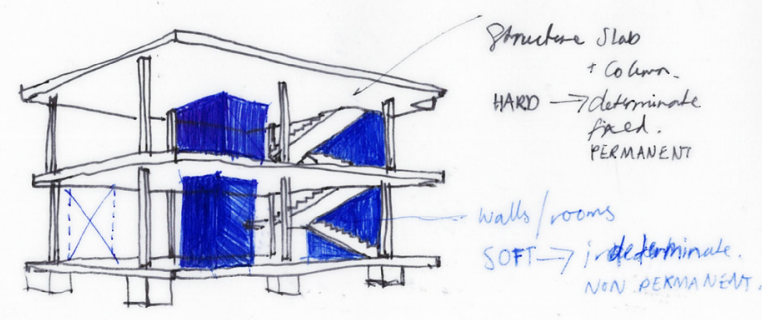

Figure 19. / Diagram explaining how hard and soft elements can be seen in Le Corbusier's Dom-ino

As a way of summarising the ideas raised by Jeremy Till and Tatjana Schneider, a flexibility matrix has been made. This will help analyze precedents in the following chapter and the design explorations to come. Realising that the idea of flexibility is a broad term and there are often many ways to describe it, this matrix collates all the factors that contribute to the flexibility of the dwelling. These factors have been separated into scale, operation and flexibility device.

Scale:

The scale of the operation undergoing change.

Operation:

The action performed to achieve the desired outcome.

Flexibility Device:

The enabling element that allows for the operation to be carried out successfully, which is further divided into spatial or physical device. A flexibility device is defined as the spatial or physical element or series of elements that execute and/or enable change in the dwelling: the tools for flexibility.

This flexibility device also analyses the soft and hard elements, the spatial and the physical, the designed elements and the constructed elements.

NOTE: Words without lie outside the scope of this research.

\begin{tabular}{|c|c|c|c|}
\hline \multirow[t]{2}{*}{ Scale } & \multirow[t]{2}{*}{ Operation } & \multicolumn{2}{|l|}{ Flexibility Device } \\
\hline & & $\begin{array}{l}\text { Spatial Device } \\
\text { SOFT }\end{array}$ & $\begin{array}{l}\text { Physical Device } \\
\text { HARD }\end{array}$ \\
\hline Element & Reconfigure & Surplus Space & Window \\
\hline Room /Zone & Join & Variable Space & Door \\
\hline Dwelling & Divide & External Circulation & Stair \\
\hline Building & Infill & Internal Circulation & Screen \\
\hline Precinct & Extend & Anticipation & Partition \\
\hline \multicolumn{3}{|l|}{ Suburb } & Construction \\
\hline \multicolumn{3}{|l|}{ City } & Structure \\
\hline \multirow[t]{4}{*}{ Region } & & & Roof \\
\hline & & & Services \\
\hline & & $\begin{array}{l}\text { SOFT } \\
\text { Interdeterminate }\end{array}$ & $\begin{array}{l}\text { HARD } \\
\text { Determinate }\end{array}$ \\
\hline & & $\begin{array}{l}\text { User determined, social } \\
\text { process of user over time. } \\
\text { NOT FIXED }\end{array}$ & $\begin{array}{l}\text { Designer determined, } \\
\text { based on predetermined } \\
\text { framework ge construction } \\
\text { and design. } \\
\text { FIXED }\end{array}$ \\
\hline
\end{tabular}

$\wedge$ Figure 20. / Flexibility Matrix used to describe flexibility in terms of scale, operation and device. 
Jeremey Till and Tatjana Schneider explain housing as a volatile subject because of changing trends, evolving technological and environmental changes (Schneider \& Till, 2007). There is nothing certain about what the future housing needs will be: the only certainty is that at the end of this century, the occupant's needs will be different from what they are today. They state that if a building is not able to respond to these changes they become at best unsatisfactory and at worst obsolete. Till and Schneider (2007) therefore propose approaches to providing a dwelling that will deal with the volatility and diversity of occupancy. Consideration of both design and construction of soft and hard elements combined with various different operations at various different scales will allow for a variety of configurations. 
Jeremy Till and Tatjana Schneider have already expressed that there is a relationship between design and construction techniques in flexible housing. Elemental, a Chilean Architecture Collective supports this idea further by creating an Incremental Housing Manual. Elemental's lead Architect Alejandro Aravena defines incremental housing as:

"Housing built by a step-by-step process whereby flexible building components are added or altered by owner-builders as money, time, or materials become available." (Aravena \& Lacobelli, 2012, p. 4)

As elemental refers to the fundamental or the essential, their projects focused on providing the core necessities of a house but were accepting of future expansion. Their affordability driven solution was to provide "half a good house." (Aravena \& Lacobelli, 2012, p. 147) The core necessities were provided in one half, and as the occupants can afford more, they can easily add to the porous frame of the second half. Authors of Elemental, Andres Lacobelli and Alejandro Aravena (2012), suggest we think of 40 square meters as not a small house, but as half of a good house. When money can pay for only half a house you need to start with the basic core building the difficult part of the house first. The first half should consider all the elements that are fixed and the most permanent. That difficult half generally includes structure, kitchen, bathroom, stairs and the roof.

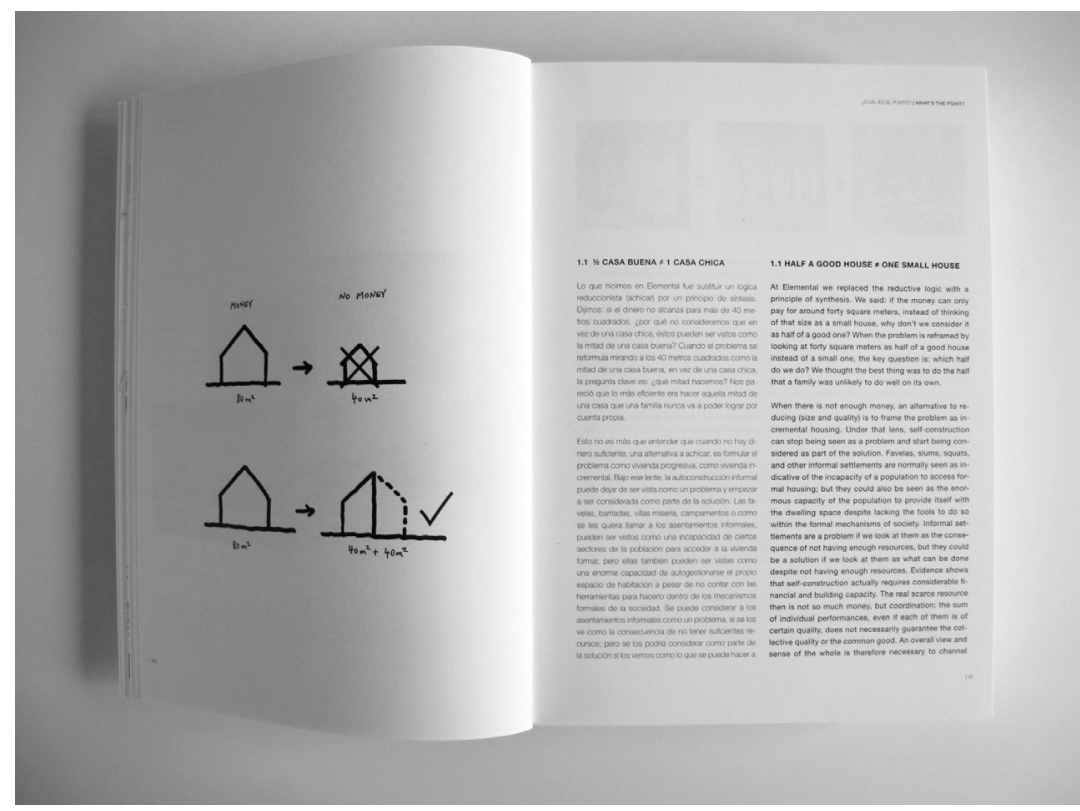

$\wedge$ Figure 21./ Photograph of the Half a Good House Diagram in the Incremental Housing and Participatory Design Manual 
To support incremental additions to the second half, the house is designed as a porous structure. It provides a support for improvised expansions. Considering that the buildings would eventually grow to almost double their initial size, Lacobelli and Aravena (2012) stressed the importance of providing a framework for growth. They advise that the structure, given its level of difficulty and importance should be initially calculated, even oversized to account for additions (Aravena \& Lacobelli, 2012). They suggest working backward from the final state of the building to account for this. Andres Lacobelli and Alejandro Aravena (2012), quote, "In incremental housing, the calculation of the structure should be done for the unit once it has expanded; the problem is that it is not possible to know how these expansions will be made"(p.467) So, the structure has to plan for the worst-case scenario.

The extent of the space destined to be the second half is framed by the roof and presents another important strategy for incremental housing. Because this space is free for users to expand into overtime, the roof limits their extension and rationalizes their individual interventions. Andres Lacobelli and Alejandro Aravena stress the importance of limiting the user's additions in order for the structural integrity of the building to not be affected (Aravena \& Lacobelli, 2012). They also mention constructing a roof over the second half also has added benefits in making it easier for users to make additions. The additional walls are non-load bearing so, therefore, less expensive and easier to add.

Elemental essentially provides an alternative housing solution. With incremental design and construction considerations, half a good house allows the users to add to the second half as they can afford. Adding as you can afford, could be described by the term incremental investment. Incremental investment could be seen as a way of dealing with housing unaffordability in New Zealand. Despite dealing with a more extreme level of unaffordability, particular framework seen in Elemental could be applied to the New Zealand context and its current affordability crisis. Incremental design could allow for the opportunity to expand as and when the money and/ or materials become available and adverts to the necessity to move which can be costly in terms of finances and time. A house should be an incremental investment, responsive to changing needs and financial circumstance. It would allow young New Zealanders to start small with the core necessities built up front, and as they could afford more, the design and construction of their dwelling would allow them to add as their needs changed. 
In summary:

Half a good house is not equal to a small one.

Build the difficult half first - Structure, roof, kitchen, bathroom, stairs

Work backwards.

For a house to be more affordable it should be an incremental investment.

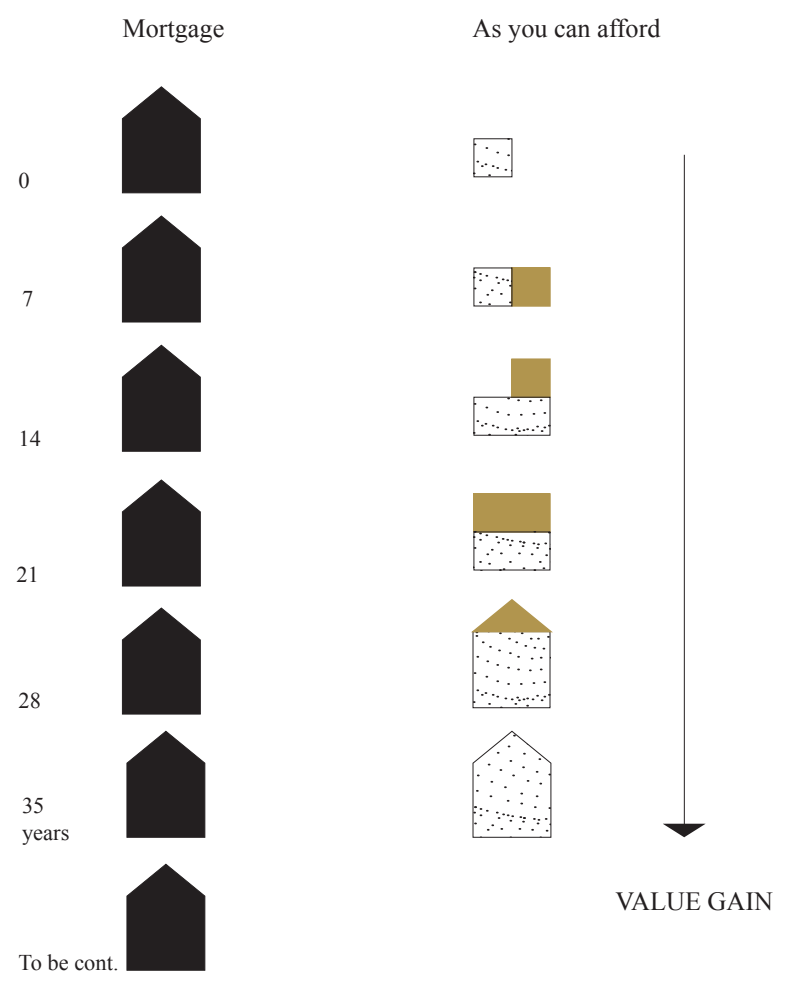

Figure 22./Diagram explaining the idea of incremental investment and its advantages over the normal mortgage. 
Building layers is a concept coined by architect Frank Duffy, which was later elaborated by Stewart Brand in his book How Buildings Learn. He refers to buildings as composed of several layers of change (Brand 1994). Stewart Brand quotes Duffy: "Our argument is that there isn't such a thing as a building... A building properly conceived is several layers of longevity of built components."(p.4) (fig. 21)

Stewart Brand states, "All building are predictions. All buildings are wrong."(Brand, 1994, p. 12) This explains how architects designing buildings simply just predict how the building will be used now and in the future in an inevitably flawed process. He suggests the only way around the issues of prediction is to accept that at best, all you can do is anticipate the inevitability of change, rather than try to predict what will happen (Brand, 1994). Brand is therefore supportive of flexibility and expresses his concern that too many buildings are becoming obsolete.

Stewart Brand suggests, separating the construction elements is acknowledging their different life spans and degrees of flexibility (Brand, 1994). The structural frame could be used as an example of a long lifespan, whilst kitchen units will have a relatively short one. Stewart Brand (1994) therefore suggests it is best to separate these elements out constructionally in order that one layer of the system can be changed or adapted without affecting the others. Inevitably this would make the building more flexible. Normal construction, therefore, binds all elements together, so that changing one layer means dealing with all the other layers. This is the reason renovations and changes to existing design end up being costly and difficult in terms of time and money.

The layers described above can be seen in Steward Brands, Layers of Change diagram, (Fig. 23). It is important to consider these different layers of buildings and how they could be separated or combined. As Elemental also suggested the separation between the structure and the changeable layers is essential (Aravena \& Lacobelli, 2012). Brands Layer diagram has been adapted for the purpose of this research portfolio. It was intended to show the separation of layers and the hierarchies they have. Important research findings from all three texts in this chapter can be seen in this diagram summarising the key ideas (Fig. 24) The services, structure, and skin have hierarchy because they are the least accepting of change and according to Brand, the longest-longest lasting elements within a building. As all three texts have mentioned, the design of these more permanent, hard, elements is essential for the design to accommodate future change. According to Jeremy Till and Tatjana Schneider, the design of these permanent parts of a building play a crucial role in achieving flexibility (Schneider \& Till, 2007). They become important in minimising obsolesce. In contrast to these hard elements, soft elements such as space, stuff, and users are all more easily changed. 

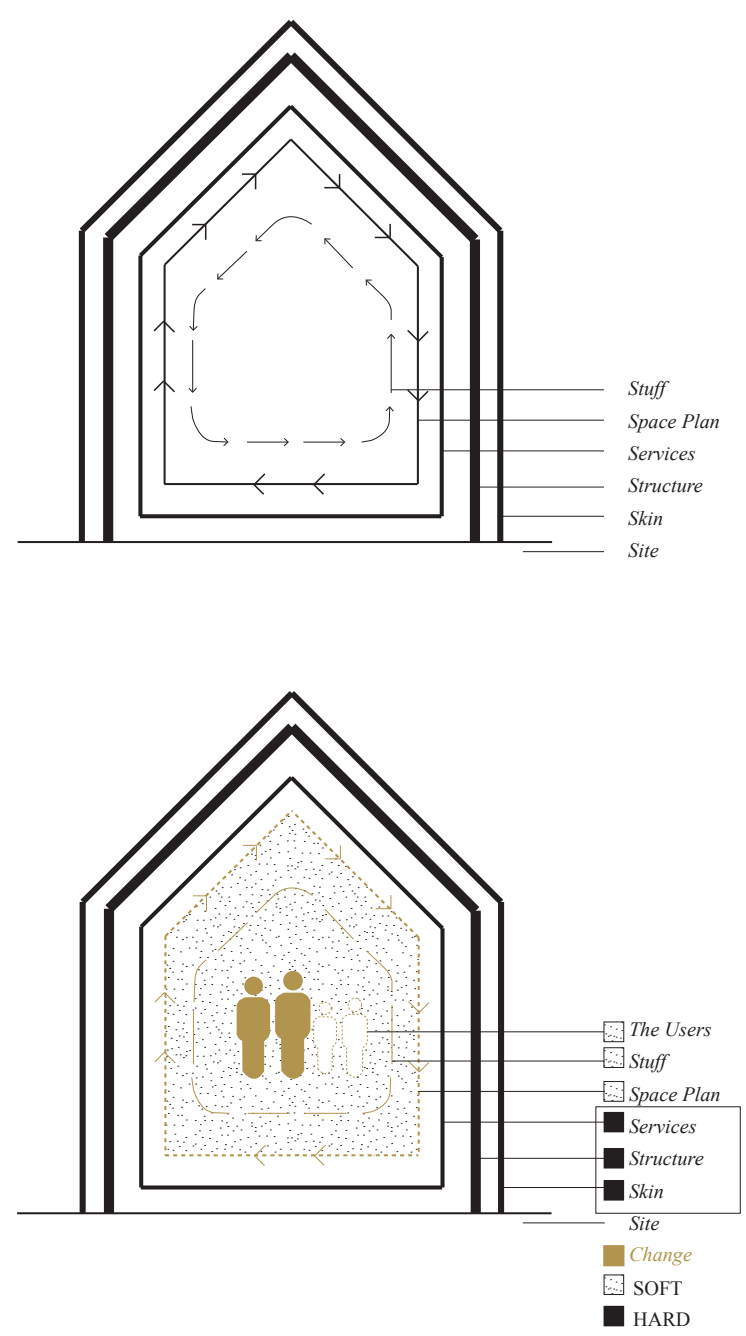

Figure 23./ Stewart Brands Layers of Change Diagram.

Figure 24. / The adapted layers of change diagram to show key findings of this chapter 
This page is intentionally left blank.

38. 
5.0 DESIGN PHASE 2. 


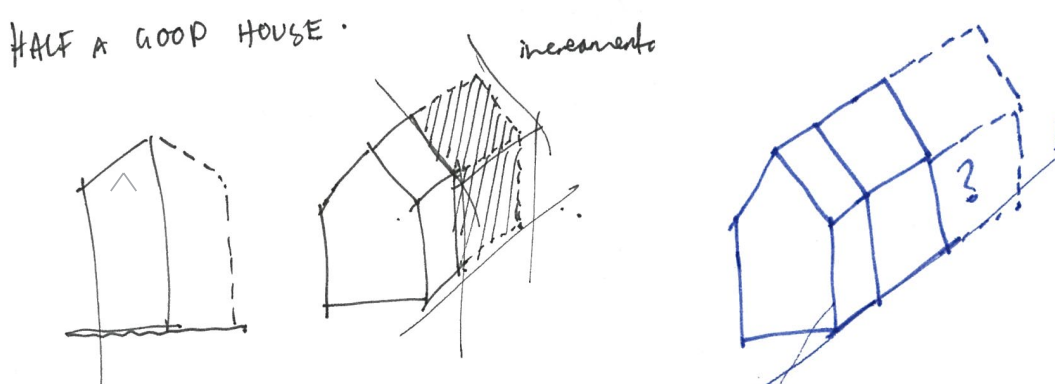

$\wedge$ Figure 25. / Diagram exploring how incremental addition, similar to Half a Good House, could be applied horizontally.

This phase expands on and develops the lessons learned in the first design exploration. With the added knowledge from key literature, this phase aims to explore not only flexible design principles, but the idea of half a good house, and the idea that the users could add modules incrementally as their finances allowed them. 


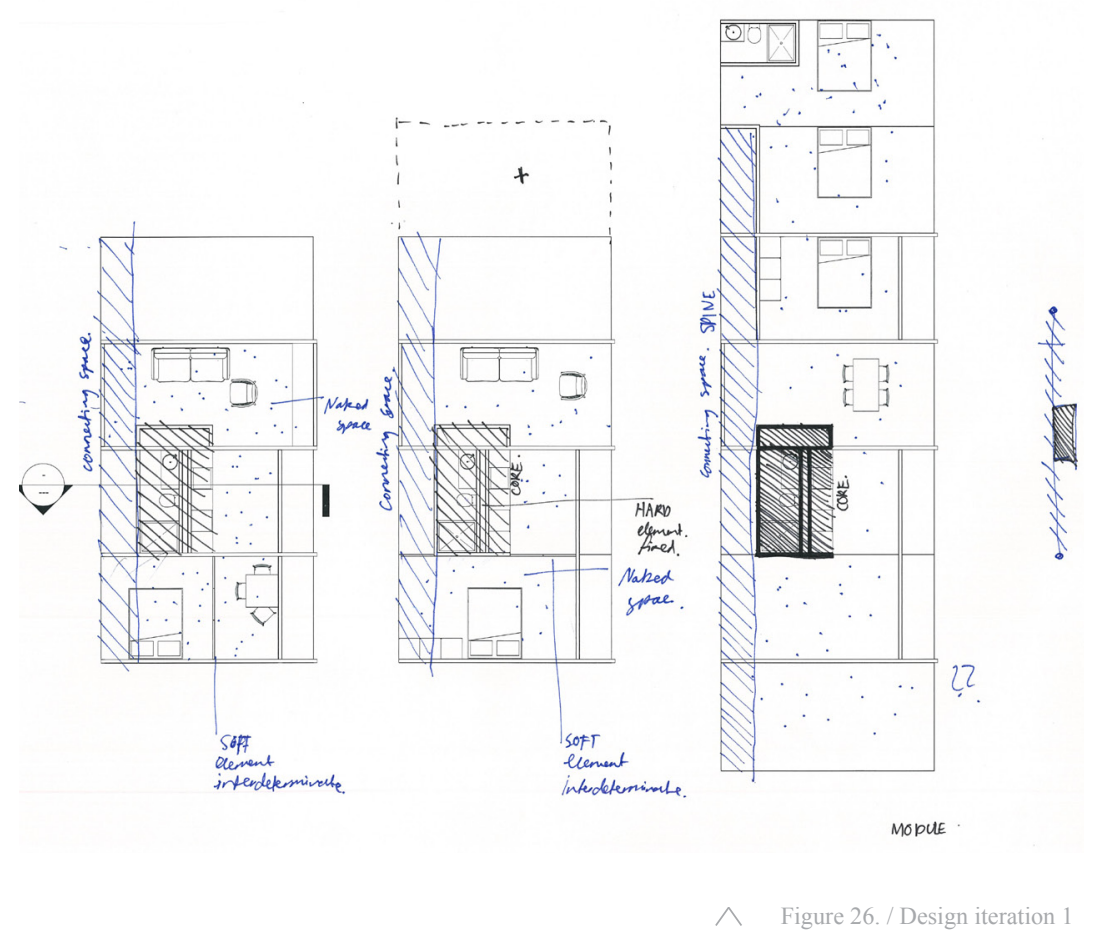

This design explores how modules could be added to either end of the design extending it horizontally. This design is more successful in its smaller, early stages, as it soon becomes very elongated. However, it was useful to see what the plan would be like when the house is fully extended. It showed how important the circulation space or the backbone became a connection to the additional modules. But it also highlighted how long and elongated this space would become. 


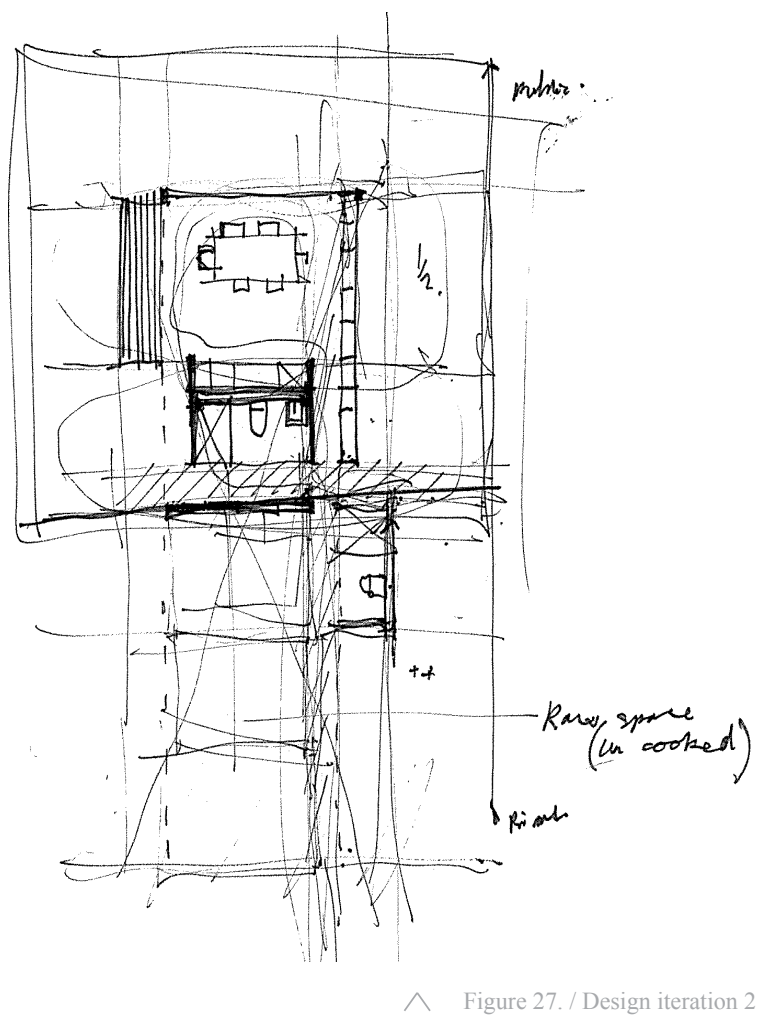

This iteration rotates the core and adds a secondary circulation corridor that divides the building in half. This particular iteration implements the idea of half a good house more so than the first. The first half contains the core and a multi-use space that could be used for living and sleeping. The second half is separated by the circulation corridor that connects the space for additional modules. This corridor allows the sleeping spaces to become more private and separated from the living areas.

\section{Critical Reflection:}

The living area in the first half is too small because in the first phase this space would be used as both a living and sleeping area

Additional bathrooms would need to be individual modules and preferably connected to the backbone or connecting space

How the modules physically join has still not been developed. The addition of modules may work in terms of layout and design but the construction detail allowing this needs to be figured out. 


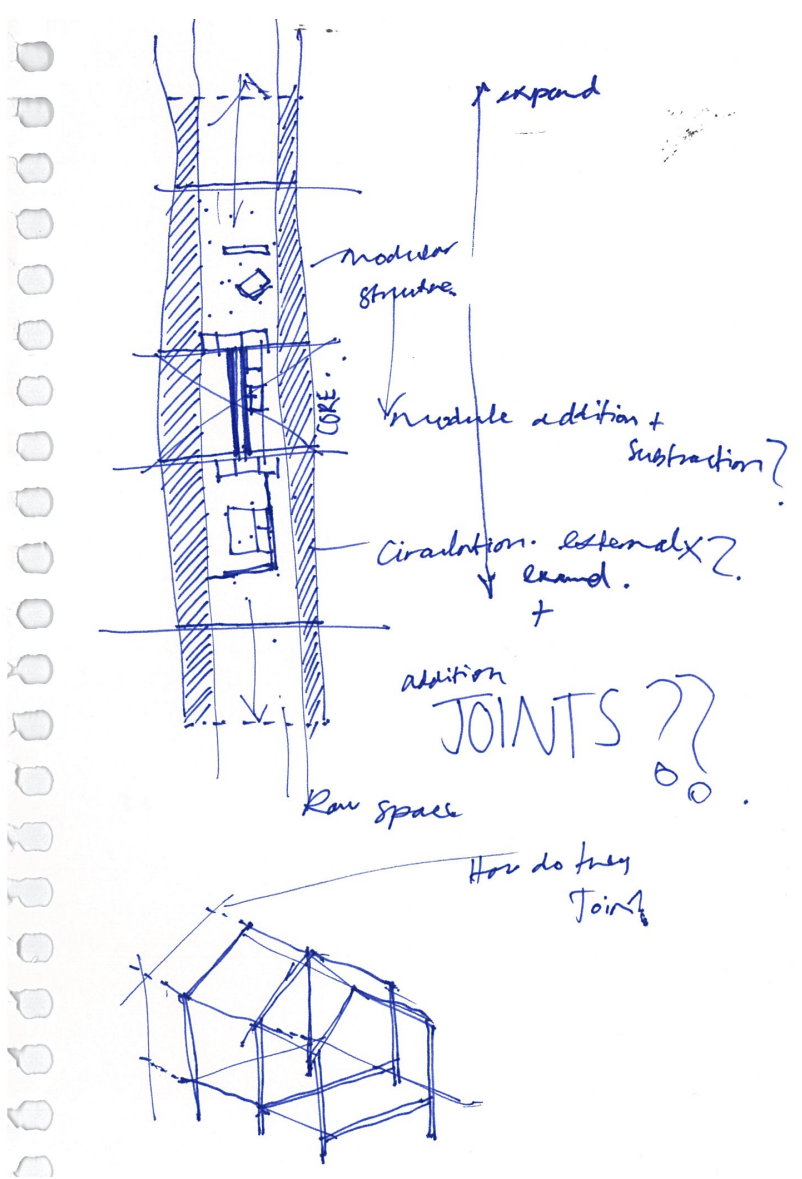

Figure 28. / Critique of Design Iteration 2

The real issue is how the modules physically join. The joining of modules requires the development of a special detail that addresses waterproofing and weather tightness issues.

Another way to construct incrementally without adding modules needs to be figured out so issues such as waterproofing and weather tightness, issues that lie outside the scope of this research, don't hinder the design research.

At this stage, these designs would only work for narrow or rectangular sites. The next design phase needs to flesh out how these same principles could be applied to a range of sites to achieve the aims of this research portfolio.

The next page explores a design solution for these issues. Creating a weathertight shell in which incremental addition occur within. 

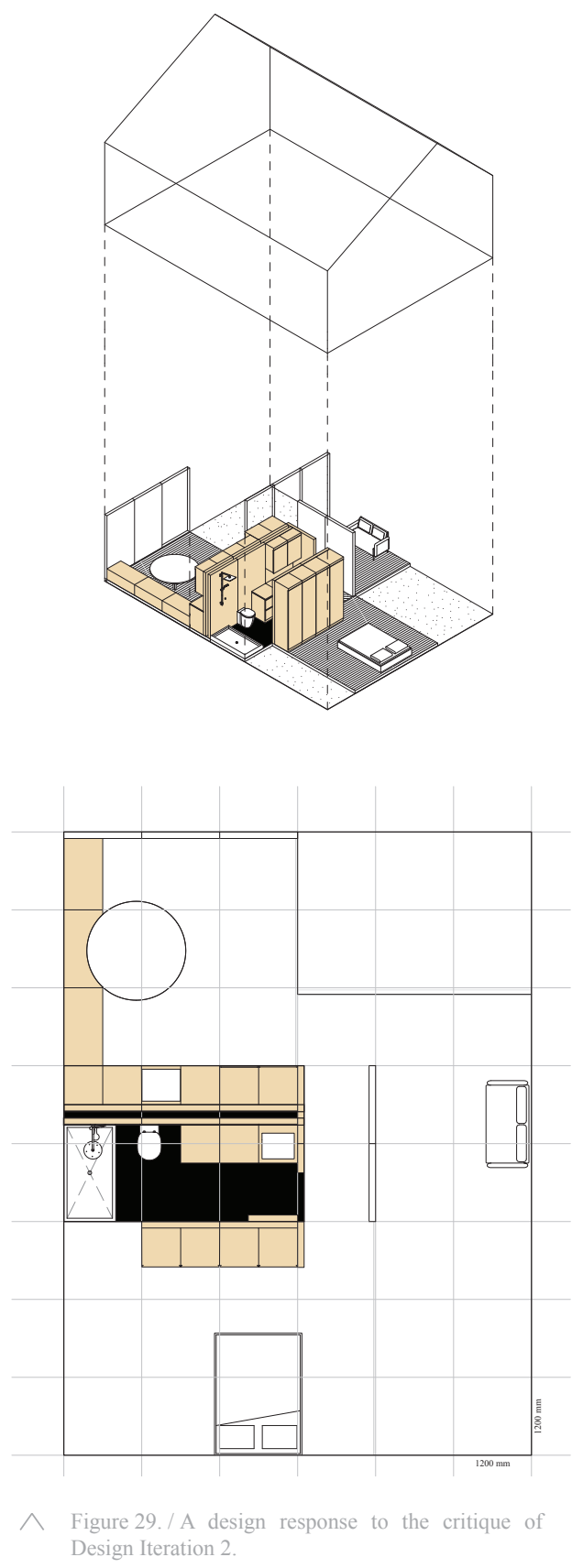


\subsection{PRECEDENTS.}




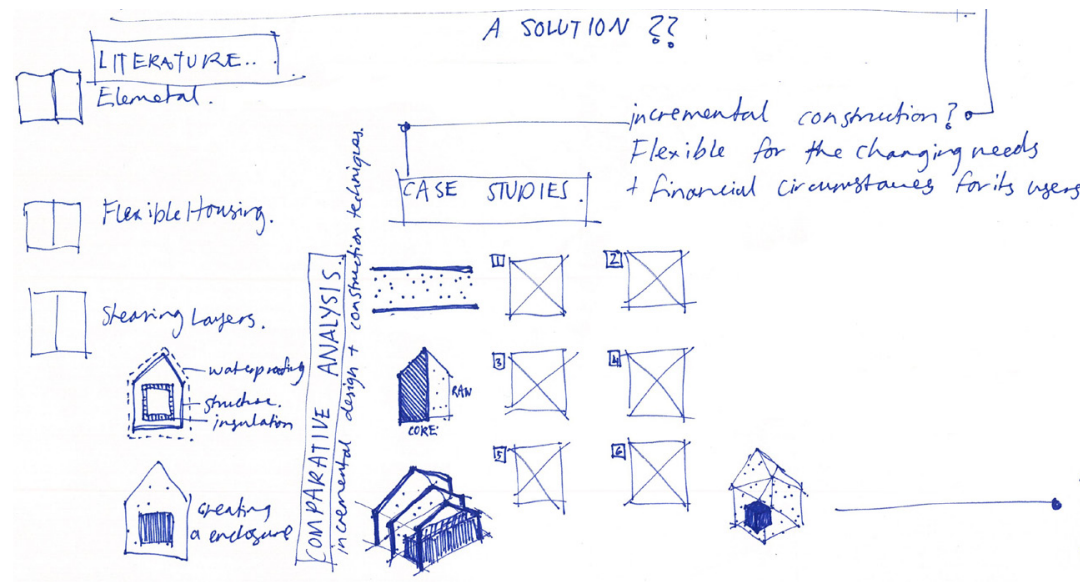

$\wedge$ Figure 30. / Research diagram explaining how the relationship between literature and precedents.

Lessons from the profession - Observations from New Zealand and Abroad.

This research portfolio has thus far considered the 'what' and 'whys' of flexible design and incremental construction. These next two chapters show how flexible design and incremental construction has been and may be achieved. It explores through existing precedence the issues of use and plan and then the issues of structure and construct. This chapter will show how flexible housing may be designed and then how it may be constructed using an incremental approach.

The following precedents have been chosen due to their consideration of flexibility, cost and construction techniques. A wide range of precedents were reviewed from which six were selected for more detailed analysis. A criterion was established which analysed with particular elements such as slack space, functionally neutral rooms, and the use of a service core have all been analysed by redrawing the plans to fully understand the design. The focus has been on elements such as structure, services, zoning, use and modular components and the effectiveness with which these were implemented, both in terms of design and construction. For each precedent, both design and construction techniques that achieve flexibility or incremental addition have been analysed. 
Scale:

The scale of the operation undergoing change.

Operation:

The action performed to achieve the desired outcome.

Flexibility Device:

The enabling element that allows for the operation to be carried out successfully, which is futher divided into spatial or physical device. A flexibility device is defined as the spatial or physical element or series of elements that execute and/or enable change in the dwelling: the tools for flexibility.

NOTE: Words without lie outside the scope of this research.

Design analysis refers to particular ways the housing has been physically planned to promote flexibility so that it can adapt to changing use.

Construction analysis refers to the way that the housing has been constructed and structured to enable future change.

\begin{tabular}{|c|c|c|c|}
\hline \multirow[t]{2}{*}{ Scale } & \multirow[t]{2}{*}{ Operation } & \multicolumn{2}{|l|}{ Flexibility Device } \\
\hline & & $\begin{array}{l}\text { Spatial Device } \\
\text { SOFT }\end{array}$ & $\begin{array}{l}\text { Physical Device } \\
\text { HARD }\end{array}$ \\
\hline Element & Reconfigure & Surplus Space & Window \\
\hline Room /Zone & Join & Variable Space & Door \\
\hline Dwelling & Divide & External Circulation & Stair \\
\hline Building & Infill & Internal Circulation & Screen \\
\hline Precinct & Extend & Anticipation & Partition \\
\hline \multicolumn{4}{|r|}{ Construction } \\
\hline City & & & Structure \\
\hline \multirow[t]{2}{*}{ Region } & & & Roof \\
\hline & & & Services \\
\hline
\end{tabular}

Figure 31. / Flexibility Matrix used to describe flexibility in terms of scale, operation and device.

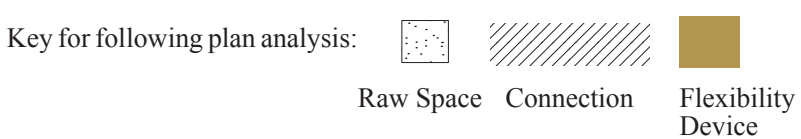




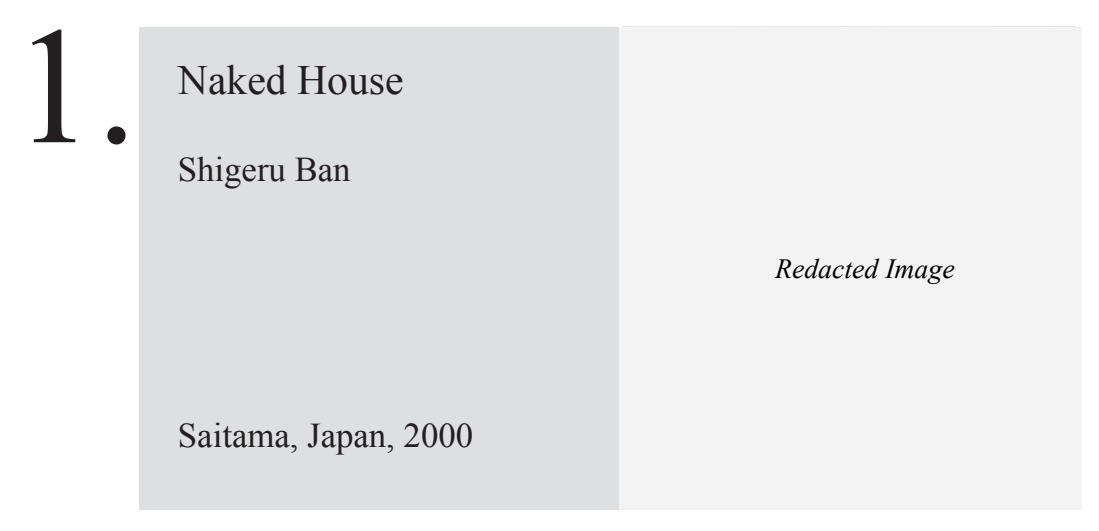

The Naked House, by Architect Shigeru Ban, unites three generations - grandmother, parents and two children all under one roof. Similarly to the aims of this research portfolio, the Naked House is characterised by unencumbered open layouts, and references flexible, bright interiors and permeability from the outside to the inside.

The interior is a single, large, two-story enclosure in which four personal rooms on casters can be moved freely (Jeska 2008). He has designed a house, "naked" of any partitions, in response to the client's request that the house had to encourage the relationship between the members of a three generations family where they could easily communicate and relate to each other (Quintal 2014).

Working within the concept of different generations fusing their lives, Shigeru Ban has created a translucent shed-like structure containing a single common space in which private areas were reduced to a minimum. The translucent plastic façade blurs the boundaries of exterior and interior creating a spatial fusion between the two. It allows natural light to flood the interior and makes the interior seem even more spacious.
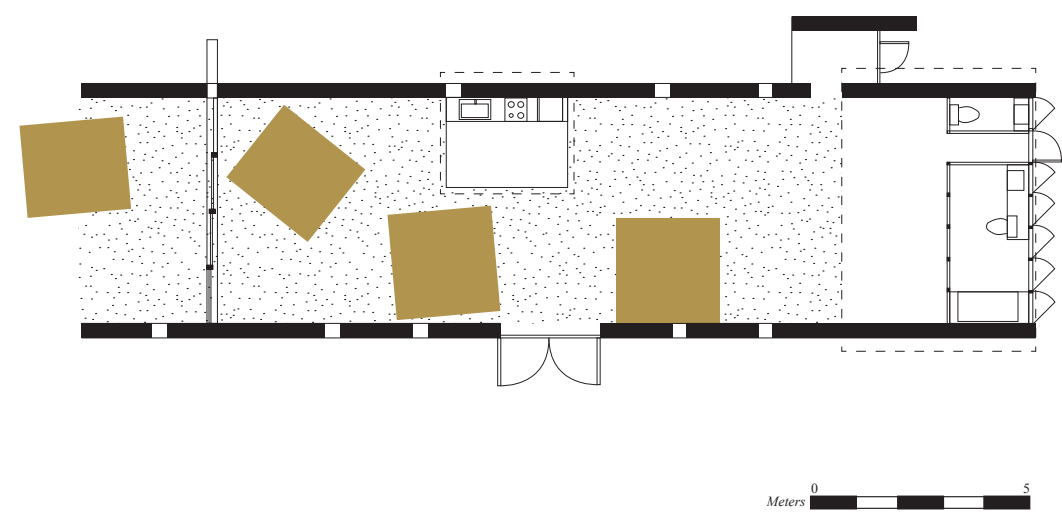
Variable and Surplus Space: Shigeru Ban has purposely made the interior space large and empty. This creates a variable space in which the four-room casters can be moved around freely creating a dynamic living environment. These rooms have been designed to move accordingly to the needs of their use. They can be put side by side and create a larger room, they can be taken outside, on the terrace, for the full use of the space inside. With multiple purposes, these rooms can easily be arranged, creating an interior space that can easily respond to the family's changing needs. According to Shigeru Ban, the Naked House, "is designed as one space which describes the course of time like water in the river that never stands still and takes on innumerable forms." (Quintal 2014)

\section{Construction}

Clear spans: The load bearing walls are located along the side of the building allowing the interior space to be clear of any load-bearing walls. This means that internal non-load bearing walls can easily be added to the interior facilitating future internal remodeling.

\section{Critical Reflection}

Varying levels of privacy may need to be applied to the moveable canasters. Although the openess of the space is to encourage interaction between the family, sliding walls along the canasters could provide different levels of privacy and a place to retreat.

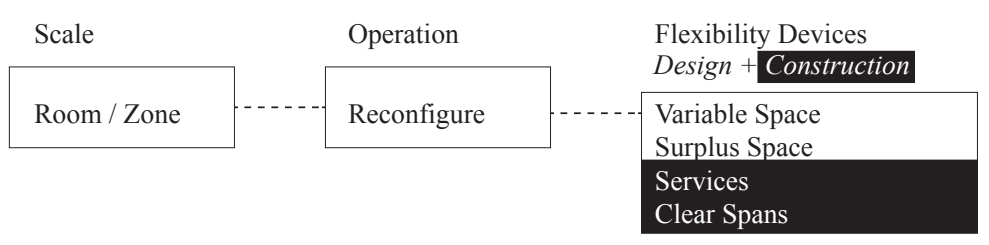




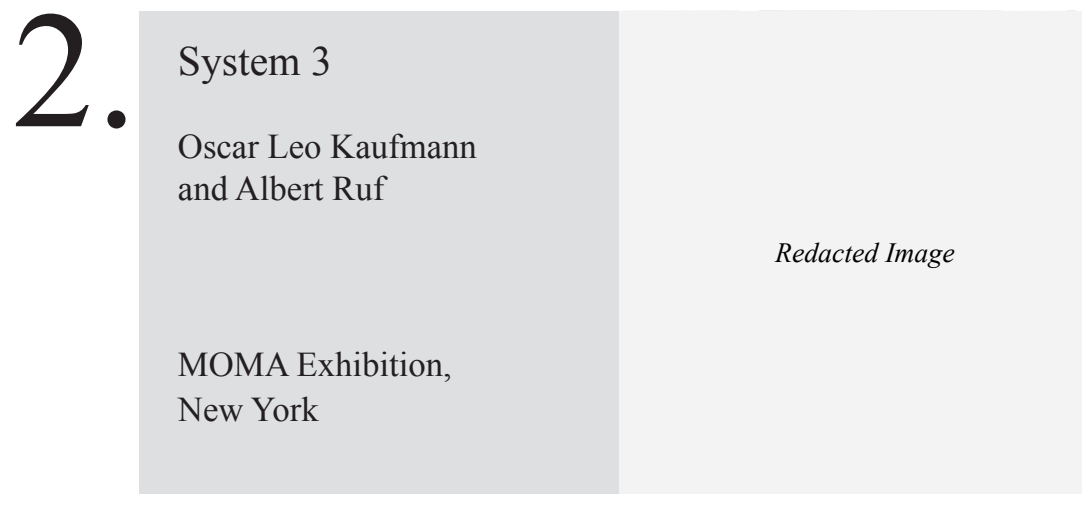

Designed by Oscar Leo Kaufmann and Albert Ruf, System 3 is the result of their quest for a building system that delivers high-quality design at low cost. They aimed to use prefabricated construction techniques to deliver a high-quality building assembled in 7 hours on site, costing approximately $\$ 180,000$ (Bergdoll and Christensen 2008).

Manufactured from laminated timber, it was commissioned by the Museum of Modern Art in New York for their 2008 exhibition titled "Home Delivery: Fabricating the Modern Dwelling". It consists of two parts, a "serving" space and a "naked" space. The serving space is effectively the service module, which contains a stair, bathroom, kitchen and all the appliances requiring power and water. The second part, named the "naked space" by the architects, encloses the space that doesn't have a set function such as living. Only consisting of planar elements like floor, walls, windows, and roof only, it is the part of the house that contains the furniture and layout decided by the occupant. Both the serving space and naked space are of equal size, put together they form a whole.
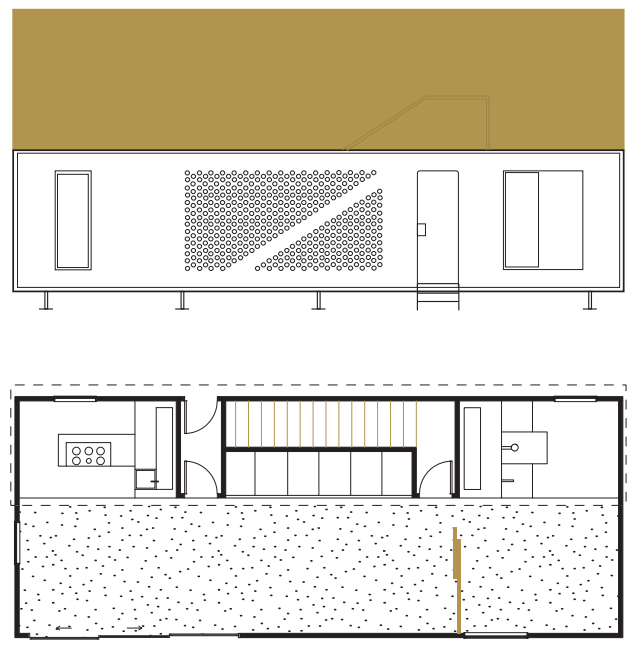
Variable Space: The "naked" space is a functionally neutral room that offers variable space. Sliding partitions can divide the room to create a more private sleeping area or more open living area offering a room with various different uses. All built-in storage and furniture is also located within the service module making the naked space even more neutral.

\section{Construction}

Services: The position of the service core and the most permanent elements in the plan, the kitchen, and bathroom allows for addition and flexibility of the unit. This dwelling is the smallest configuration, but the system is flexible enough to facilitate expansion into larger multi-level buildings. The core has stair access to the roof, which can serve to connect floors in the case of vertical expansion of units. Since the designs of the dwelling consist of flat floor and roof plates, this vertical stacking is possible. The modularity of system 3 makes it possible to change or expand the house at any time without limitation.

"The house is never finished - there is always a possibility to change, add or reduce it." Oscar Leo Kaufmann.

\section{Critical Reflection}

The modernist rectangular form allows for limited sun control and passive design principals, which similarly create a sharp demarcation between the interior and exterior, with no sheltered intermediate space to link the two. In the New Zealand environment, some form of shade from the sun is necessary to control the interior environment and reduce the potential for overheating.

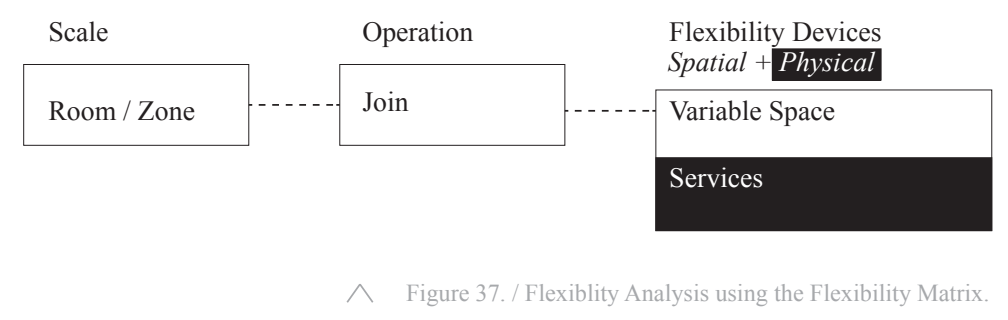




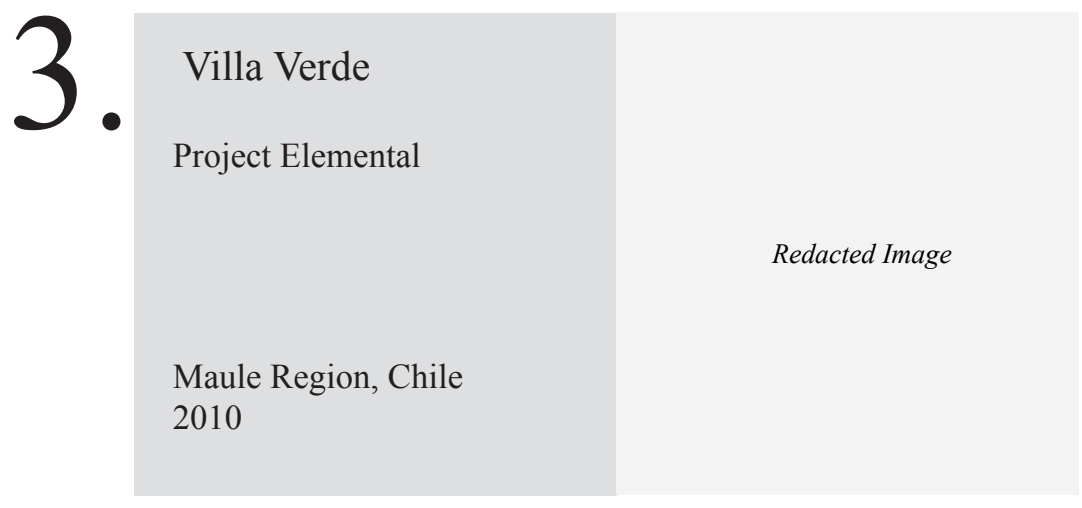

Applying the principle of incremental construction, Villa Verde from project Elemental is another precedent extremely relevant to this research portfolio. It is an example of the idea half a good house, mentioned in the previous chapter in the review of Elemental, the incremental housing guide (Aravena \& Lacobelli, 2012). Signature to project Elemental, this half-finished housing typology prioritizes complex components by only constructing the necessary parts first and includes a framed empty space that allows for addition as the users' needs and financial circumstances change.

The half a good house typology began as a way of dealing with extremely low budgets with the idea that the houses could gain value over time. Their design for Villa Verde is an attempt to show that there is value in this incremental construction process, whether it is used at the cheaper or more expensive end of housing ("Villa Verde Housing / ELEMENTAL," 2013). Fundamentally, it is a demonstration that all homeowners are aspirational, and that for many homeowners the best way to account for this aspiration is to provide flexibility and space to expand (Greenspan, 2016).
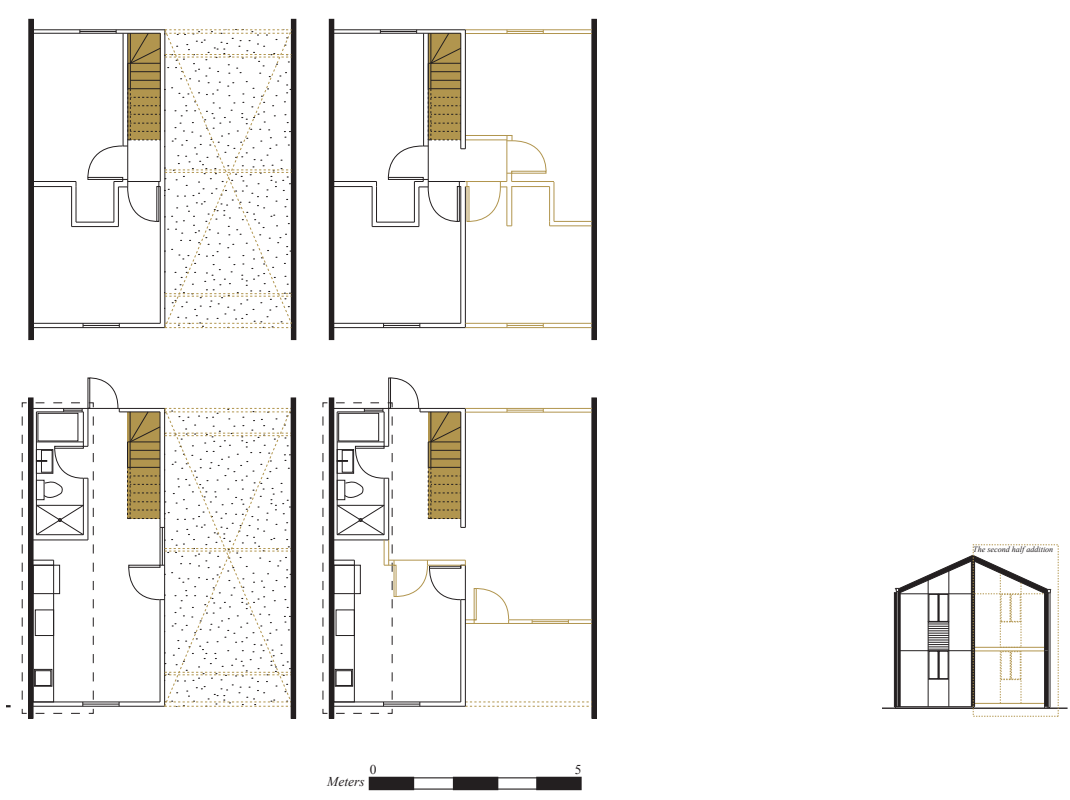
Raw Space: The houses are simple two-story homes, each with a wall that runs down the middle, splitting the house in two. The other side remains empty and is simply just a framed empty space waiting to be filled in by the occupant as their needs and finances allow them to do so. Residents in their own time have the opportunity to expand into the adjacent empty space. The design is prepared to change over time, just as the evolving family needs and aspires to do.

Anticipation: Project Elemental have defined a layout which considers expansions as part of the project so changes are made very welcome. Elemental has designed the most difficult part of the house so that expansions can be done in an easy, economical, and safe way(Aravena \& Lacobelli, 2012). The scheme accommodates the required program in half of the maximum allowed volume. The other half is initially a big porch able to accommodate expansions of the original home or even a second house. This is the space that ultimately can increase their assets thanks to a larger house or additional income.

\section{Construction}

Structure: The house is designed as a porous structure, a support for improvised expansions. The pores (spaces destined for future expansions by the families) are surrounded by solid structures to contain and rationalize individual interventions. This limits the possibility for users to ruin the structural integrity of the building with their individual additions. Considering that the building would eventually grow to almost double its initial size, the structure allows for this growth by doing structural calculations for the final size of the house.

Roof: The roof controls the extent of the building. As mentioned in Elemental, the incremental housing guide, it is one of the most expensive parts of a building so therefore creating the extent of the building first allows for incremental addition.

Services: The services are located in the half of the house that is constructed first. According to Elementals Incremental Housing Guide, elements such as the bathroom and kitchen should be constructed first as they are fixed and often difficult to construct. By installing these fixed elements first, the incremental of the remainder of the building becomes a lot easier and cheaper for the users.

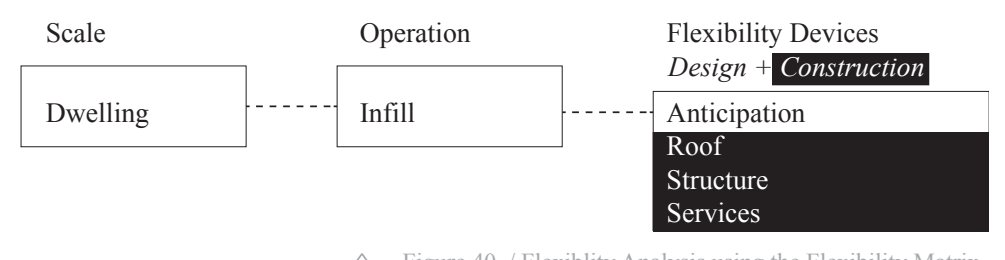




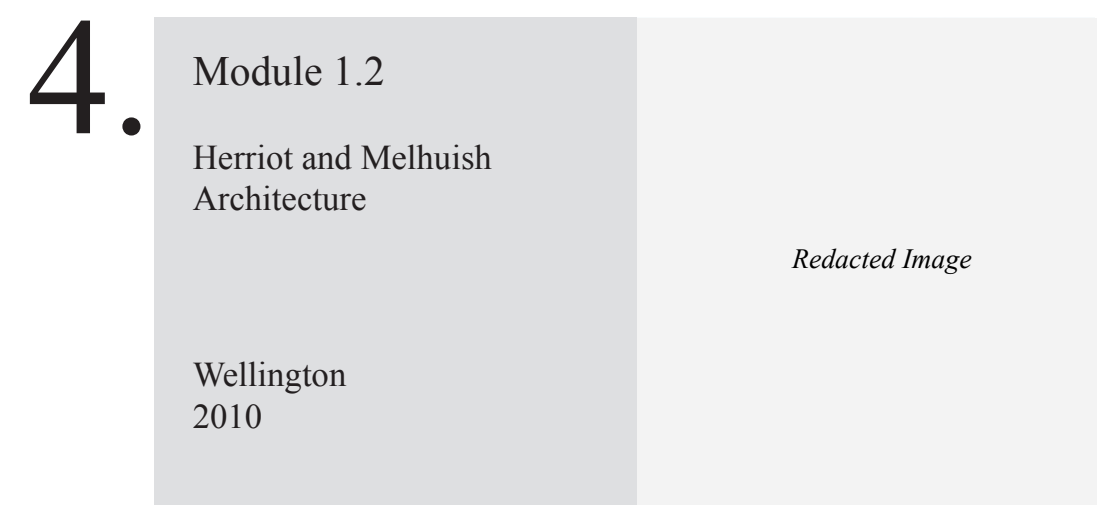

Module 1.2 by Wellington architects Herriot and Melhuish (HMA) and engages a hybrid, service module + panel approach, which in this case explore structurally insulated panel (SIP) technology. It was designed as an entry in the Department of Building and Housing 2008 Starter Home Design Competition ("Starter Homes," 2009).

Simplicity of form is combined with a modern aesthetic to deliver a high performing home that utilises a combination of engineered timber construction and innovative building technology ("Cheap start homes with style ", 2009). On the south side of the house there is a long slim service module and the remaining space is shared between private and communal zones. The proportions of the service module allows the unit to incorporate both zones of the house, the kitchen adjoining the communal living zone to the west, and the bathroom and laundry zone in the more private bedroom zone to the west.

Design

Circulation: A central corridor is located in the service module essentially dividing the service module and living/ dining/ sleeping spaces resulting in a direct and efficient circulation path that runs the length of the building.

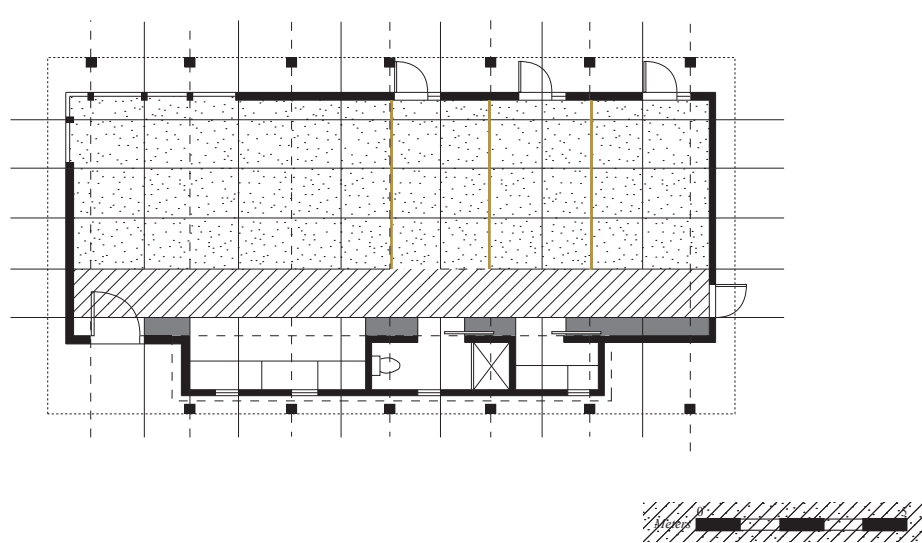


Variable Space: Similar to the precedent System 3, the separation of fixed service elements and "naked" undefined living space creates variable space that can easily be adapted by rearranging non-load bearing partition walls. This creates a flexible living space that can easily respond to the users changing needs.

\section{Construction}

Structure: The structure of the house is expressed independently from the building, essentially an LVL portal frame with $2.4 \mathrm{~m}$ structural bays inset $600 \mathrm{~m}$ from the building edge. The standardised portal frame allows the floor area of the house to extend in $2.4 \mathrm{~m}$ modules, allowing the same standard planning arrangement and service module to extend from a one-bedroom solution to a four-bedroom solution. The isolated structure also allows the non-load bearing internal partitions to be organised as per individual user requirements. This is an example of how modular incremental addition could work to provide an alternative planning arrangement for the users. It also shows an example of how isolating the structure can allow internal non-load bearing internal partitions to be arranged as the users please.

Service Module: The prefinished service module is delivered and craned into position adjacent to the building platform. Services are connected and pre-cut LVL portal frame erected. SIP panels are delivered pre-cut and flat-packed directly to a site The building is enclosed, and clad before internal fit-out occurs using prefabricated modular wall panels and joinery items.

\section{Critical Reflection}

The concept plan for the two bedroom design is comparably large at $93 \mathrm{~m} 2$, perhaps too driven by the proportions of the space devised by the module size. There is also a concern that when the building is extended to a four-bedroom home, the bathroom will not be large enough and potentially another bathroom will need to be added.

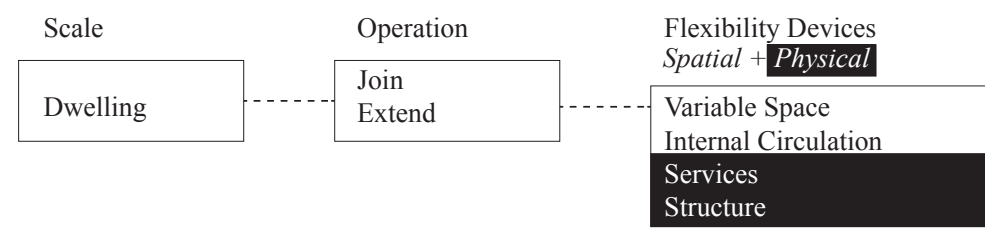

Figure 43. / Flexiblity Analysis using the Flexibility Matrix. 


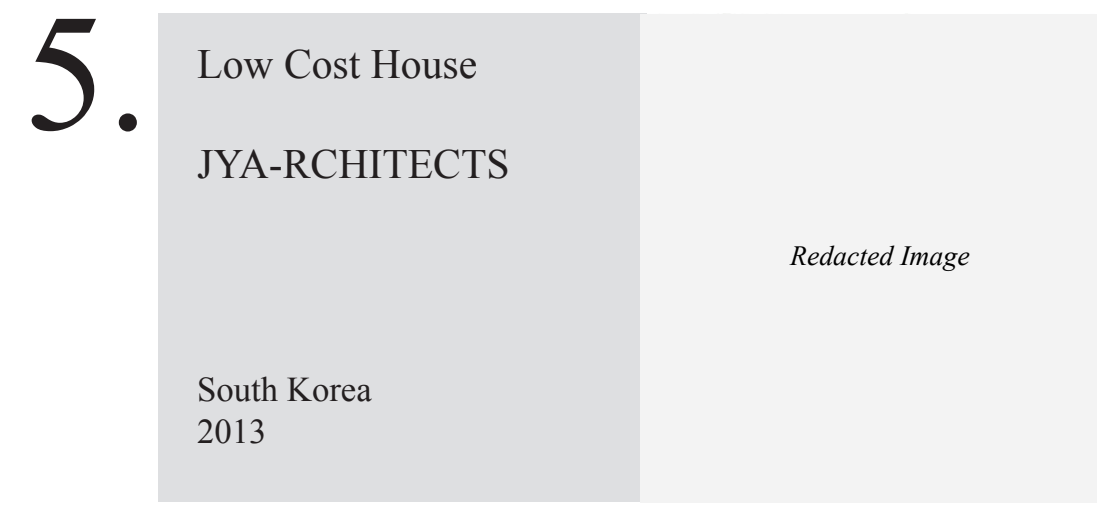

The Low-Cost House by JYA-Architects was part of a series of houses designed to improve the living environment for low-income families (JYA-rchitects, 2013). Each of the homes in the Low-Cost House Series demonstrates a different solution associated with building on a small budget. This precedent is, therefore, an example of affordable housing and deals with issues such as housing a large family in a confined space. Flexible design techniques have been used to offer a dynamic living space and incremental construction techniques have also been employed to allow for potential changes to the interior.

\section{Design}

External Circulation and Variable Space: The intention was to create a house within a house, with three insulation layers, where undefined spaces are generated between the "indoor house" and the "outdoor house" that increase the spatial richness of the dwelling (JYA-rchitects, 2013). 'Undefined', 'variable' spaces have been created between the inside and outside of the house, creating external circulation and extending its spatial flexibility beyond the interior.

Service Core: Combining the most permanent elements in plan such as the kitchen and bathroom allows the remaining space to be a lot more flexible in terms of use.
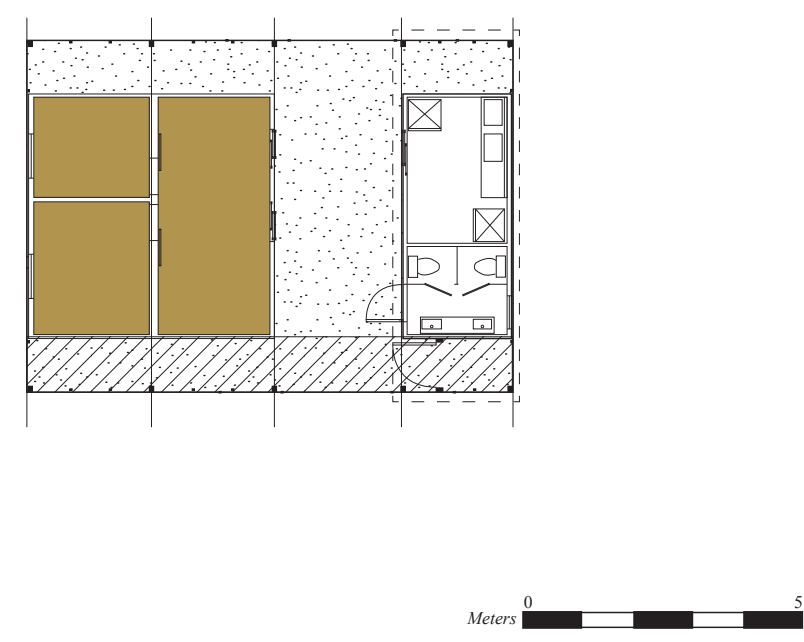
Moveable sliding doors: The two containers placed beside each other offer the most amount of flexibility in the design. Sliding doors can create more open play areas for the children or closed private areas for sleeping.

Functionally Neutral Rooms: These containers have been purposely left with a neutral function to allow for greater spatial flexibility for a large family. By removing the hierarchical order contained in the labeling of rooms - i.e. dining room, living room, - each space becomes an independent entity which can be used according to the needs of the users, which inevitability changes over time and even day to day.

\section{Construction}

Although not designed for incremental construction they have still chosen to use prefabricated materials to minimize costs. They chose to use prefab containers in order to minimize both construction costs and time. The frame that creates the exterior waterproof layer does, however, support changes to be made on the inside.

Roof: The use of a frame that creates a house within a house also allows for incremental addition on the interior. The pitched roof offers an opportunity for more rooms to be added above the containers. It is mentioned that this space is already used as a play space for the children (JYA-rchitects, 2013).

\section{Critical Reflection}

The enclosure that creates a house within a house is perhaps to enclosed and only offers a relationship to the outside when sliding doors on each side of the enclosure are open. The translucent cladding of this enclosure does however does create a really private environment indoors with natural light that constantly floods the interior. Because the roof is also this transparent material light can enter from all sides.

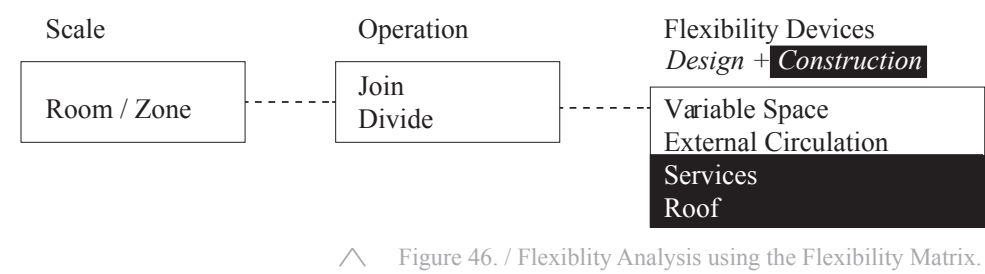




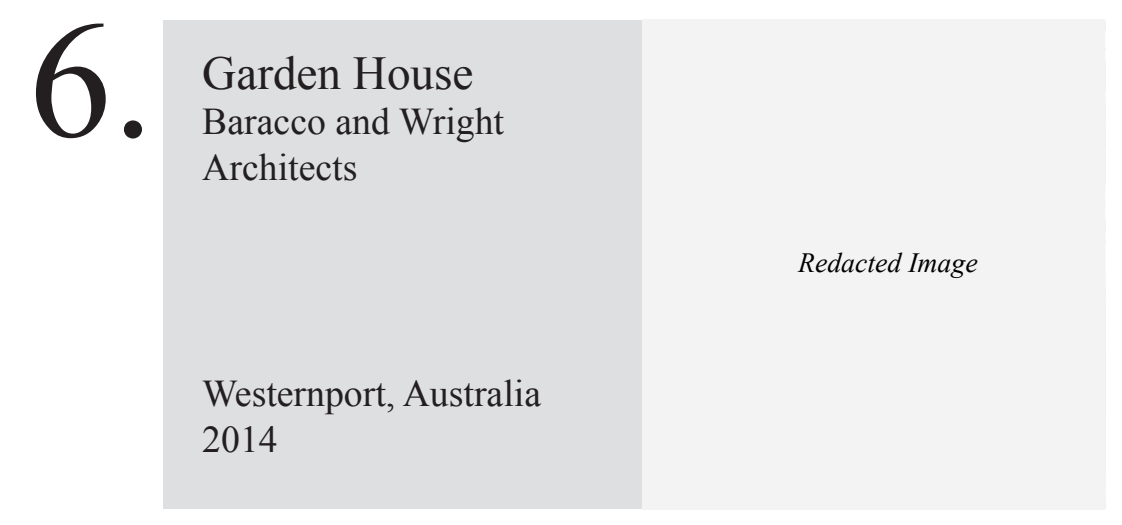

Designed and owned by architects Louise Wright and Mauro Baracco, the Garden House, is an example of the minimalist's design dictum, 'less is more'. It is, after all merely a raised platform covered by a transparent 'shed'. The dwelling is conceived more as a shelter or tent than a house, even the way it was sited parallels an experience of camping, searching for a clearing to stay for the night (Baracco and Wright 2017).

There are just three zones inside: a separate bathroom at ground level which backs onto a small kitchen, a bedroom loft accessed by a ladder and the living areas. The most separate and private area is the raised loft. The largest zone in the Garden House is the living area. It incorporates the dining space, kitchen and a space for sitting and relaxing. The dining table is purposely large as it is used for a range of functions, dining, work and even play. The extremely simple structure is a quietly radical design, dissecting the typical dwelling through the removal of all walls, and the expected delimitation between interior and exterior conditions (Baracco and Wright 2017).

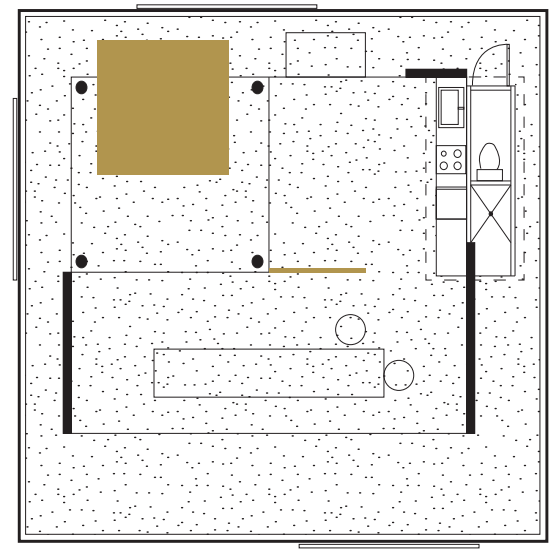

$$
\text { Meters }
$$


Variable space: The interior doesn't have any walls that divide rooms, therefore the whole area is functionally neutral. The interior is divided into zones rather than rooms supporting the variability of the space. This means the interior can be used as the owners please. Louise and Mauro comment that the layout often changes at different times of the day or even times of the year depending on needing sun or shade (Baracco and Wright 2017).

\section{Construction}

As Garden House is essentially a kit shed with a few modifications made to the openings, erecting the building was remarkably quick and only took two weeks. Construction was also relatively inexpensive, had minimal impact on the site and produced very little waste. The form is off-the-shelf kit set shed of steel and polycarbonate cladding with the build costing around $\$ 70,000$ to construct minus land (Redman 2016).

Structure: The form of the house is constructed from a prefabricated shed, providing an affordable, strong and easily constructed skeleton for the skin of transparent polycarbonate sheeting. Layers are clearly seen because the form of the shed enclosure, is dematerialized and undressed as possible. The polycarbonate sheeting forms a waterproof layer over the building, like a tent fly.

Clear Span: The structure is a typical shed portal frame. This allows the interior to have no need for structural walls, therefore changes to the interior can be easily made without ruining the structural integrity of the building.

\section{Critical Reflection}

New Zealand Building regulations would not allow this particular design to be built because there is no insulation in the exterior cladding. As Australia has a different climate and building regulations, to replicate this design in New Zealand, insulation would need to be added. This would mean the building couldn't be so open and would need interior walls with some kind of insulation value. Although this would enclose the interior, it would create privacy possibly needed in more urban environments.

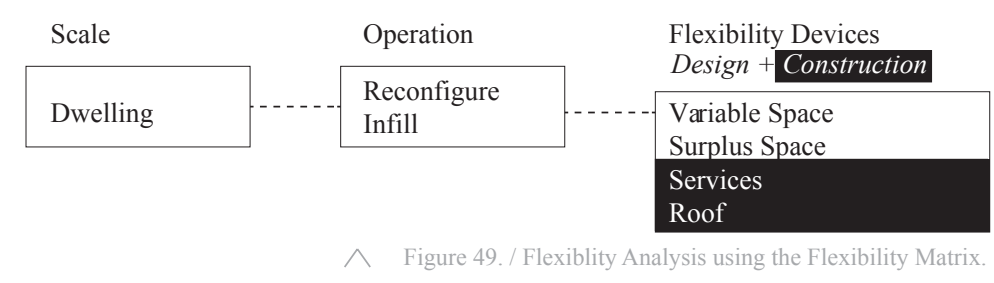


This page is intentionally left blank. 


\subsection{THE TACTICS.}


To summarise the knowledge of both the literature and precedents, a series of tactics to design flexibly and construct incrementally have been created. Jeremy Till and Tatjana Schneider express their concern that many flexible housing schemes have not fulfilled their potential for the simple reason that later users and designers are not aware of the flexible design features that have been incorporated (Schneider and Till 2007). It is therefore vital that these flexible design and incremental construction tactics be summarised and passed on in the architecture profession.

Multiple design and construction strategies are presented in this chapter. Because housing is so contingent on other factors - contextual, social, financial or technical there is no one solution or approach (Schneider and Till 2005). That is why there are multiple tactics that can work at a range of different scales from the whole dwelling, to just an element in a room. A one - fit solution to the architectural question this research portfolio is asking will not meet the varying needs and approaches of a wide range of clients and designers. This chapter, therefore, offers a range of tactics and strategies and leaves it to the designer to choose ones that are most appropriate to his or her particular context. The tactics combine design and construction strategies analysed in precedents and the knowledge from literature to present a way of achieving the aims of this research portfolio. They have been developed with the intention of being applied to a range of sites typical to the New Zealand context to provide an alternative housing solution that addresses housing affordability.

Dwelling

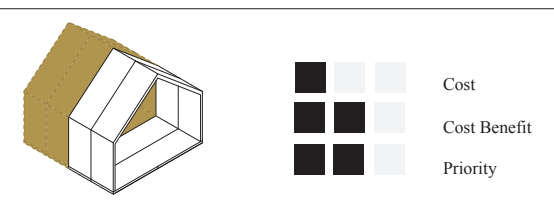

Scale

The Tactic

Cost, Benefit + Priority 
As this research portfolio is trying to address housing affordability cost is, therefore, an element that needs to be considered. During the previous precedent study, it was difficult to quantify exactly the cost of incorporation of flexible housing principles, particularly if one does not account for whole life costs. Alongside these tactics, a very rough indication of the cost of each of the flexible principles, together with their potential benefit over time has been included. Where cost is identified as neutral or low, the implication is that this particular principle can be achieved for little or no cost; often it will be the implementation of the design idea rather than a direct cost. It is intended that if cost and affordability are a concern, the tactics that can be achieved for little or no cost should be used. Where the cost is assessed a medium or high, the implication is an upfront cost but this should be weighed up against the long-term cost benefits in terms of potential savings. The combination of the extent of initial cost and long-term cost-benefit gives an indication of the priority of the particular flexible intervention. A high priority is one that all designers should consider in flexible housing developments.

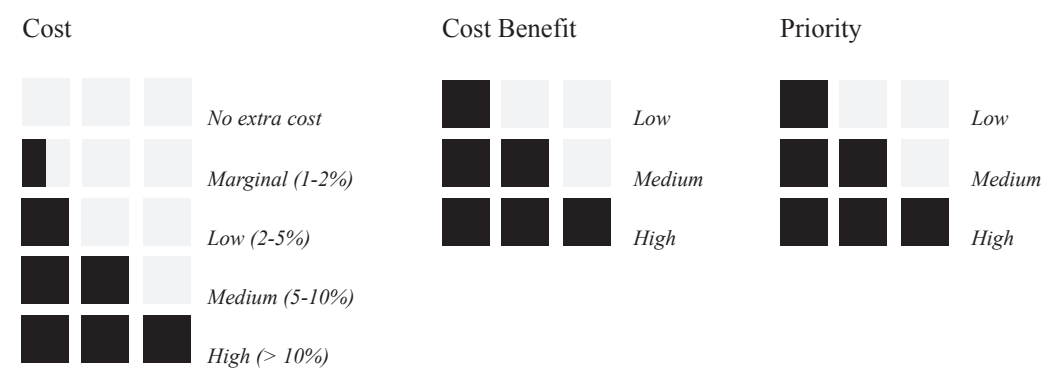




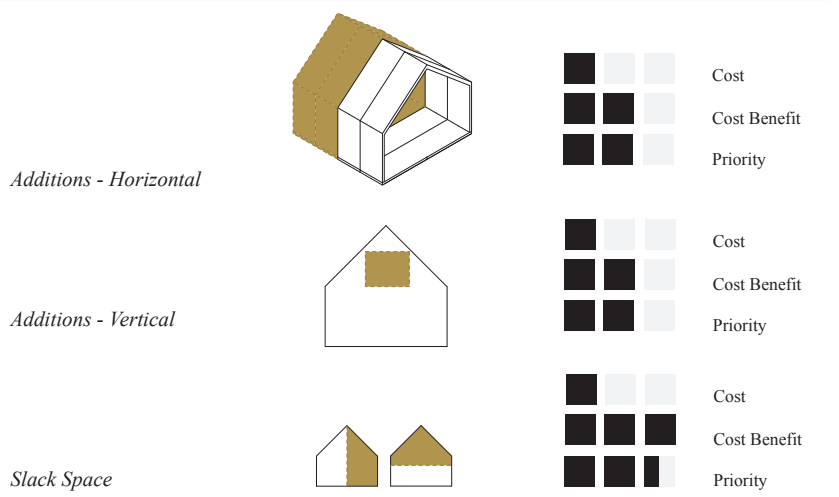

Room / Zone

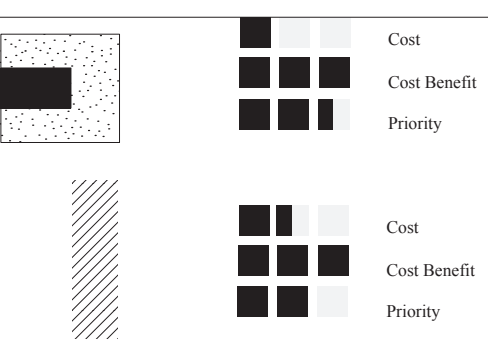

Circulation

Q 1 Priority

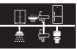

DE corr Beresit

The Service Core

口ص日

\section{Element}

Moveable \& Sliding Walls

Divisible Room

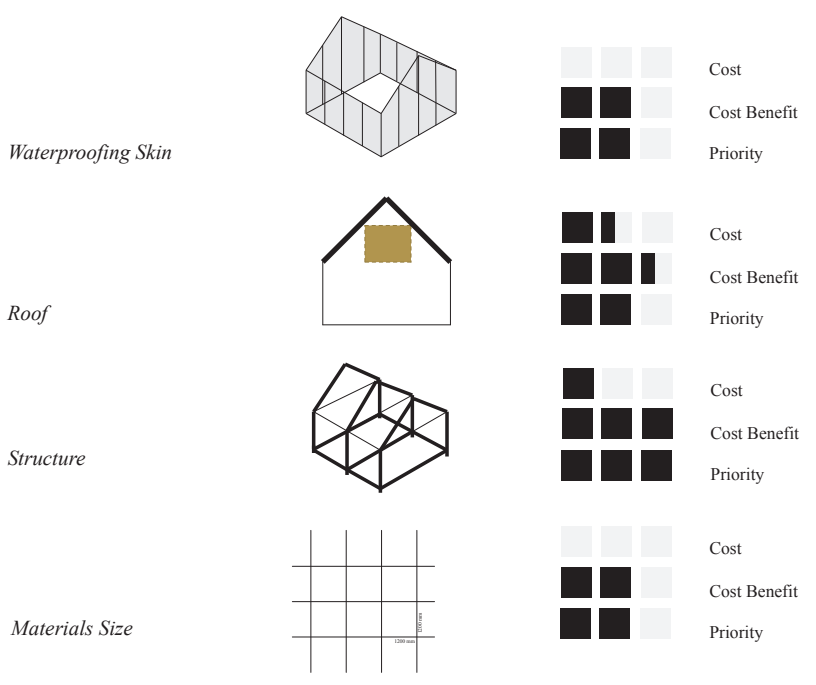


Additions - Horizontal:

Additions horizontally can be easily done if the potential for additions is envisaged at the design stage. Elementals strategy to work backward and design for the final state of the building applies to this tactic. The initial plan form needs to anticipate future extensions rather than limit them. Considerations at the room/ zone level such as circulation should be incorporated with this tactic to ensure it's possible to access this addition.

Additions - Vertical:

Vertical addition can be achieved by moving up into the roof space or by adding space on top of existing structures. Considerations surrounding access and also head height for the space should be made. For a pitched roof, trussed rafters should be avoided where possible to allow the roof space to be occupied at a later date.

Slack space:

Space that is typically outside the housing units that can be appropriated by the users over time, providing more flexibility in use. This tactic was used in Project Elementals, Villa Verde where they provided half a house with the remaining half not defined but suggestive of potential use, allowing occupants to use the space accordingly.

\section{Raw Space:}

Raw space is space not completely finished. No internal walls are fixed and the occupants are provided with an empty space in which they can arrange. According to Jeremy Till and Tatjana Schneider in there book Flexible Housing, it is anticipatory space, suggestive of future use rather than determined use (Schneider and Till 2007).

\section{Cooked Space:}

Cooked space is the opposite of raw space, space that contains fixed elements and is not space that can be easily changed. Examples are spaces such as kitchens and bathrooms where moving elements are not so simple because of wiring and plumbing.

\section{Circulation:}

Circulation space is an important planning component. Ideally, it should be possible to access future additions through existing circulation space. Alongside the service core, the proposed heart of the dwelling, it should work like a backbone providing connection to various different rooms and zones.

\section{Service Core:}

The core should act as the heart of the dwelling where all permanent components are clustered together. Precedents have shown the importance of clustering the bathroom and kitchen together so they can share the same plumbing stack for ease of construction.

\section{Dwelling}
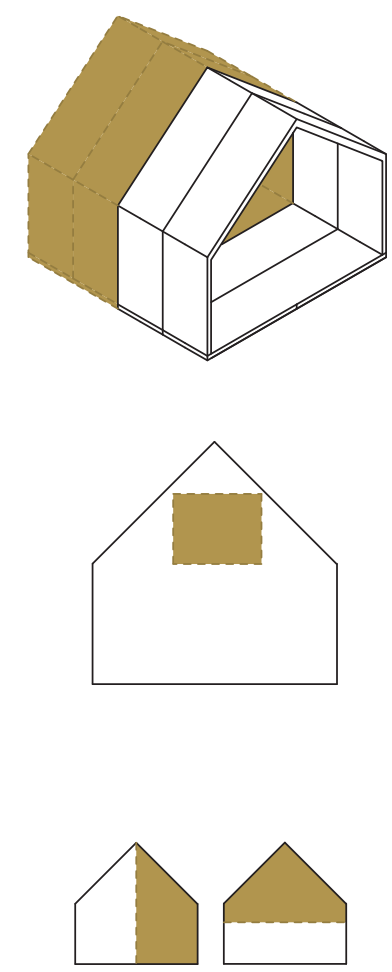

\section{Room / Zone}
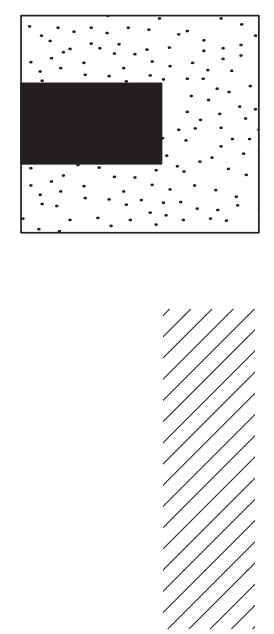

田的象 효욜 
Moveable \& Sliding Walls:

Moveable and sliding walls are used to allow different layouts within a room. They increase the way a room or zone might be used. In precedents moveable or sliding walls have offered a more private enclosure at times or more open area as needed.

\section{Divisible Room:}

This tactic can be used to temporarily or permanently divide up the room allowing the room to have a number of different uses. This tactic works best when the room is functionally neutral allowing the room to be changed depending on the needs of the users.

\section{Multi-Use furniture:}

Furniture that is usually built in to allow the users the change the use of the room. Again, the room should be considered functionally neutral so that the furniture can accommodate the range of uses the room can have. For example, a wardrobe could also become storage for an office.

Considering the construction components are separate layers offers a greater flexibility in terms of design and supports incremental construction.

\section{Waterproofing Skin:}

This tactic encourages the creation of a building envelope and embraces Elemental's theory of working backward by first defining the extent of the building with all additions allowing changes to be easily made within. It was developed from the analysis of precedents such as the Garden House and Low-Cost House that created a house within a house by creating waterproof skin that separates the interior allowing for greater flexibility inside. Creating this building envelope removes all previous issues raised in Design Exploration 2 surrounding the joining of modules and their weathertightness.

Roof:

This tactic encourages the idea that the roof frames the extent of the building creating an enclosure in which additions can easily happen underneath. This supports the previous tactic to create a waterproof enclosure.

\section{Structure:}

The structure should be porous to support expansions and additions that do not affect its structural integrity. It's about considering the growth of the house but using the structure to restrict it so the users cannot ruin the buildings structural integrity. Again encouraging Elementals theory of working backward, the structure should be calculated to support the building once it has expanded.

Material Size:

This tactic expresses the need for a consideration of the materials used for construction and the sizes associated with that material. The use of a $1.2 \mathrm{~m}$ grid set out for planning allows for efficient material use.

\section{Construction Layers}
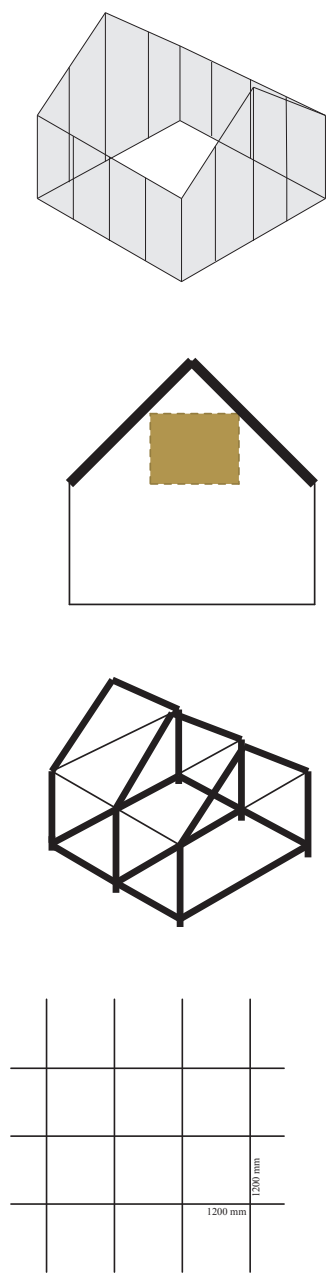
8.0 DESIGN PHASE 3. 


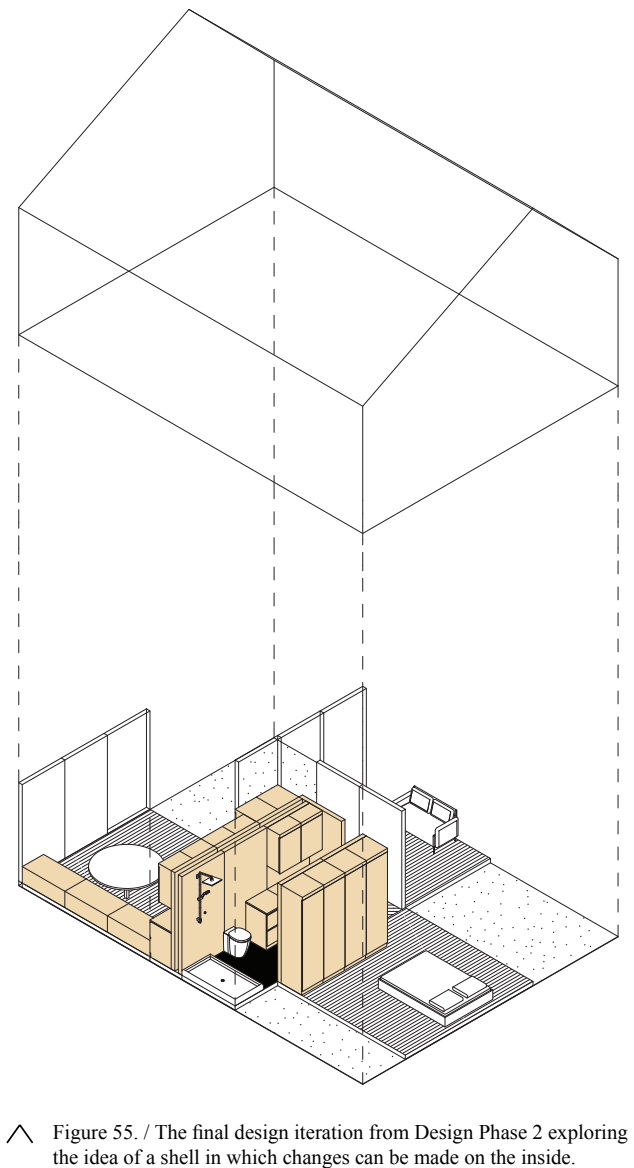
the idea of a shell in which changes can be made on the inside. 


\section{house in the house.}

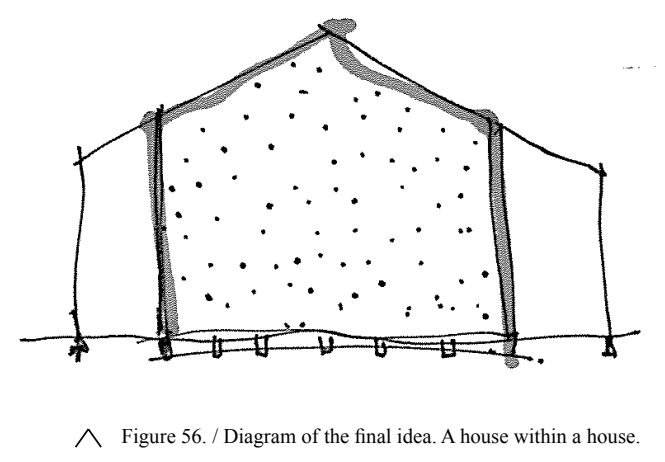

In response to the research of Design Phase 2, Phase 3 focuses on issues surrounding waterproofing and weather tightness. Phase 2 focused on translating the idea of incremental addition and flexible design techniques researched in literature into a series of design iterations. Issues arose surrounding the modules and how they are incrementally joined and how weather tightness issues caused by the joints could be resolved. The following chapter showed a range of precedents and presented some interesting solutions for flexibility other than modular addition. Precedents such as the Low-Cost House and Garden house, create an exterior shell and waterproof layer which frames the interior space in which changes can be made as the users please. Key research from both the literature and precedents were then summarised by a series of flexible design and incremental construction tactics. Multiple tactics that could be applied at a range of different scales have been suggested above however, this chapter focuses on explaining the important ones and the important tactics that help answer the research question. It presents a possible alternative housing solution that has a lower cost because of its form of construction, creating a shell - the waterproof layer and a frame that allows for growth on the inside as the user's needs or finances change. This chapter explains the concept of a house within a house, a house that grows on the inside. 


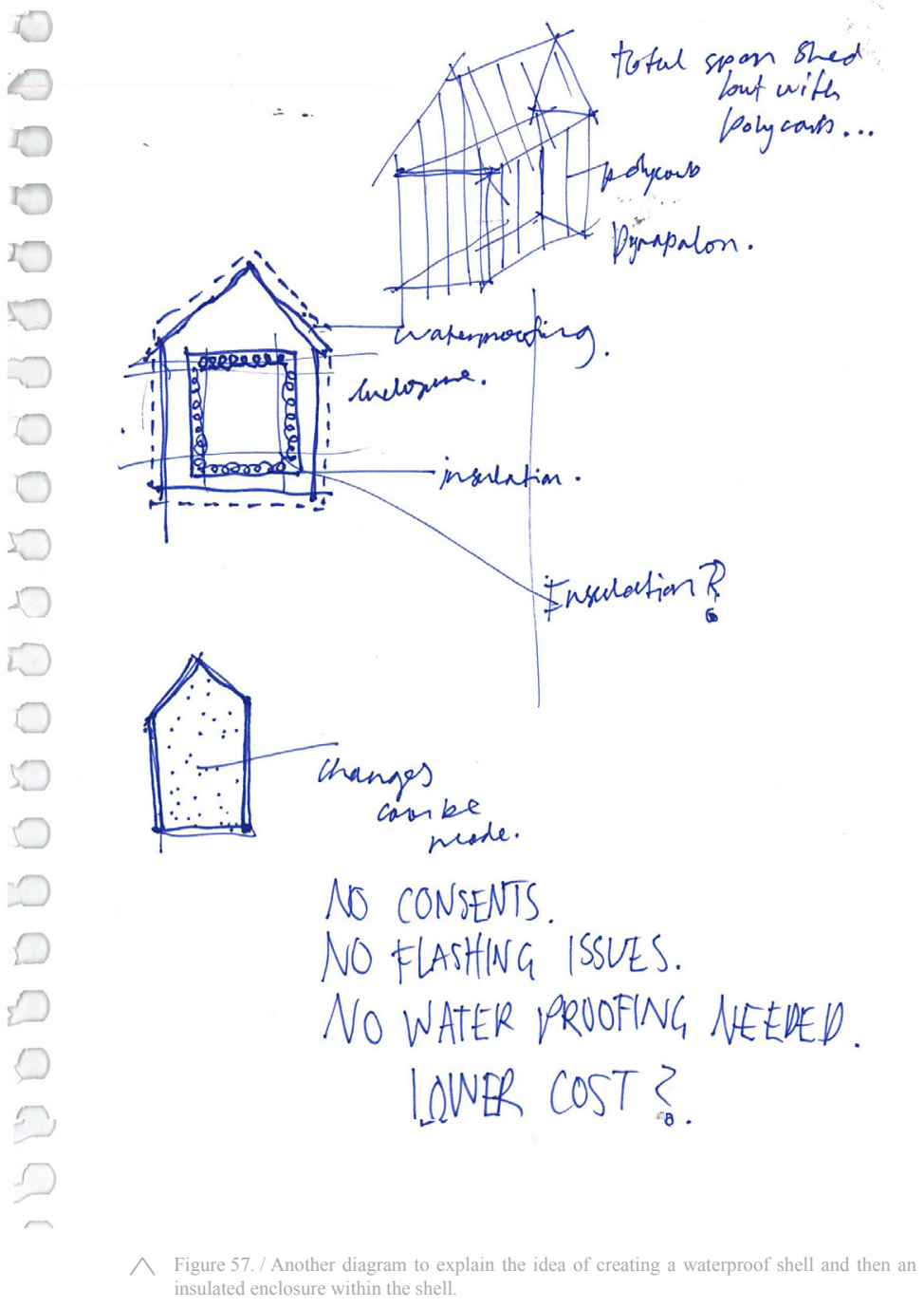


The design research of this portfolio so far is hugely supported by Bernard Leupen's theory of the Frame and Generic Space (Leupen, 2006). He offers a new way of looking to flexibility in a way that supports the design research in previous design explorations.

Likewise, Leupen (2006) mentions that the way buildings are used always changes radically and repeatedly. His emphasis is on the frame and not on what can be changed, but what can be permanent and lasting (Leupen, 2005). He takes not the changeable, but the permanent, or durable component of the house, the frame within change can take place and suggests this is the most important component of flexibility (Leupen, 2006). Till and Schneider also mention that the design of these inflexible, permanent parts of a building plays a crucial role in achieving flexibility and minimising obsolesce (Schneider \& Till, 2007). Just as Bernard Leupen suggests it is the frame that defines the space for change, this research portfolio suggests it is both the frame and the waterproof shell it creates that allows change to occur on the inside. In the New Zealand context, it is the creation of this frame and waterproof shell that reduces issues surrounding weather tightness when changes to the layout need to be made. In previous design phases, such as design phase one, the focus was so much on the changeable. The design of additional modules that could be added or subtracted as the user's needs or finances changed. With similar motives to Leupen, the critique of these design phases suggested a new way of thinking and instead not trying to design the changeable, but designing the permanent so well that changes can be made to the inside (Leupen, 2005). As the title of this research portfolio suggests, the focus turned to creating a house that grows on the inside.

Bernard Cache in his book, Earth moves, also suggests the importance of the frame in architecture (Cache, 1995). Cache (1995) distinguishes three functions that the frame performs: it separates, it selects and rarefies. Expanding on these three functions, this research portfolio suggests that if there is a focus on the design of the frame and the shell it creates, then it frees. Take, for example, a loadbearing column. It relieves the wall from acting in loadbearing capacity, it frees the wall. The non-loadbearing wall can then be moved freely. The column frees the wall. The frame and waterproof shell it creates is a building layer that is most permanent, as suggested earlier by Steward Brand, and separating this layer allows changes to be easily made within (Brand, 1994). Walls can be moved freely as they are non-load bearing and can be easily changed within the shell without issues of waterproofing and ruining the structural integrity of the building. By determining what is permanent, i.e. the frame and shell it creates, design opportunities can be created to deal with future unpredictability. 
This idea could also be related to Dutch Architect Herman Hertzberger's polyvalency theory - the idea that a building can be both lucid and permanent (Hertzberger, 2014). Polyvalency is the French word for multipurpose but in an architectural sense it means almost the same thing. A polyvalent building is able to retain its form, but change in the sense of how it is interpreted (Hertzberger, 2005). Bernard Leupen's idea of the frame creates a polyvalent structure and the shell is capable of adapting to a variety of functions, while remaining essentially the same.

In summary, the stronger the frame is articulated, the more it will claim to be treated carefully, the more important it becomes, the more it frees, and the better it will be used.

"Buildings based on the frame concept provides freedom in future use."

(Bernard Leupen, 2006, p. 197)

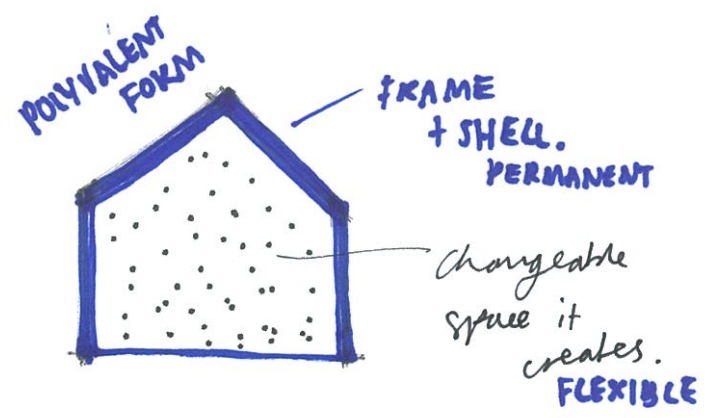

$\bigwedge$ Figure 58. / Diagram explaining Bernard Leupen's idea and how the design of the frame + shell can create a changeable polyvalent space inside. 


\section{Roof + Sinutrue. \\ MOST EXPENSIVE
MOST PERMANENT.}

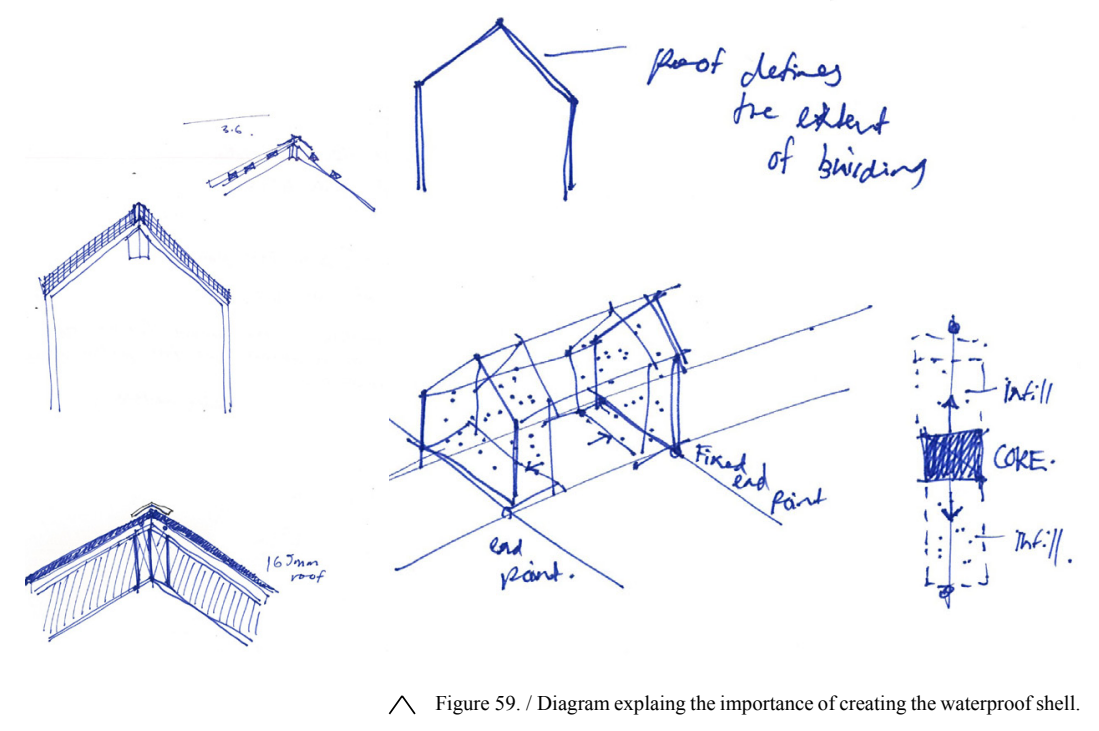

The creation of the shell is an important component of this final design idea. As mentioned in the literature review of Alejandro Aravena's project Elemental, the roof + structure are the most expensive and as explained by both Steward Brand and Bernard Leupen, it is also the most permanent. It is the roof and structure that defines the extent of the building and creates a waterproof shell that allows changes to be easily made within. Shed-like portal frames will created the structure. Inspired by the shed like construction of the Garden House precedent, the frame will be relatively cheap and simple to build. The portal frames will also allow loads to be transferred without the need for load-bearing walls. This way all walls internally are non-load bearing and easily moved. As mentioned above when researching Bernard Leupen's idea of the frame and generic space, this portal frame structural system has a purpose of freeing. It allows walls and changes to the internal layout to be changed freely. 

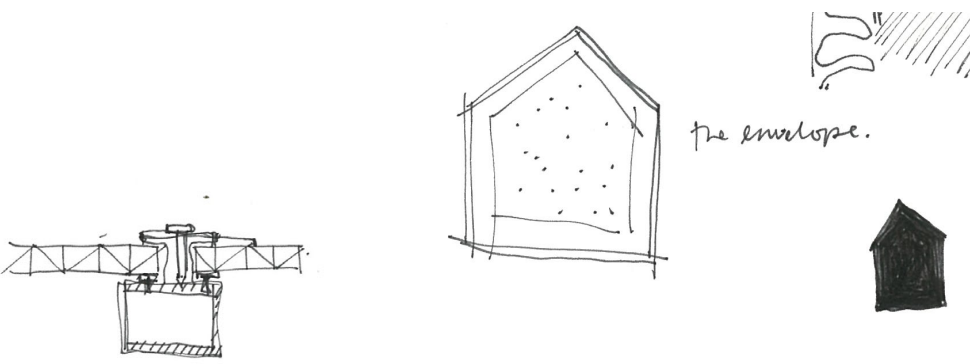

the envelope.

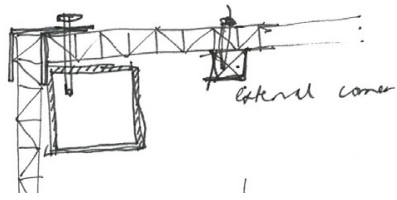

Figure 60 . / Details of the polycarbonate cladding that encloses the building $\checkmark$ envelope and creates the waterproof shell.
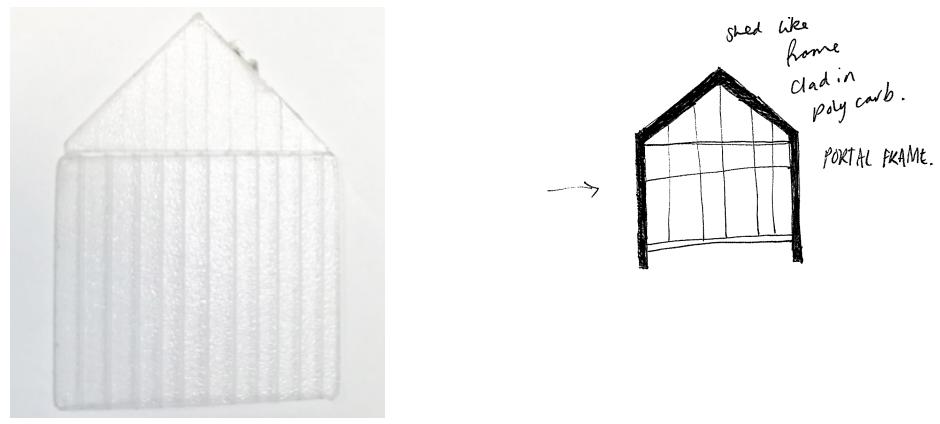

Polycarbonate will be used to clad the shell as a waterproof layer and enclose the building envelope. The polycarbonate creates a shell that keeps out the rain and wind and creates a waterproof layer that allows changes to be easily made within. Polycarbonate as an exterior cladding is cheap and easy to install and has benefits of strength and lightness (EPSE, 2012). Unlike other forms of exterior cladding, it offers light qualities and creates a relationship to the exterior. With its translucent properties and ability to let light in, the building can appear permeable by day and a glow from within at night. It can also offer an aspect of privacy from neighbouring buildings more so than glass. Polycarbonates thermal efficiency also stabilizes and evens out the temperature of the space, cutting down on the cost of utilities and reduces the buildings carbon footprint (EPSE, 2012). 


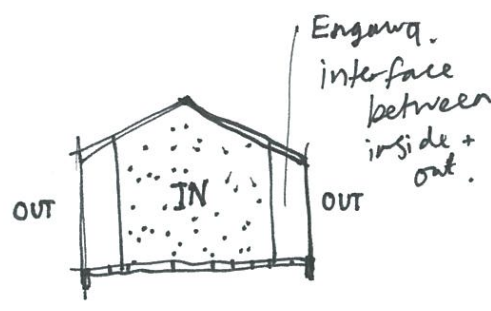

$<$ Figure 61. / Diagram explaining the concept of an Engawa. Figure 62. / The Garden House and its covered porch with a connection between the interior and exterior that could be seen to have engawa influence. Baracco and Wright 2014.

Redacted Image

In Japanese architecture they create an Engawa, resembling a porch or sunroom ("Engawa," n.d.). This space is similar to the areas between the interior spaces and the exterior shell seen in the diagram above. This space is not a separation but a connection between the interior and exterior. It has a continuous and discontinuous relationship with the indoor space at the same time. Continuity contributes to making the house feel more spacious and open, while discontinuity contributes to making the indoor space feel thermally compact and weathertight. 
The acronym SIPs, refers to prefabricated Structurally Insulated Panels. SIPs are high performance composite building panels used in floors, walls and roofs for residential and light commercial buildings. SIPs are made up of a thick layer of polystyrene foam and sandwiched between two structural skins (Formance, N.d.). They provide structural framing, insulation and exterior sheathing all in a solid, one piece component. These two structural skins can be made with a variety of materials including strand board, treated plywood or fibre cement. These variables allow for panels to be optimized to suit the specific needs of any project.

SIP Panels will form the insulation layer within the building envelope - the polycarbonate shell. Because the shell and its polycarbonate material has no insulation value, the insulation will come from the SIPs creating the thermal environment within the building envelope. When the users need to add extra rooms (grow on the inside), the use of SIPs means they can easily do this within the shell. SIPs are manufactured under factory conditions and transported to a construction site, where they can be quickly assembled to form a tight, energy-efficient building envelope. The simplicity of SIPs and the fact they are a solid one-piece component means they are easy to install. Aligned on a bottom plate and then bonded together with expanding foam, the panels are easy to install and offer the possibility for homeowners to install them as they wish (Fig. 63) They are also lightweight and easy to carry into position.

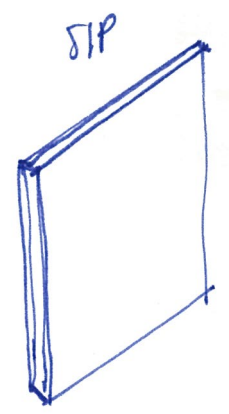


Redacted Image

$\wedge$ Figure 63. / Photo of two men positioning SIP panel onto a bottom plate. Premier SIPS NZ 

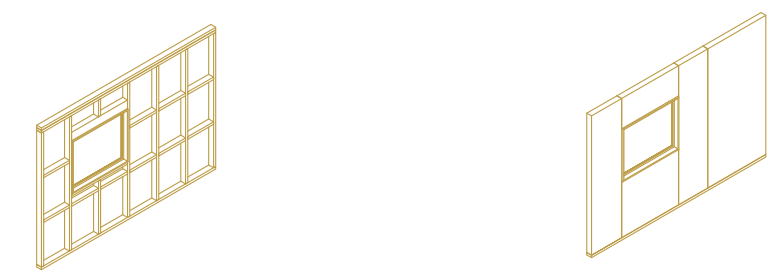

STICKS

SIPS

$\wedge$ Figure 64. / Diagram explaining the simplicity of SIPS vs stick (traditonal timber frame).

Comparing SIP's to conventional (stud and \& batt) framing is not a true "apple to apple" comparison. As expressed in a report by Michael A. Mullen's and M. Arif on the use of Structural Insulated Panels in residential construction, there are several key factors to consider (Mullens \& Arif, 2006). Labour, insulation, and energy savings in the long run needed to be factored. SIP's arrive onsite pre-cut and are ready to install straight off the back of a truck eliminating the time needed to perform the individual operations of framing, insulating and wrapping stick-framed walls. With SIPs you can achieve price parity against conventional stick frame construction due to prefabricated manufacturing and reduced onsite labour requirements. The construction process is more controllable and precise through the use of factory manufacturing. Mullen's and Arif (2006) showed a 50\% decrease in on-site construction time between SIP and timber frame.

The use of SIPs within the polycarbonate shell eliminates the need for exterior cladding and interior finishes could be left raw reducing the associated costs with cladding and finishing. As mentioned by in Project Elemental, 30\% of the cost of construction is spent on the structure and $70 \%$ on the finishing - this proportion should be inverted (Aravena \& Lacobelli, 2012). 70\% on the structure, and less than $30 \%$ on the finishing. By reducing finishing costs, there is more money to be spent on prefabricated materials such as SIPs.

SIPs also eliminate the time and money spent on installing insulation. The panels come pre-insulated so no need to install pink batts adding to the ease of construction. With an R-value of 4.5, they are well above the minimum insulation requirement creaking a super-insulated and airtight enclosure. SIPs have up to $75 \%$ better cumulative R-value than a comparatively sized timber frame walls with conventional fiberglass insulation. This marked improvement makes the investment in heating systems unnecessary which makes further savings on the build cost and then running costs in the future. As mentioned by NZ SIP, the key to building an 'affordable house' is to achieve both an affordable build and more importantly, ongoing low running costs. 


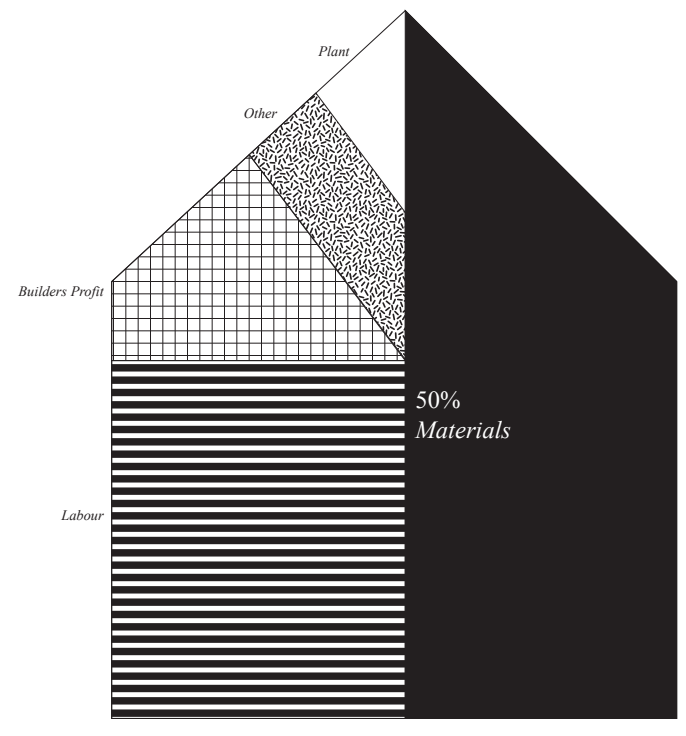

$\bigwedge$ Figure 65. / Diagram explaining residential construction costs. Based on figures from New Zealand Productivity Commission 2012 
Material and labour has been identified by BRANZ in their report, 'New House Price Modelling', as costs that could be greatly reduced (Page, 2008). The use of prefabricated materials has been identified as a way of reducing build costs. The above diagram shows materials account for $50 \%$ of residential construction costs as found in a recent Housing Affordability Inquiry by the New Zealand Productivity Commission (New Zealand Productivity Commission, 2012). In 2017, material costs have risen even more, with construction costs alone increasing an average 2.1 percent per annum (Johnson et al., 2018). But as mentioned in earlier chapters, using a prefabricated material can reduce up to $15 \%$ of total construction costs as well as a $50 \%$ time saving because less labour is required. Both materials and labour are costs that need to be reduced in order to achieve the aims of this research portfolio creating an alternative, affordable, housing solution. This alternative housing solution will prove that designing and constructing using prefabricated materials will allow the users to add onto the building in stages as they can afford. This way they won't have huge upfront build costs they can simply start with a small affordable building that provides the framework for incremental additions at a later stage. As a way of further proving the construction methods of this final idea are an affordable solution, the material costs of one of the proposed dwellings will be compared to a similarly sized dwelling built using traditional construction methods.

Tools for building affordably:

The use of SIPs instead of sticks will reduce both labour and material costs.

Reducing material finishing costs such as painting and the GIB, plaster labour required will lessen the build costs.

Keeping onsite labour to a minimum by using prefabricated materials will lessen build costs.

Designing and constructing in a flexible and incremental way so that the building can be added to as the users' needs and finances changes. 
9.0 THE FINAL DESIGNS. 

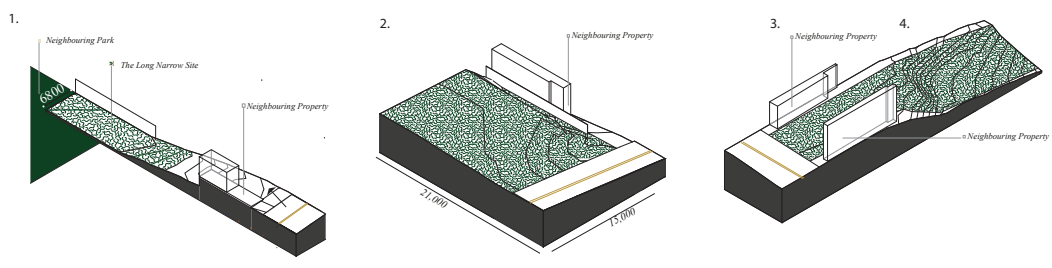

THE UN-USED BACK YARD SITE

$\wedge$ Figure 66. / The four test sites.

Although this research portfolio is not site specific it is important to have test sites that have varying differences in size and typography. The sites demonstrate how the design and construction tactics could be applied to a number of different sites in varying locations typical to the New Zealand context. Four sites have been chosen to test how the use of these design and constructions could be applied to varying sites with varying sizes and typography's.

1. A narrow infill site. Only 6.8 meters wide it tests the minimum width these tactics could be applied too.

2. A typical wide site. This typology tests how the tactics could work in a more square formation.

3. and 4. A site that could have two dwellings making use of an unused backyard that has a steep typography. This site tests both a relatively normal flat site and a more difficult sloping site with steep terrain. 


\section{Test 1
Site 1.}

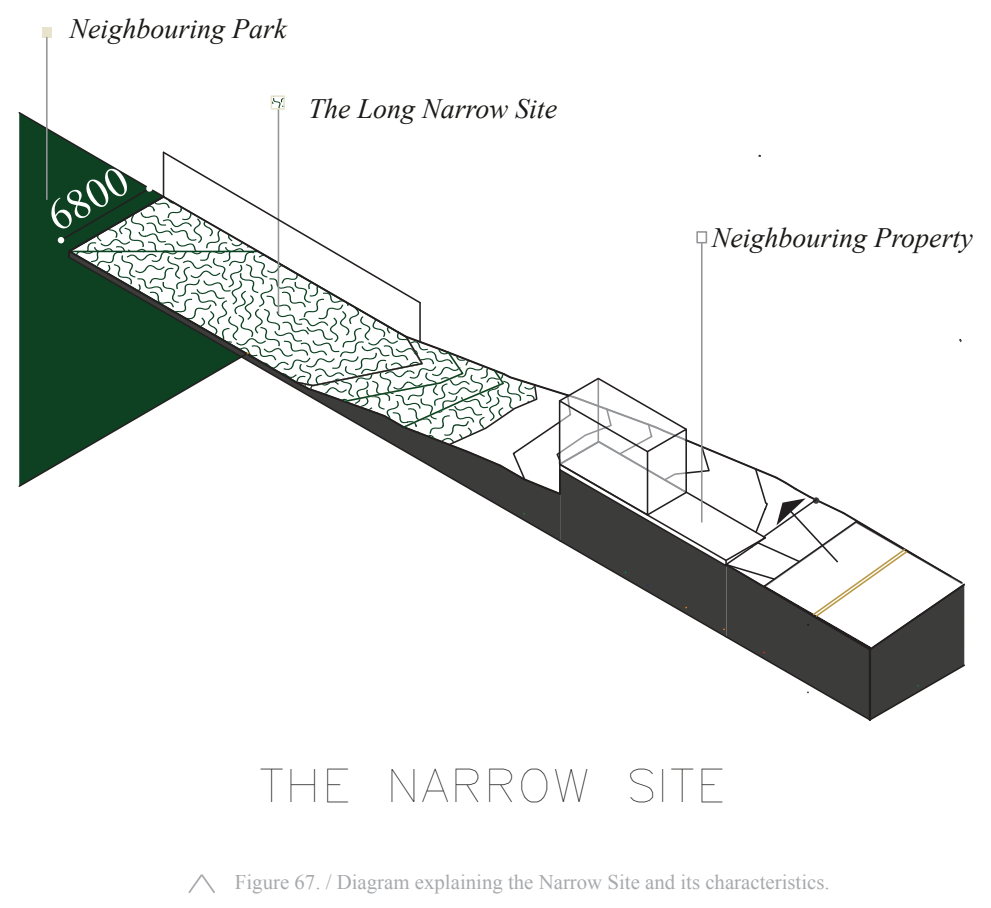




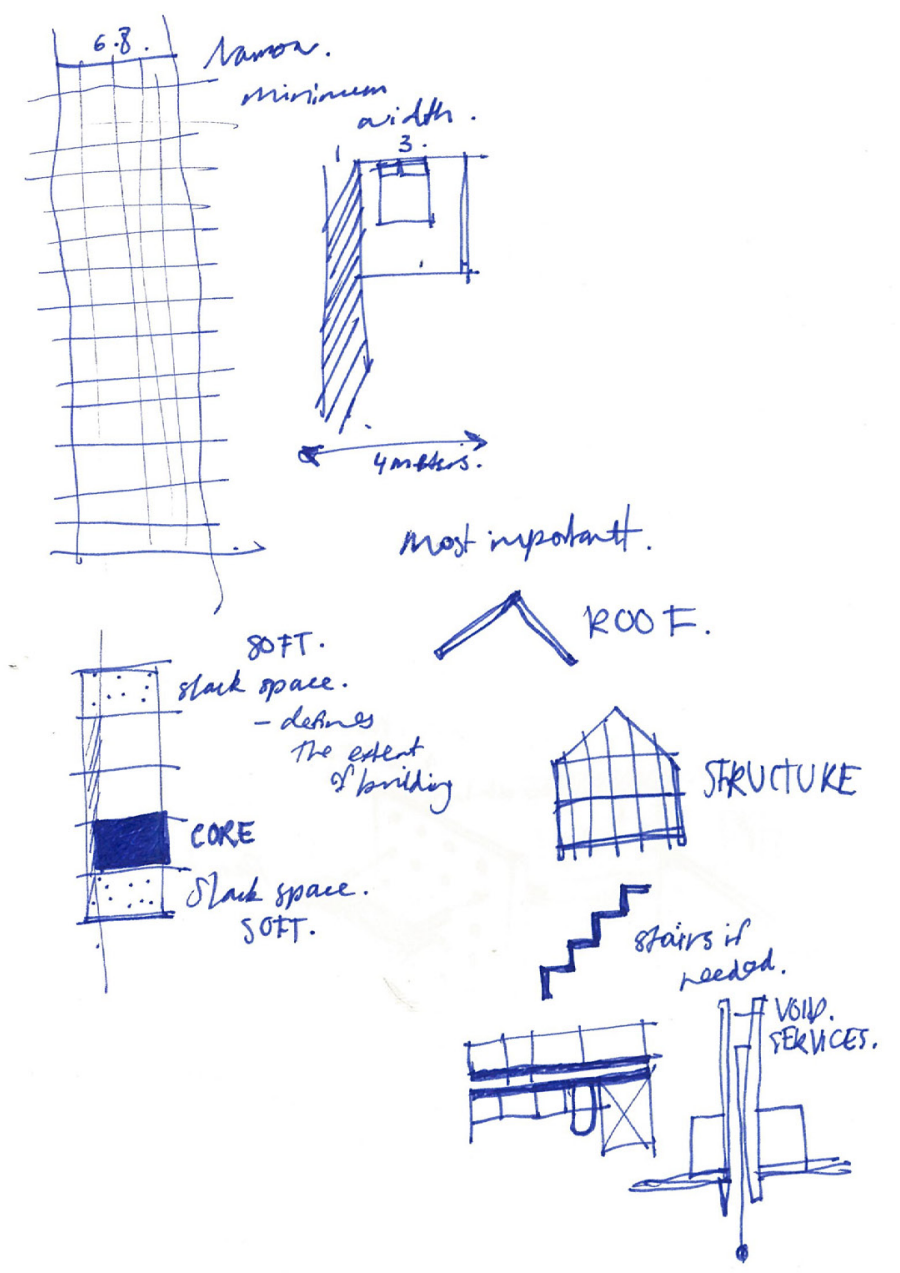

Figure 68. / Sketches explaining the tactics used for the Narrow Site 

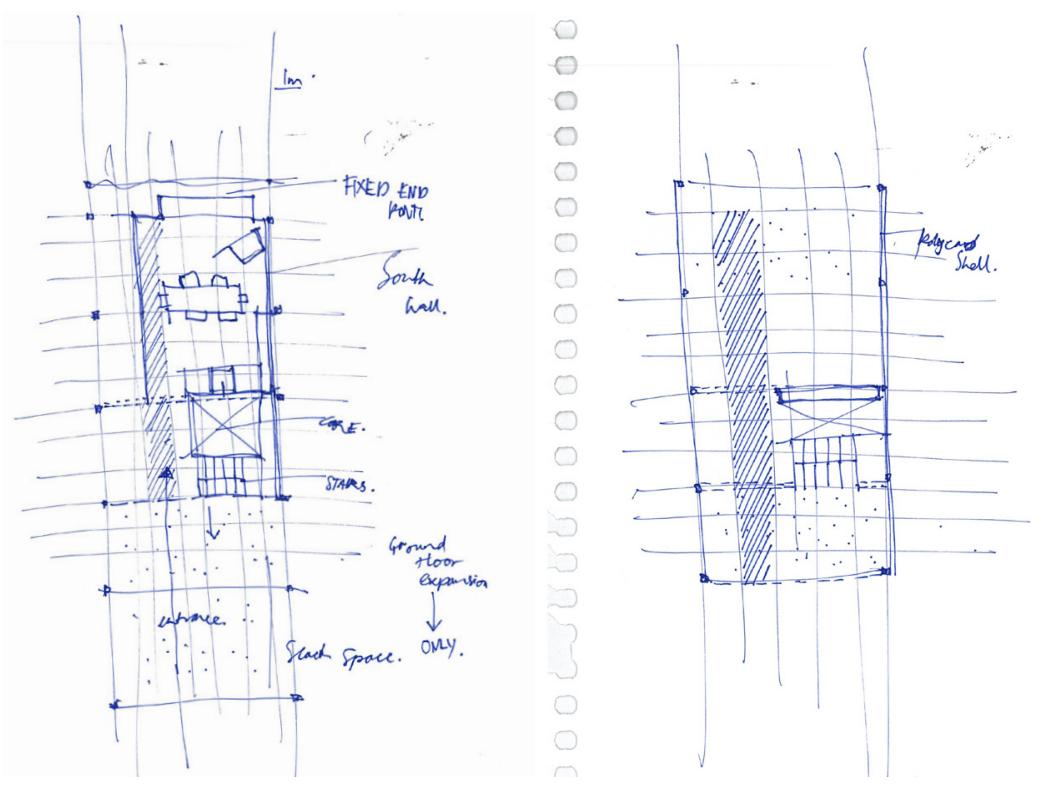

$\wedge$ Figure 69. / Sketches explaining the floor plan for the Narrow Site 

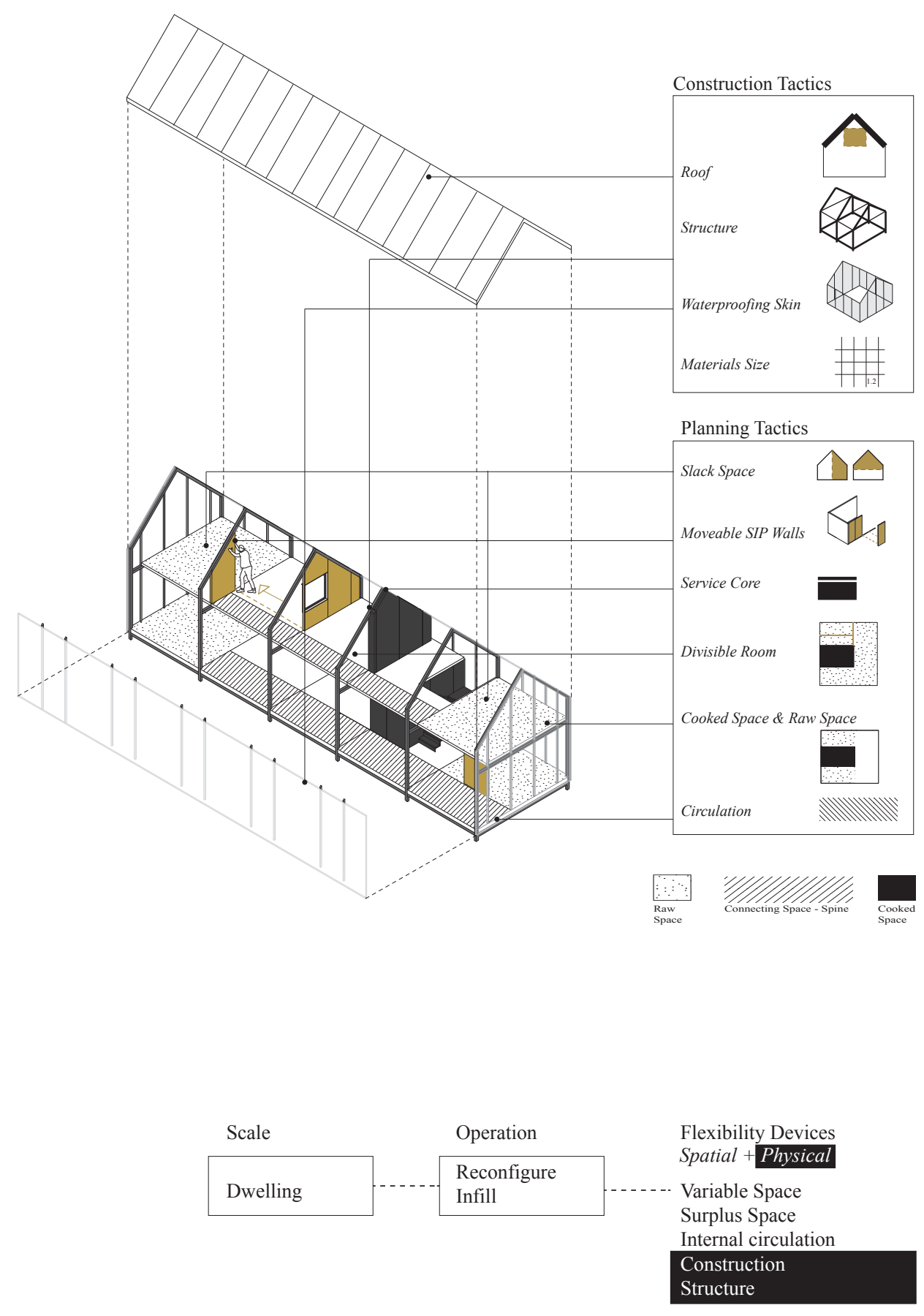

$\wedge$ Figure 70./ Flexible design and incremental construction tactics used. 

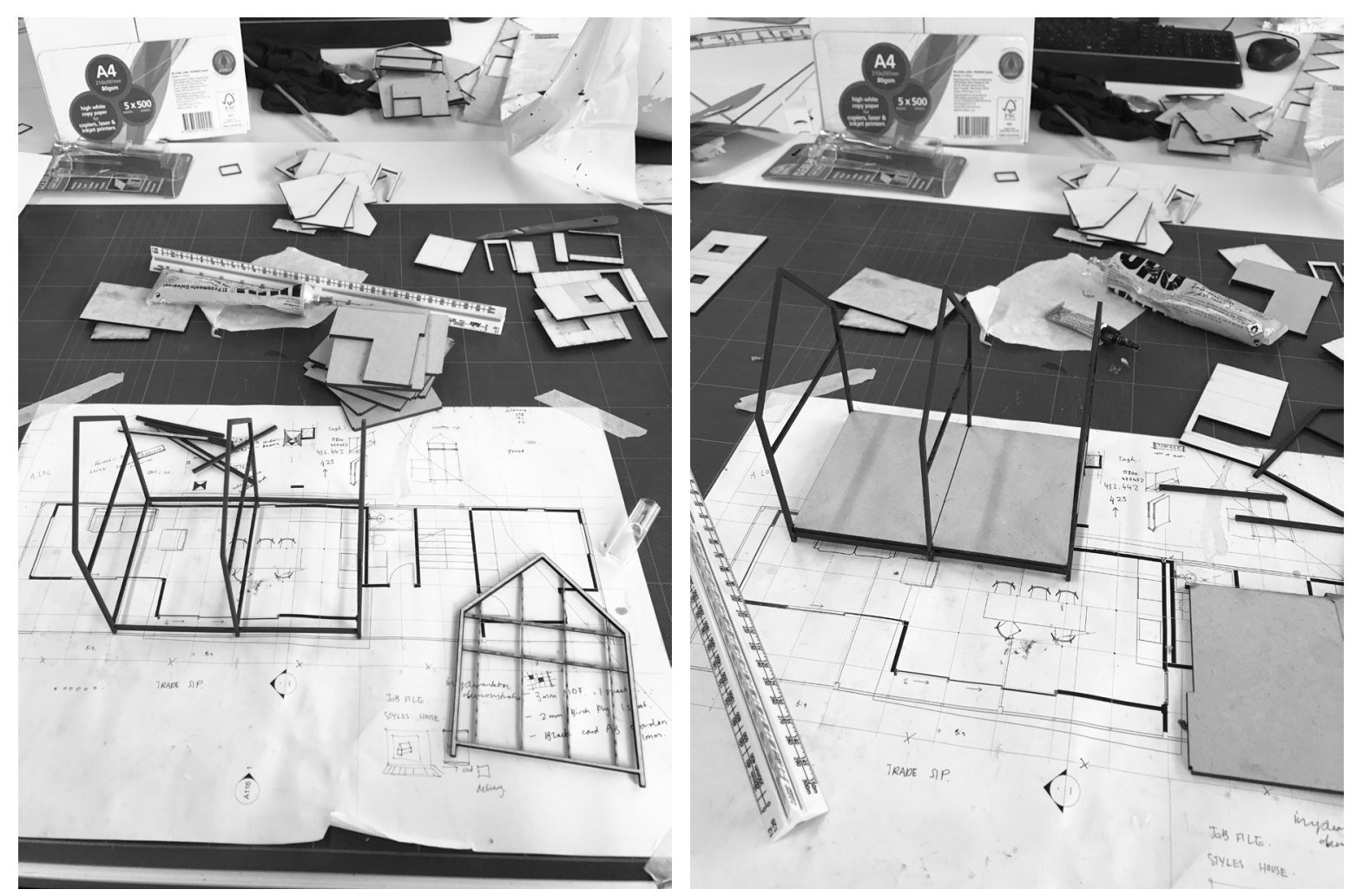

$\wedge$ Figure 71./ Photographs of the modeling process used to figure out the

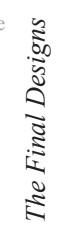




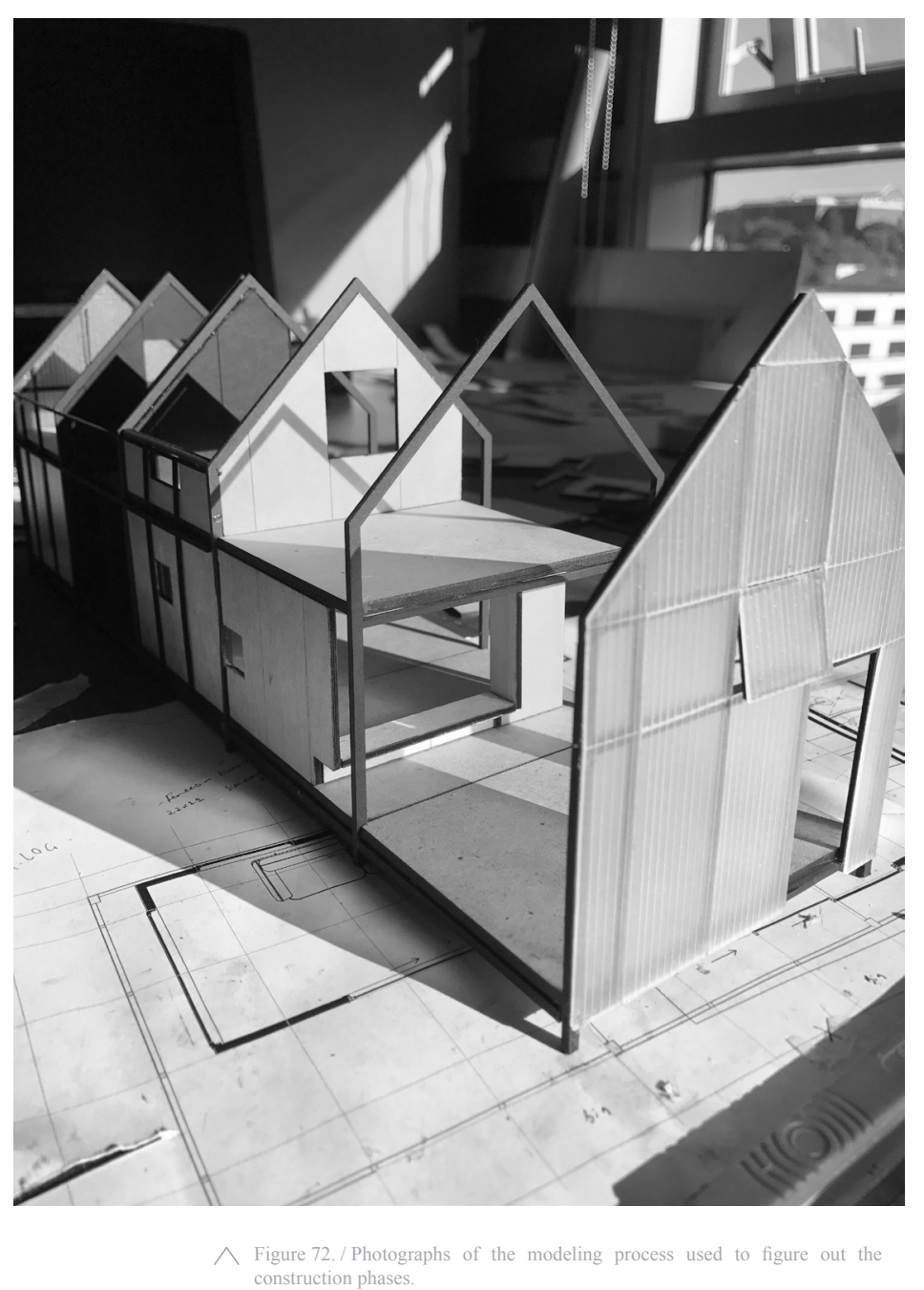




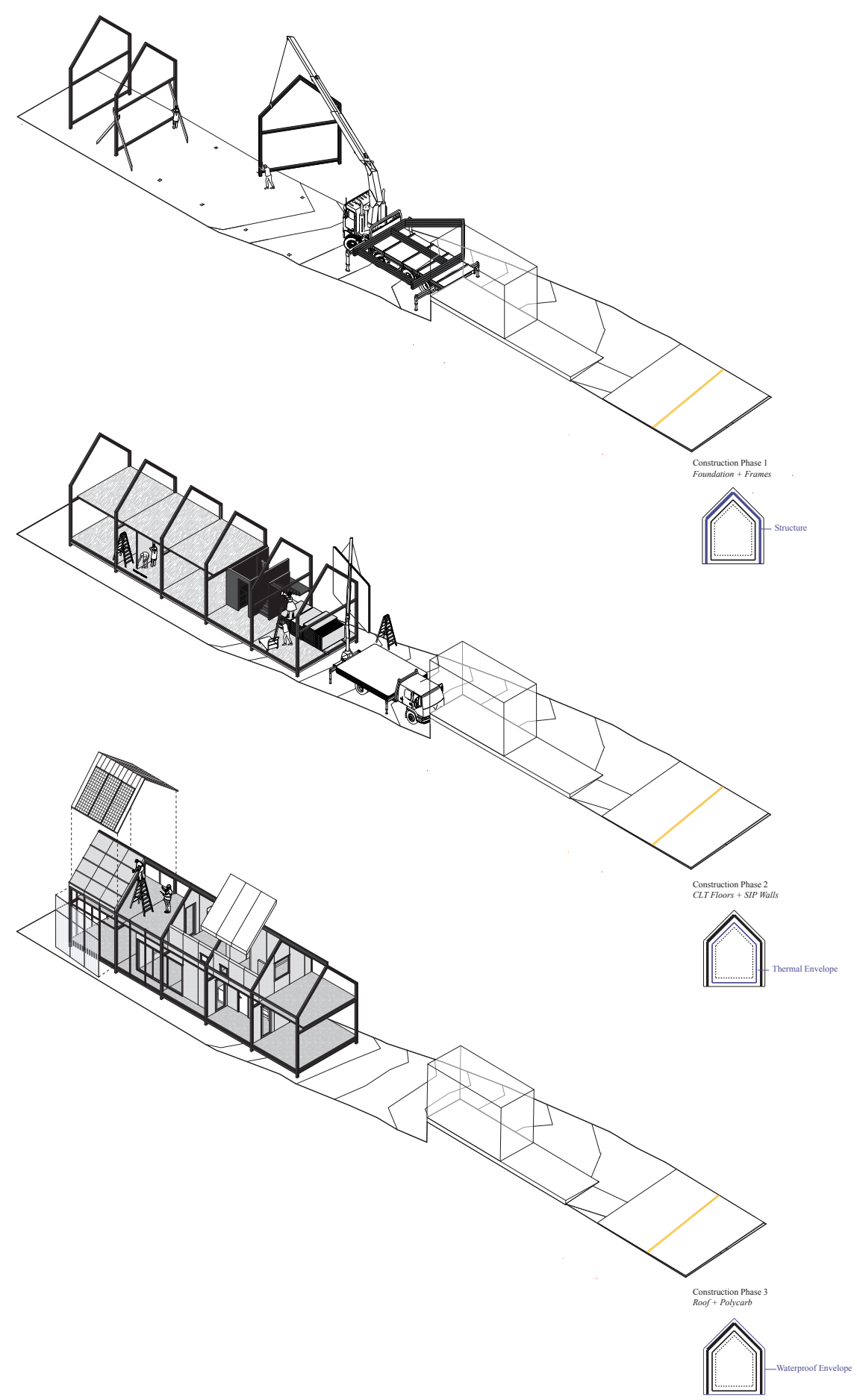

$\triangle$ Figure 73./Diagrams explaing the phases of the construction process from the structural framework to creating the thermal envelope and finally the waterproof shel 


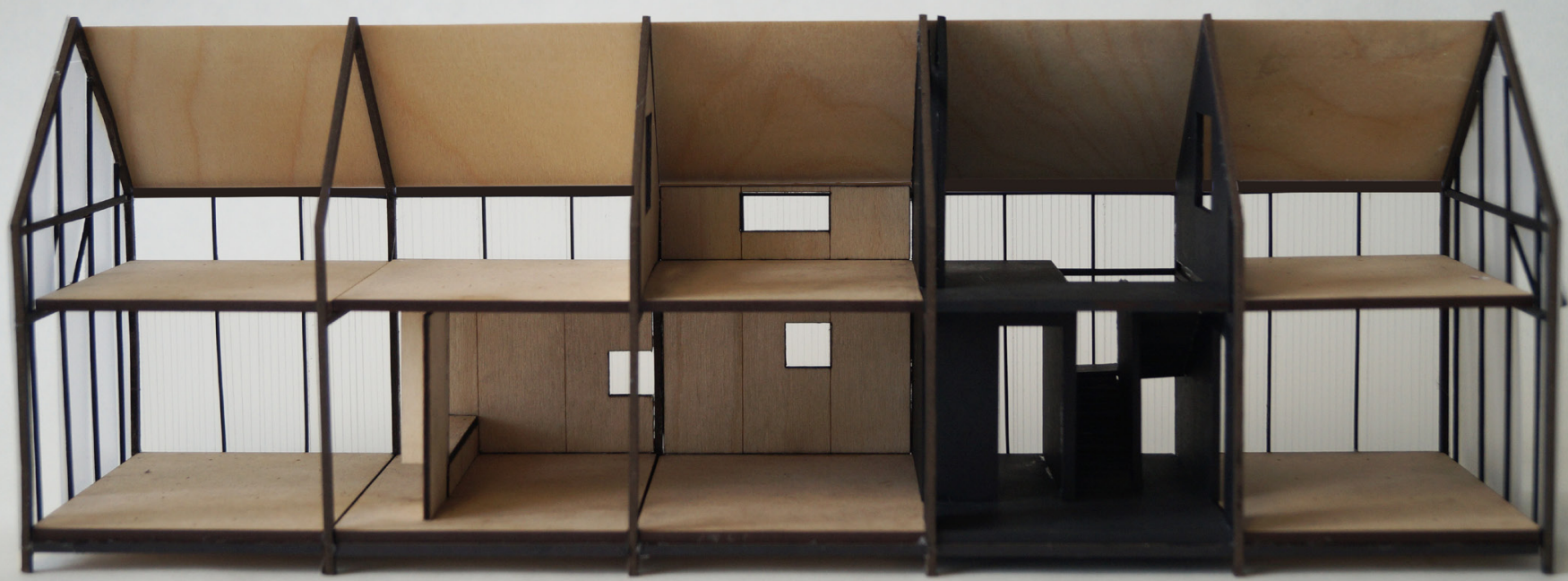

Figure 74. / Photograph of the physical model at stage 1 showing the 5 bays and the slack space either end for expansion at a later stage. The core has a different materiality to highlight its location. 


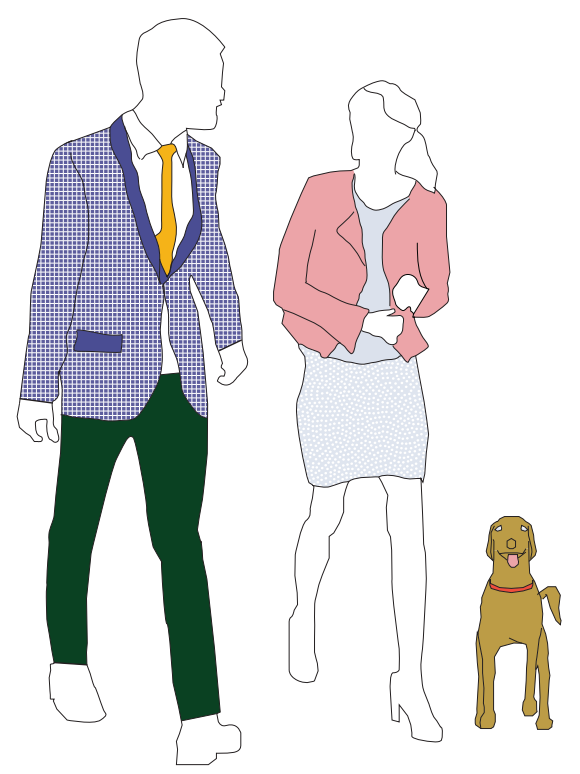

Figure 75. / Meet Kate and Harry, a young professional couple, and their dog Jack. 

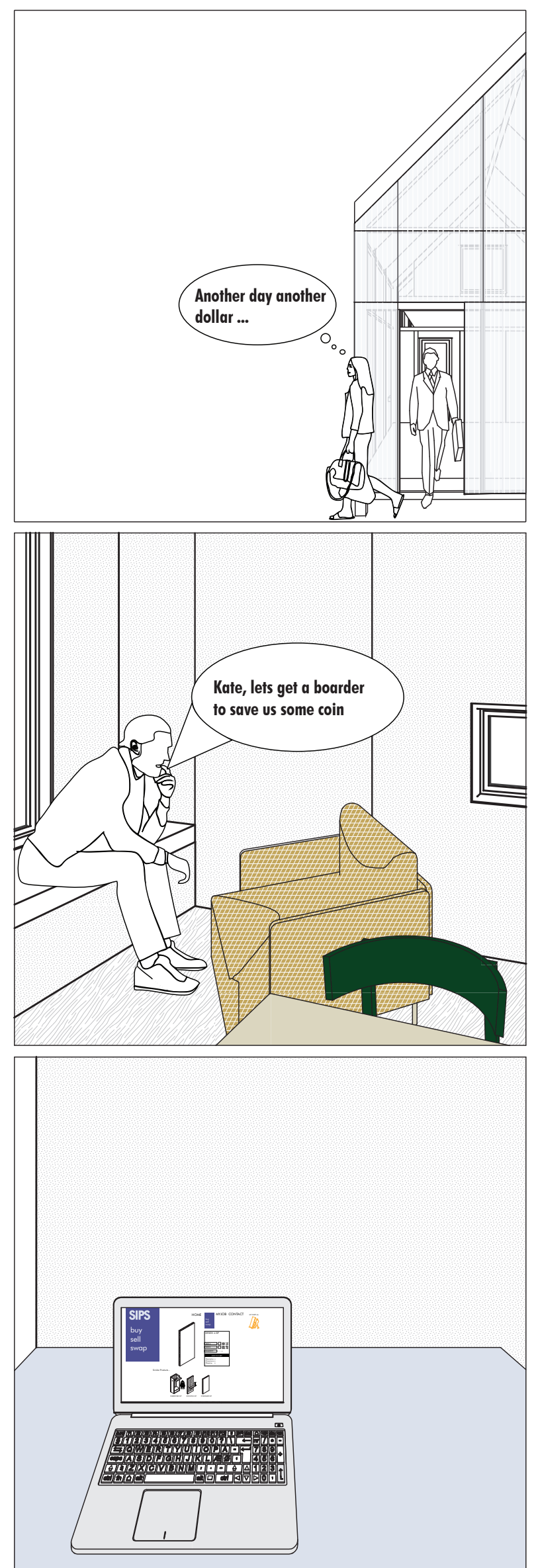

Figure 76./Comic Strip explaining the phases Kate and Harry go through and how the house can adapt to their chnages needs and financial circumstance. 

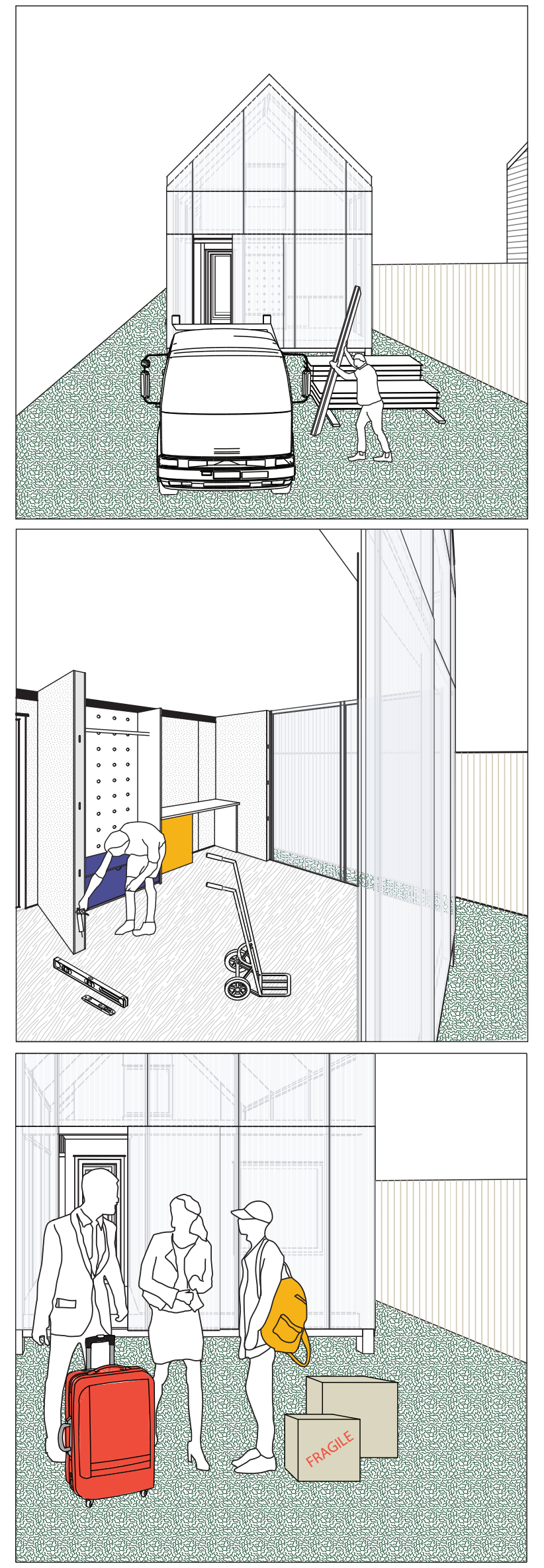

Figure 77./Comic Strip explaining the phases Kate and Harry go through and how the house can adapt to their chnages needs and financial circumstance. 


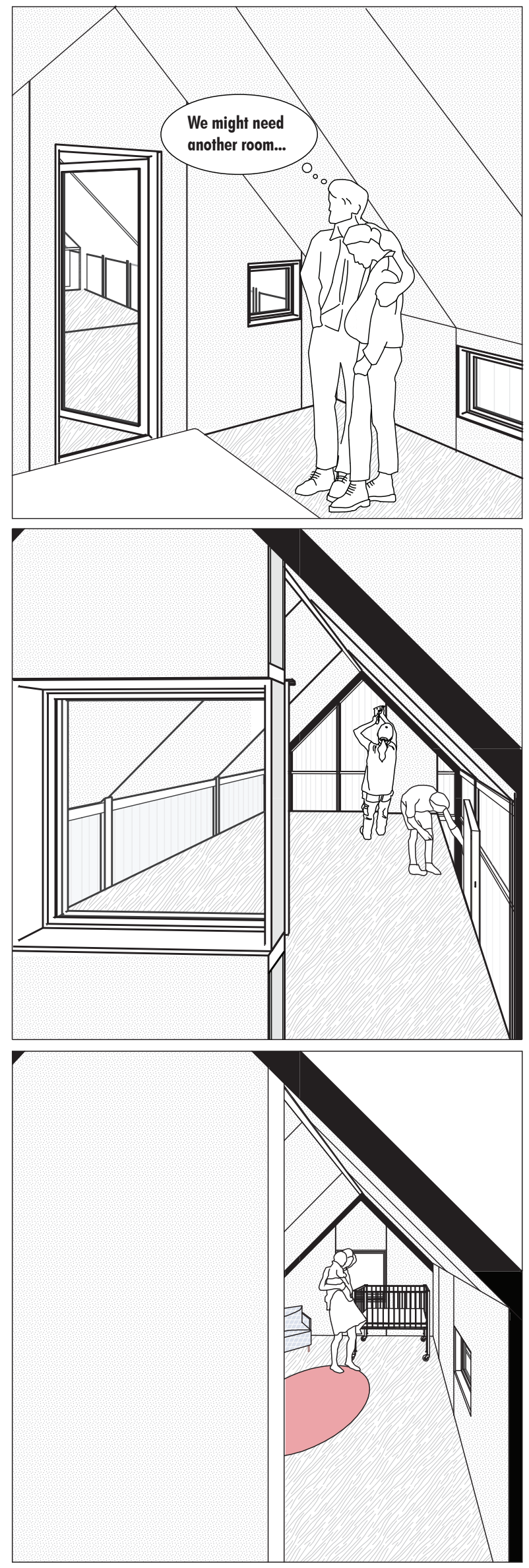



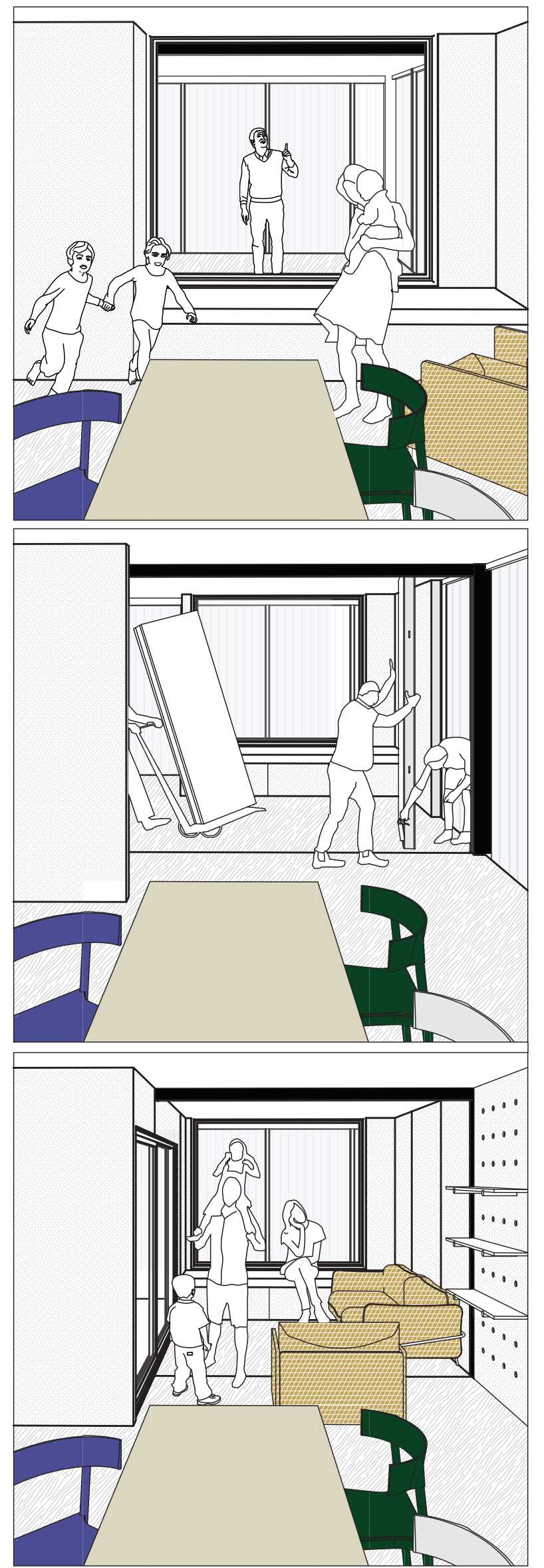

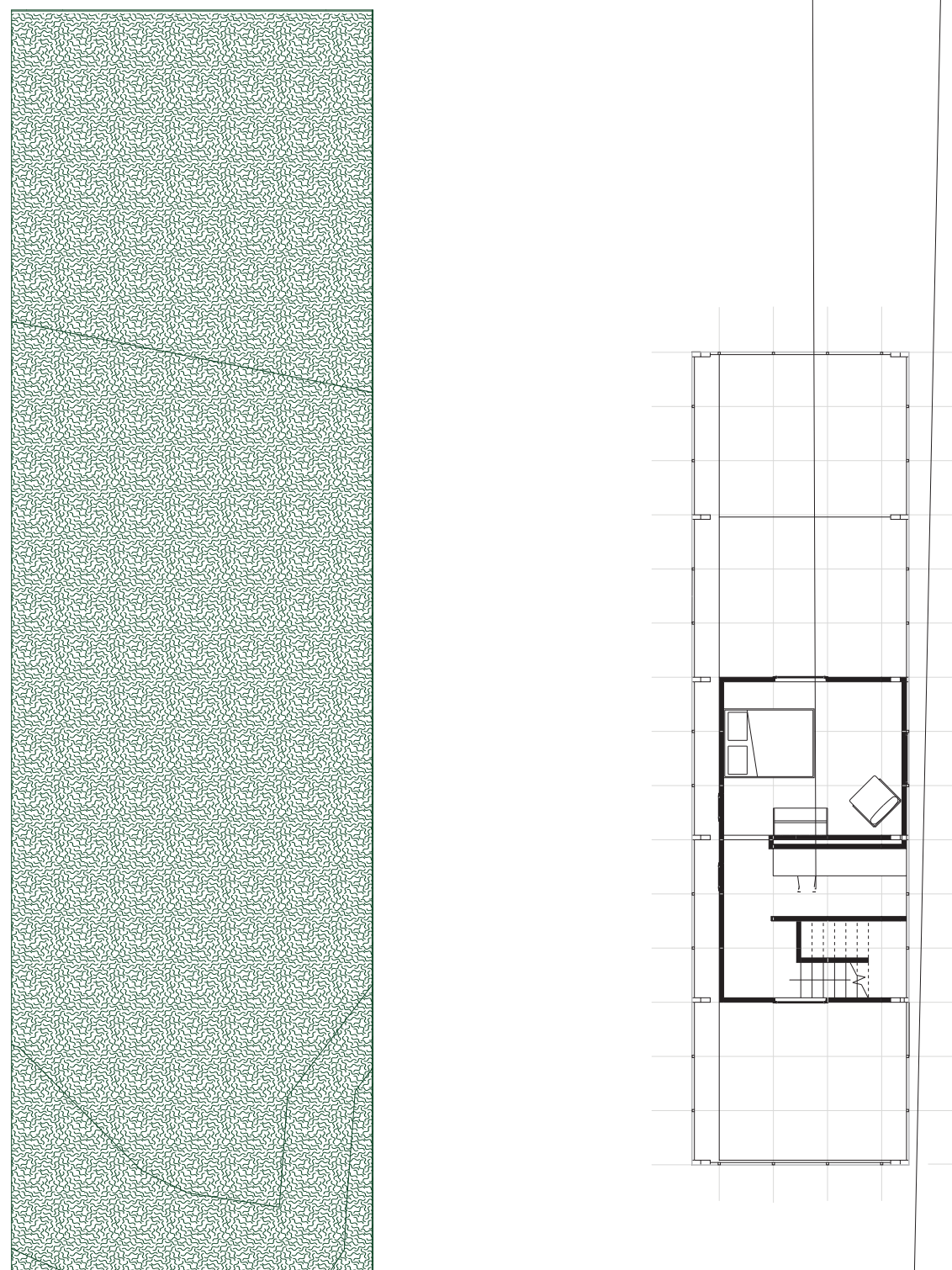


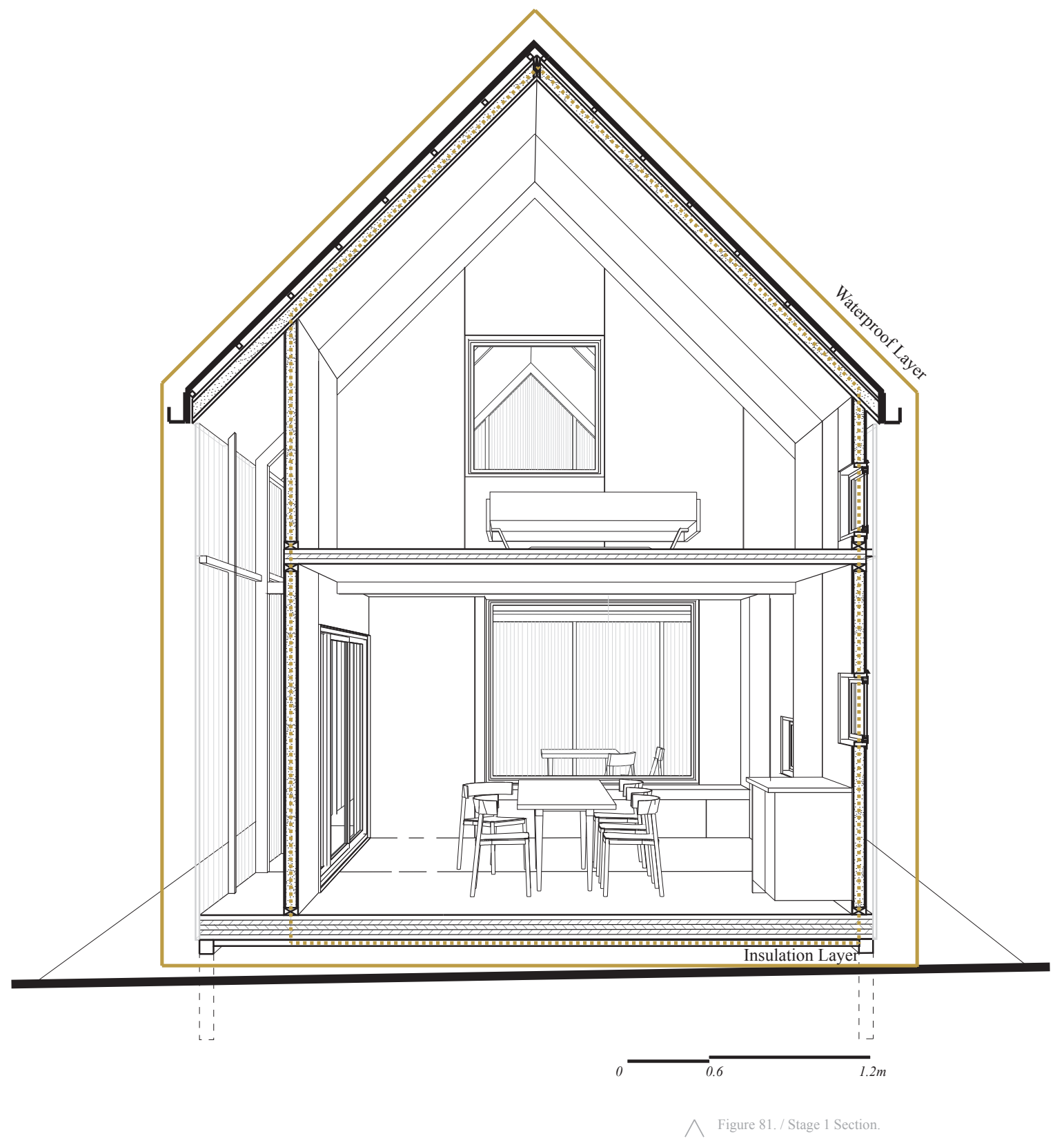



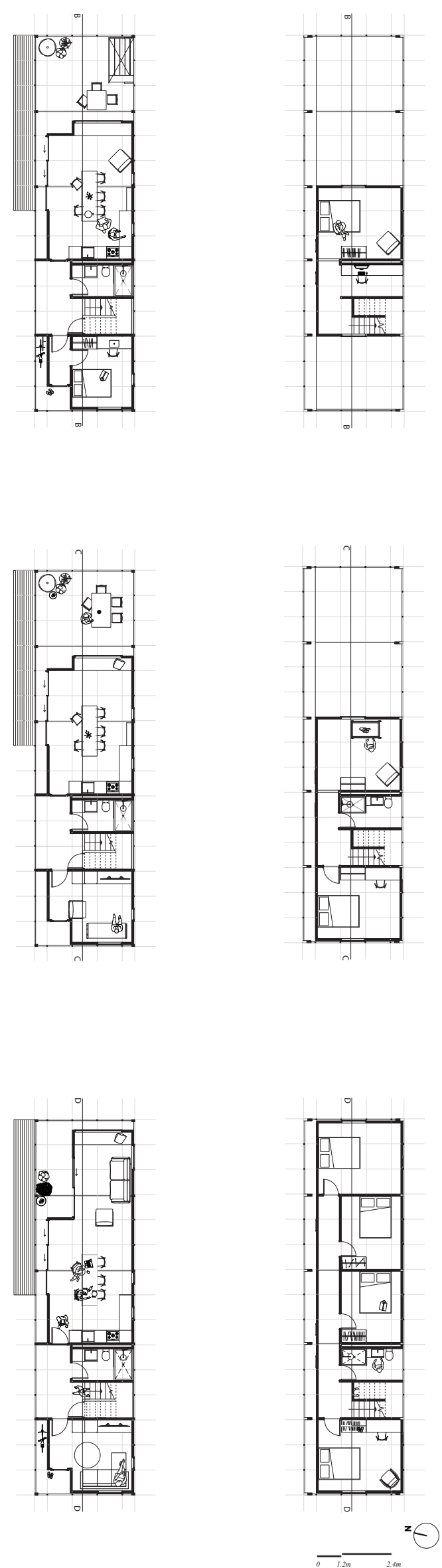

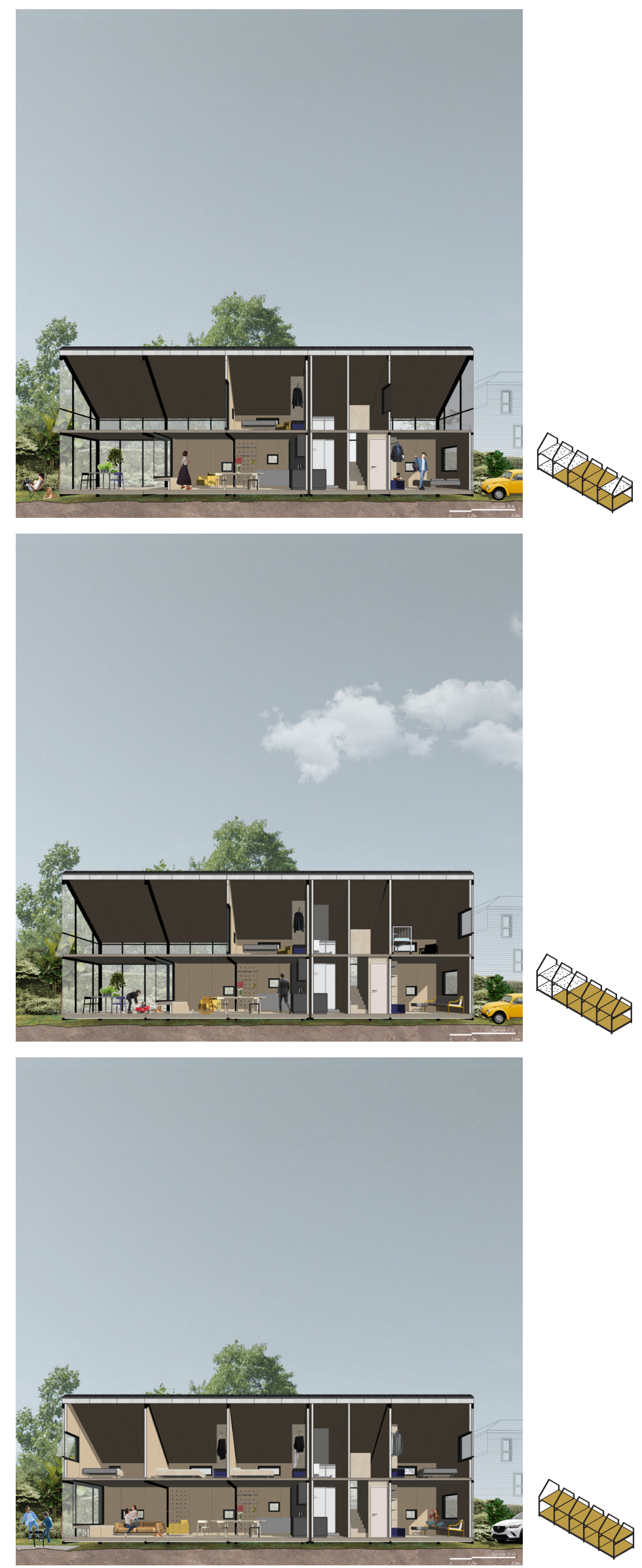

$\bigwedge$ Figure 83. / Sections of Stages 2,3 and 4 with diagrams explaing the incrmental addition. 


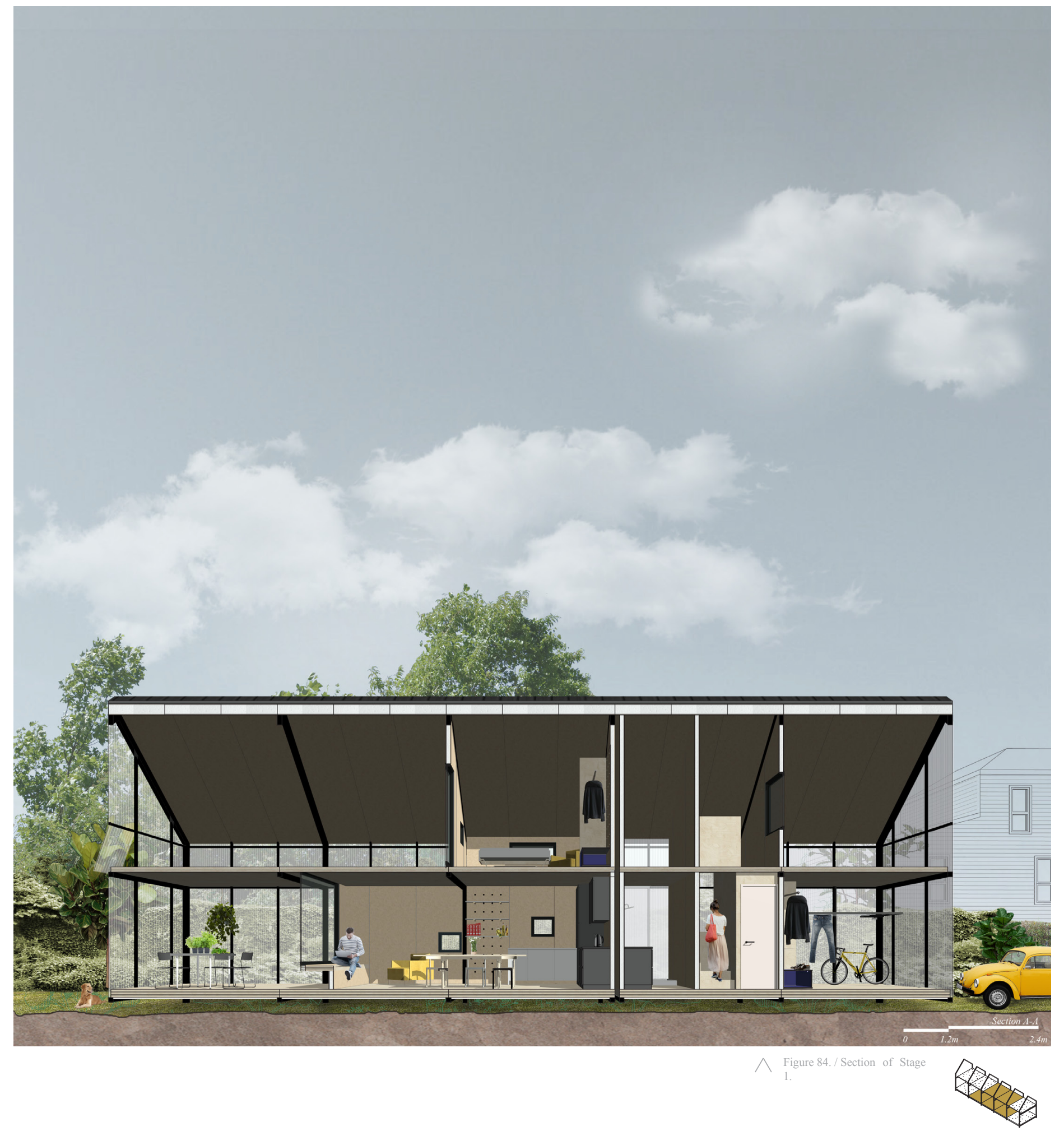




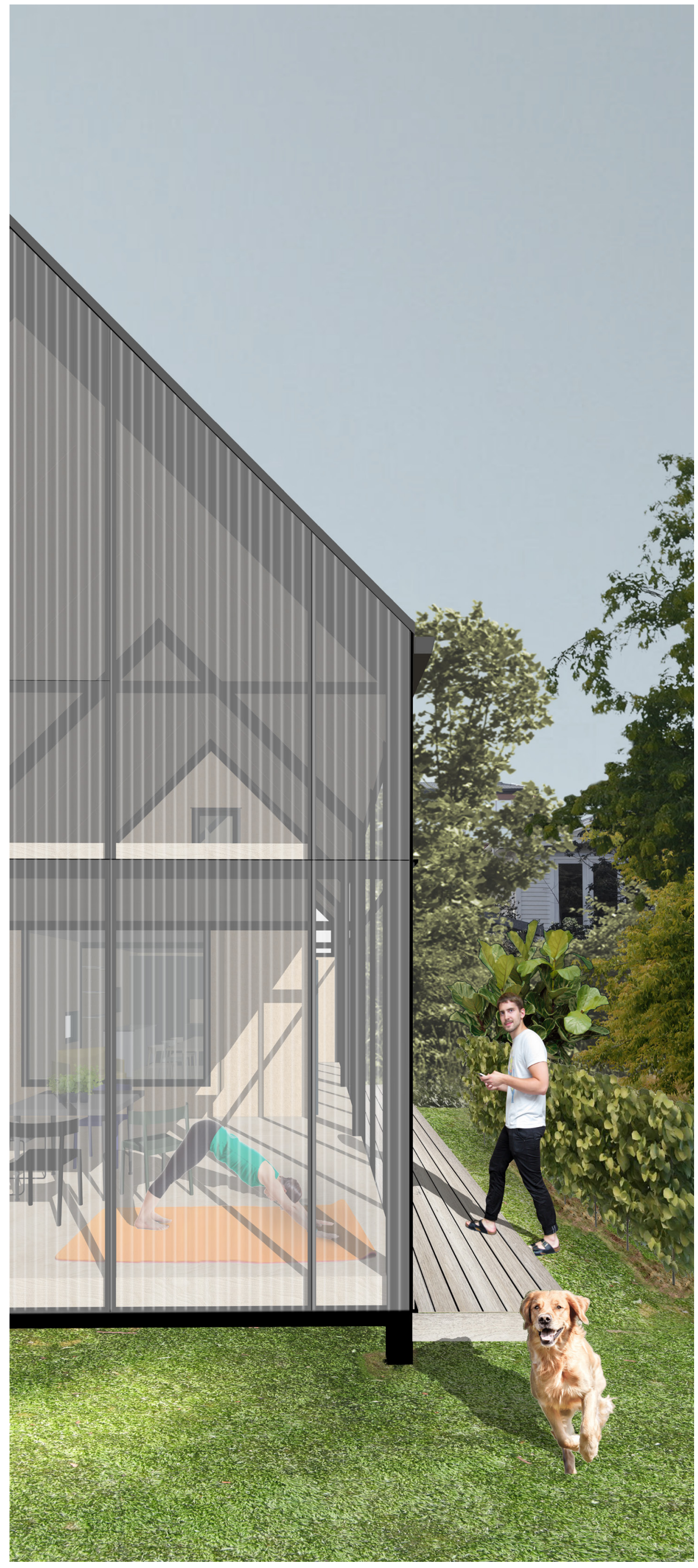




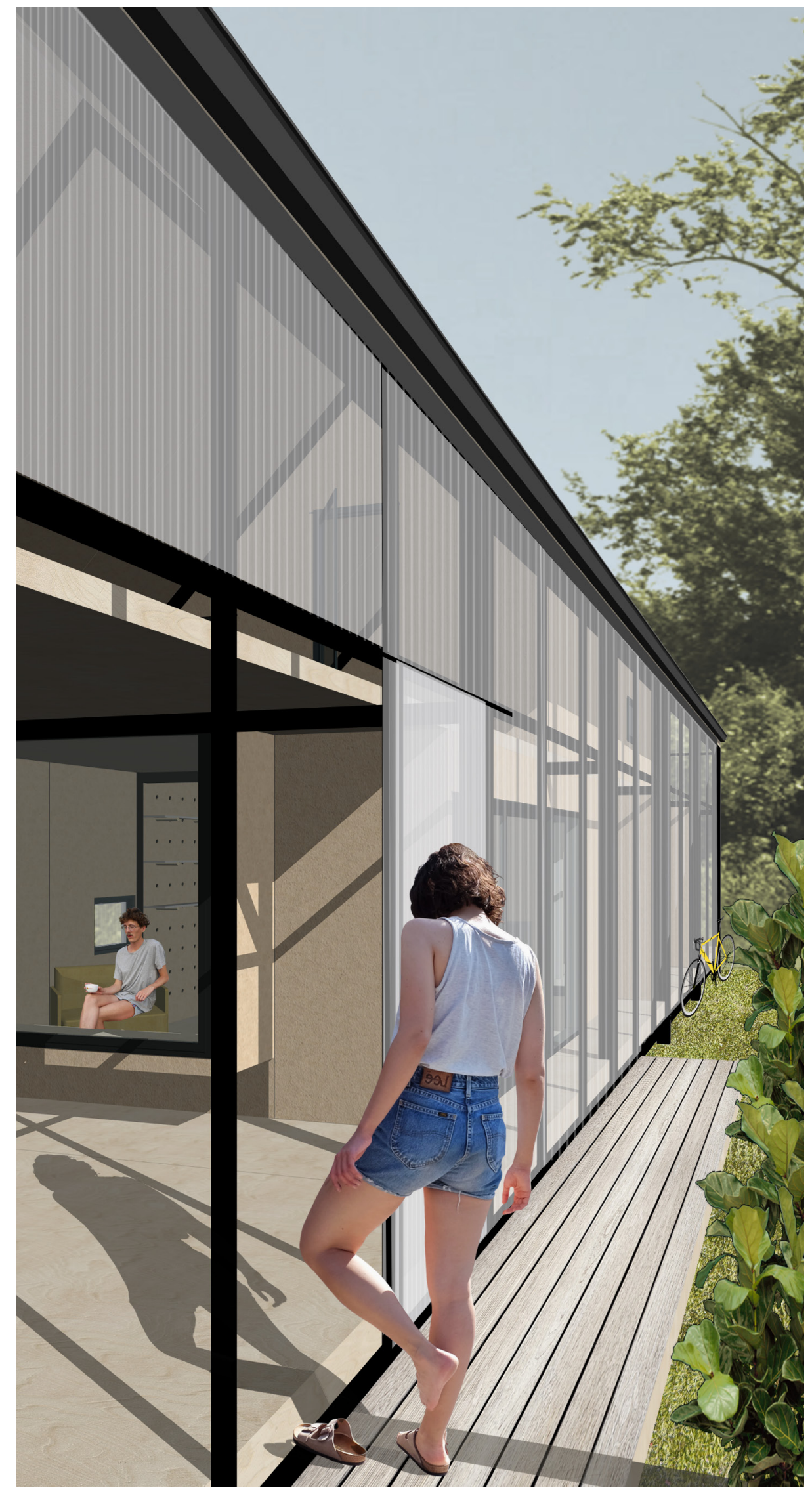




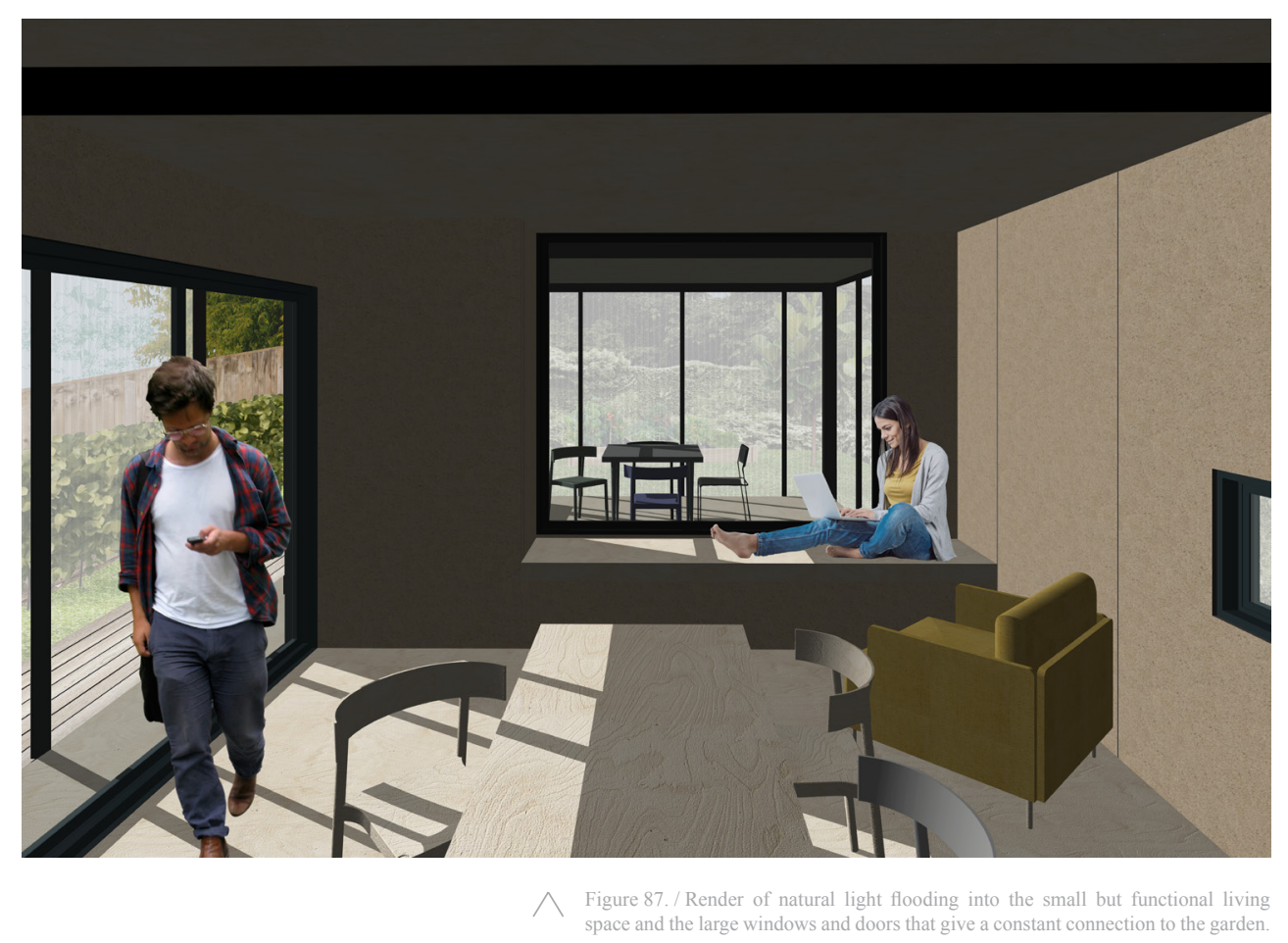




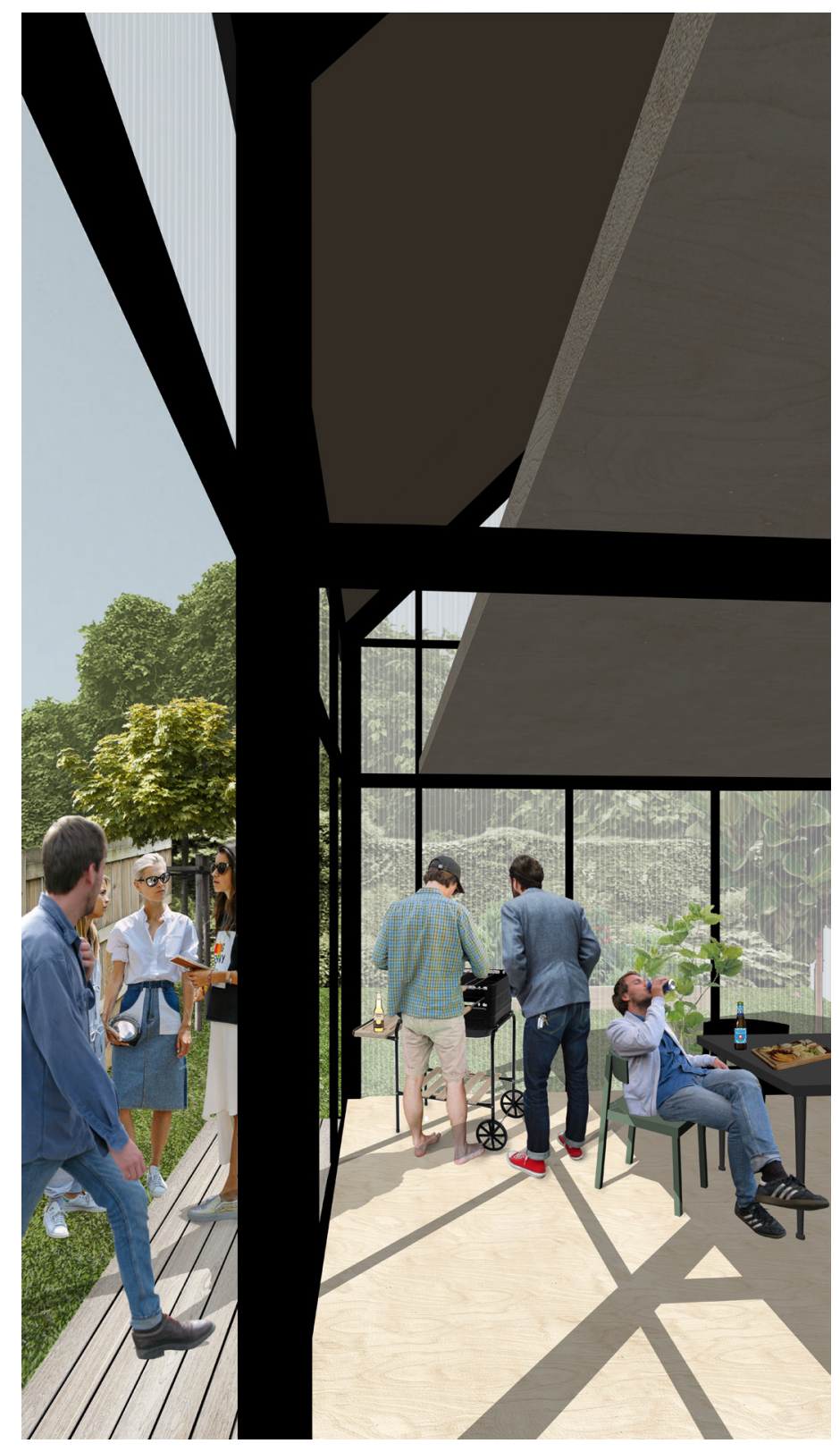

Figure 88./Render showing showing how in the summer the house expands could provide sheltered outdoor entertaining.
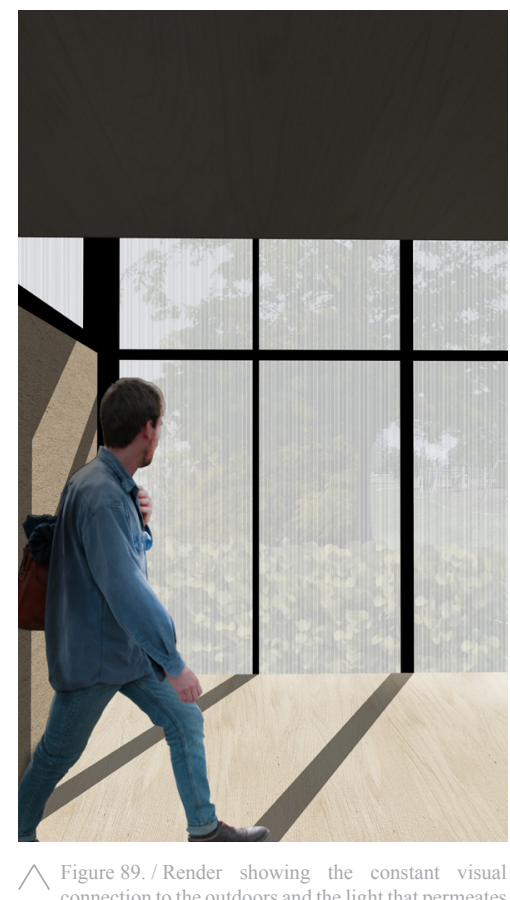
connection to the outdoors and the fight 


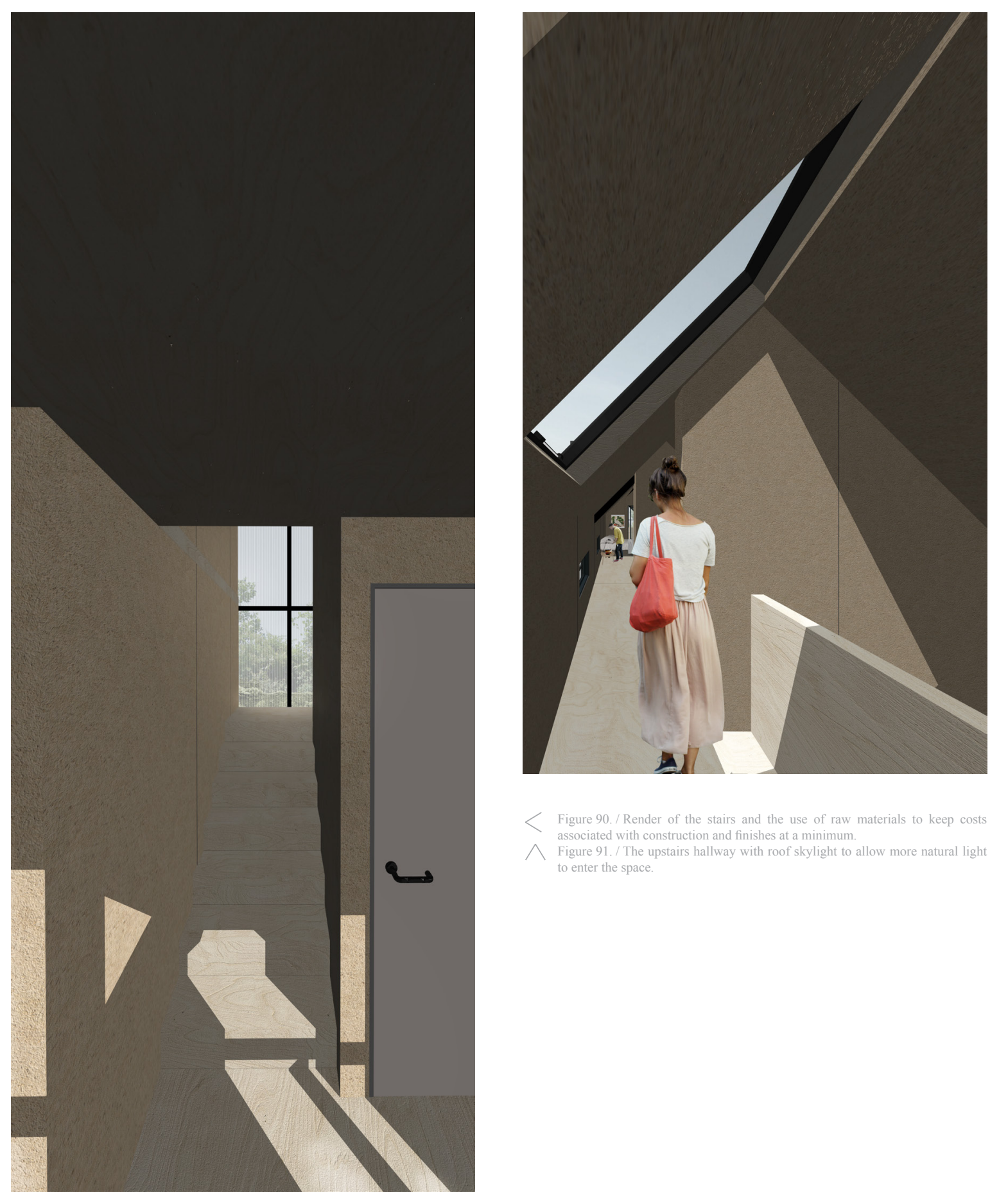

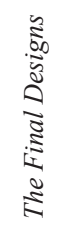




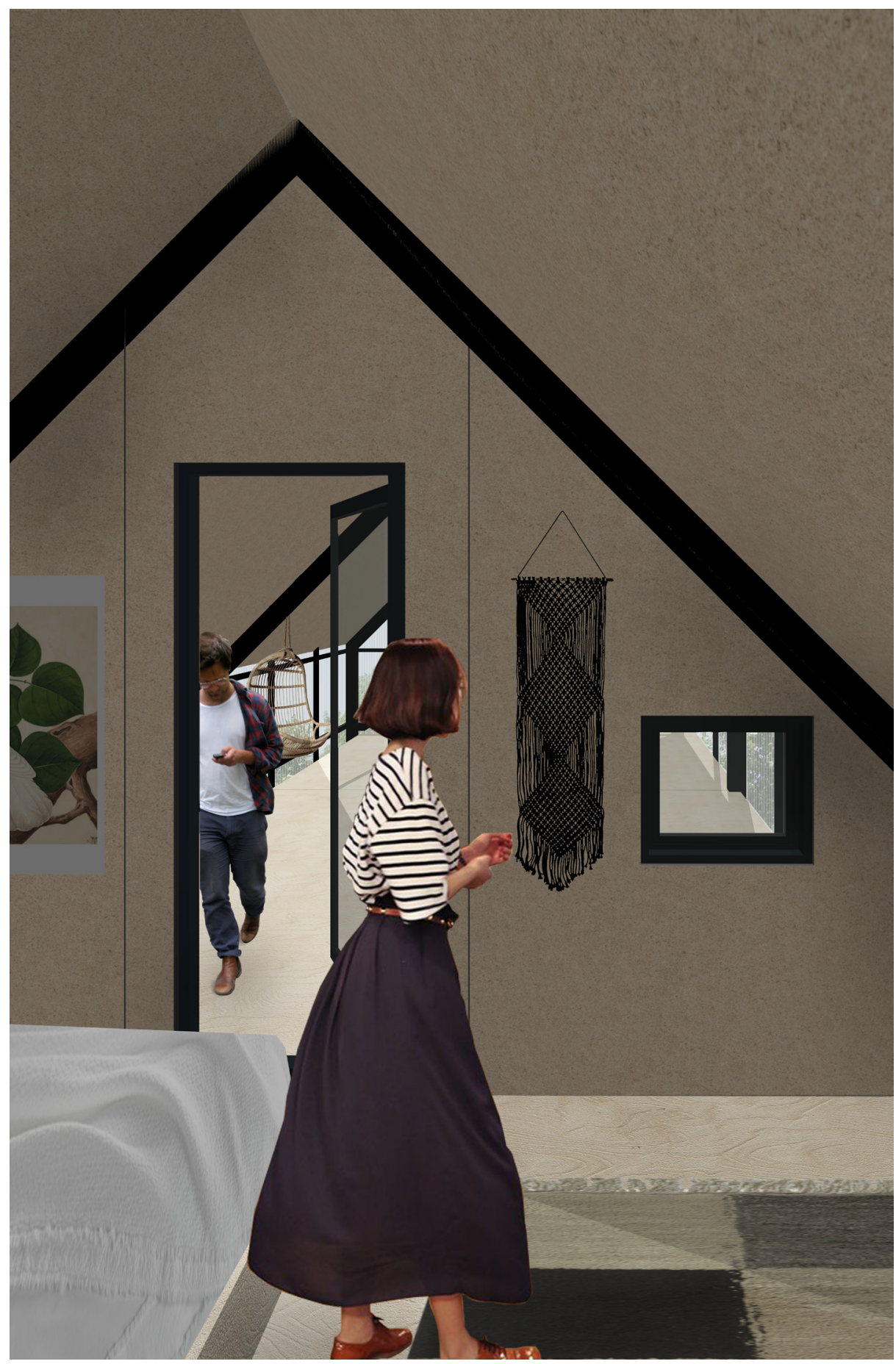

Figure 92. / Render of upstairs bedroom that is a lot more private and enclosed. 


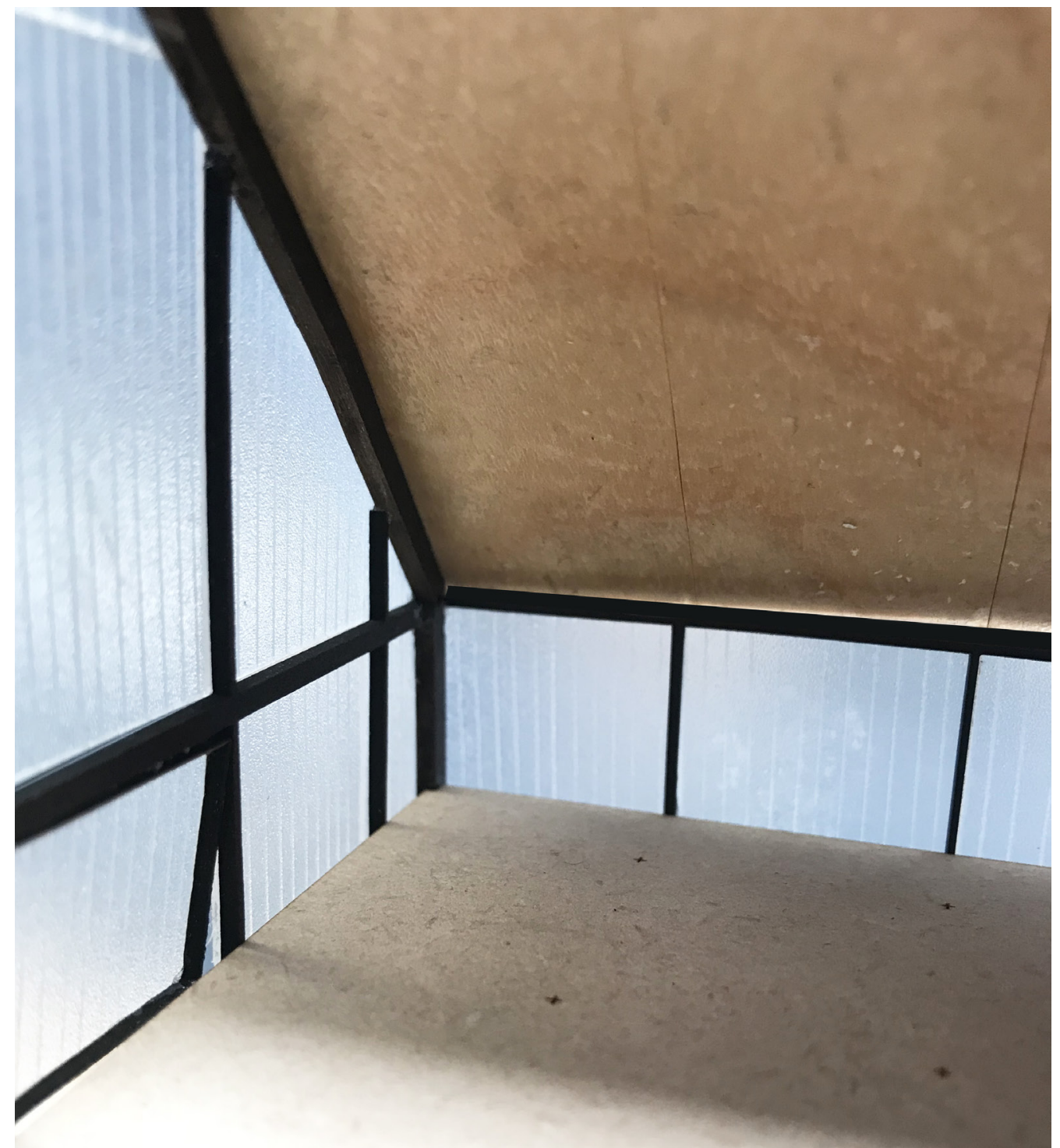




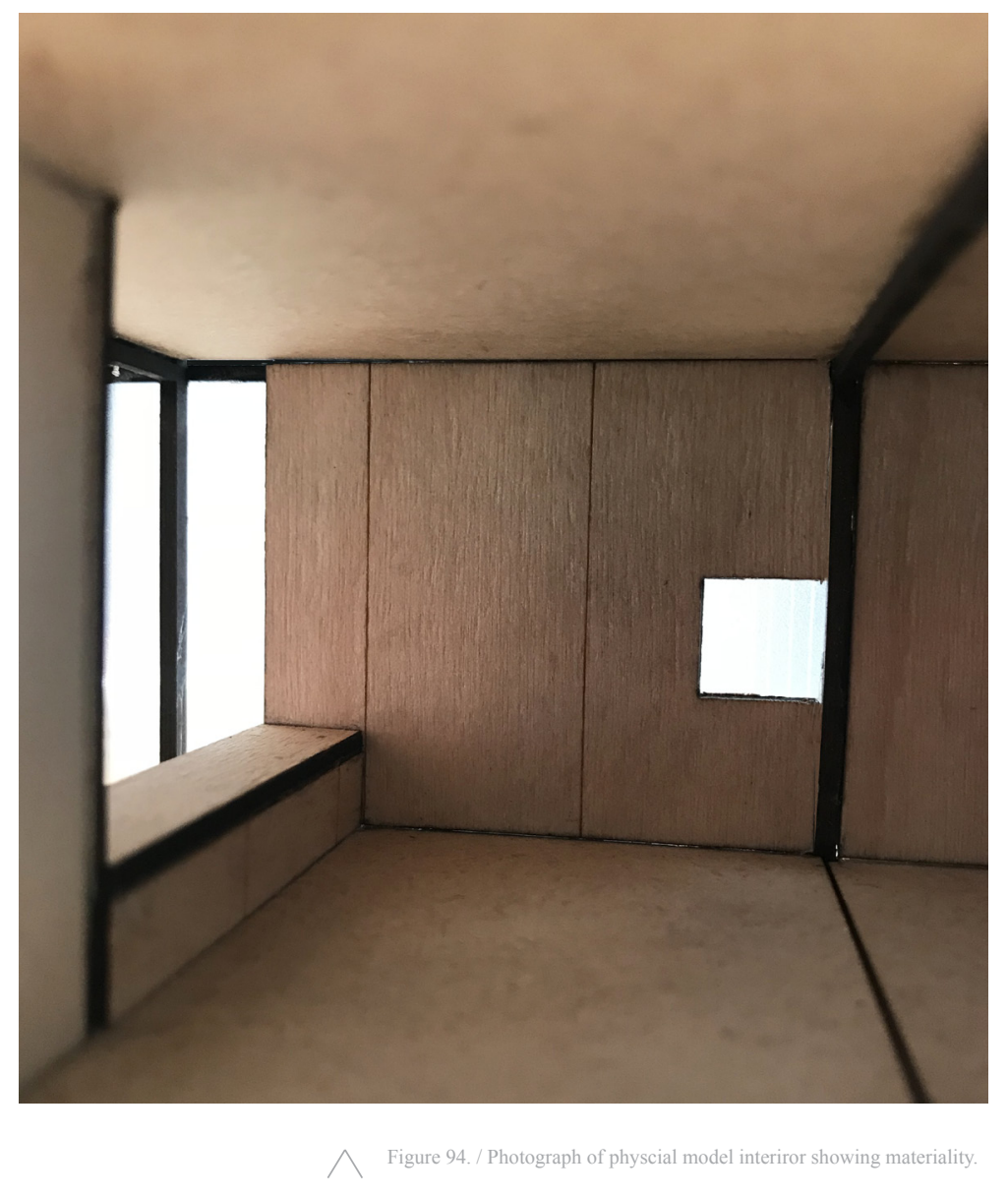




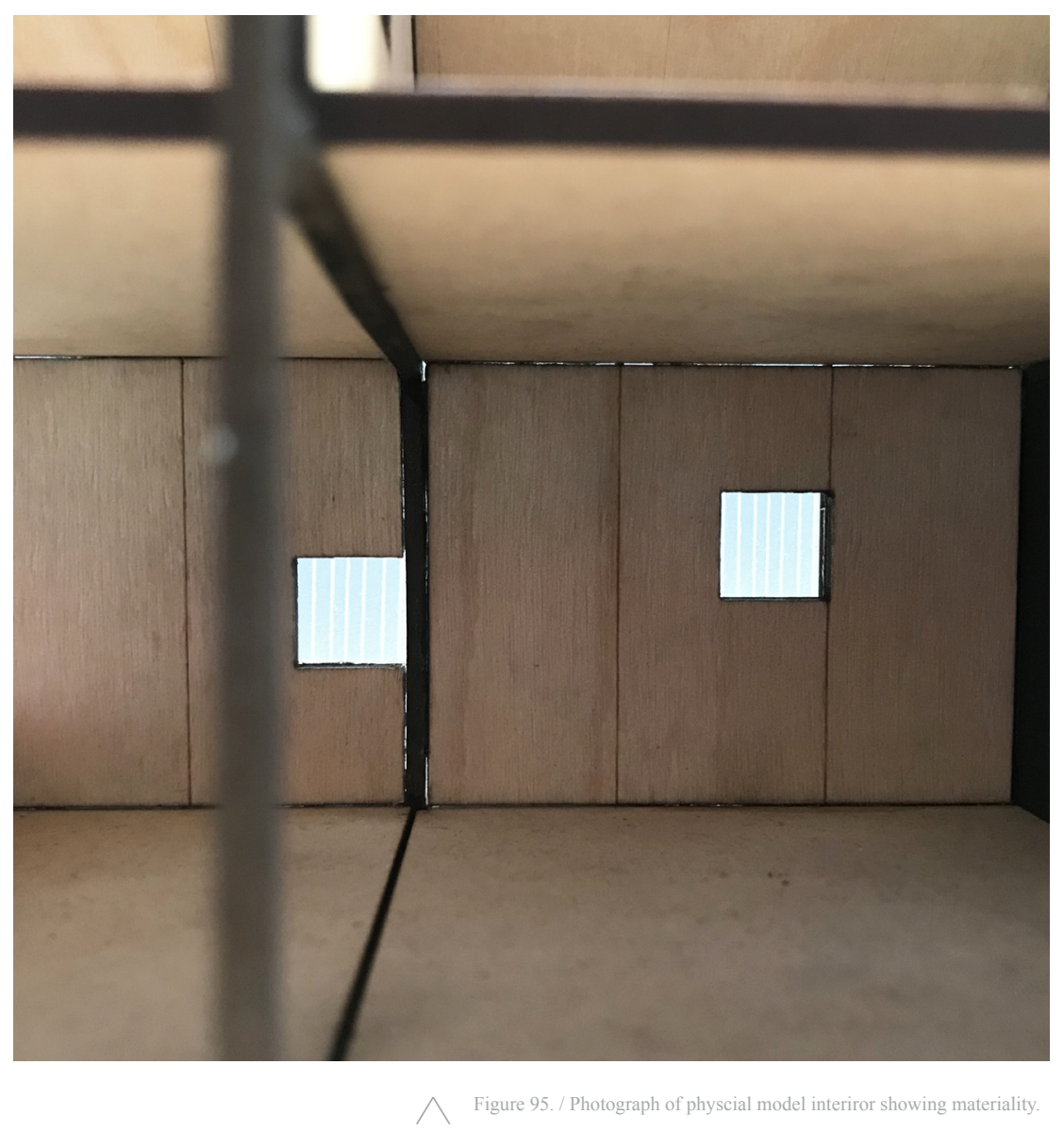




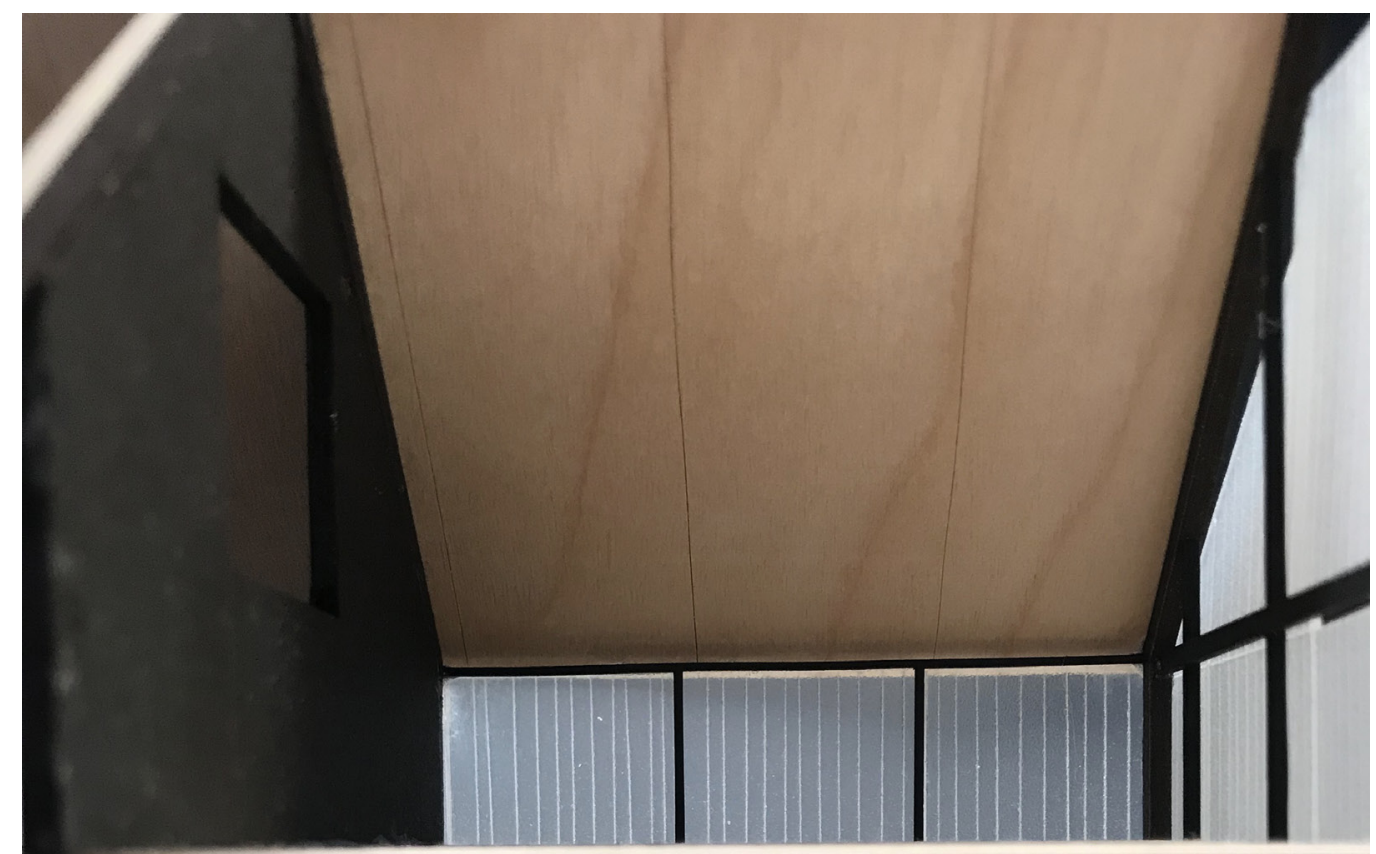

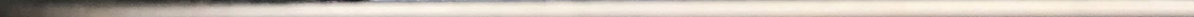

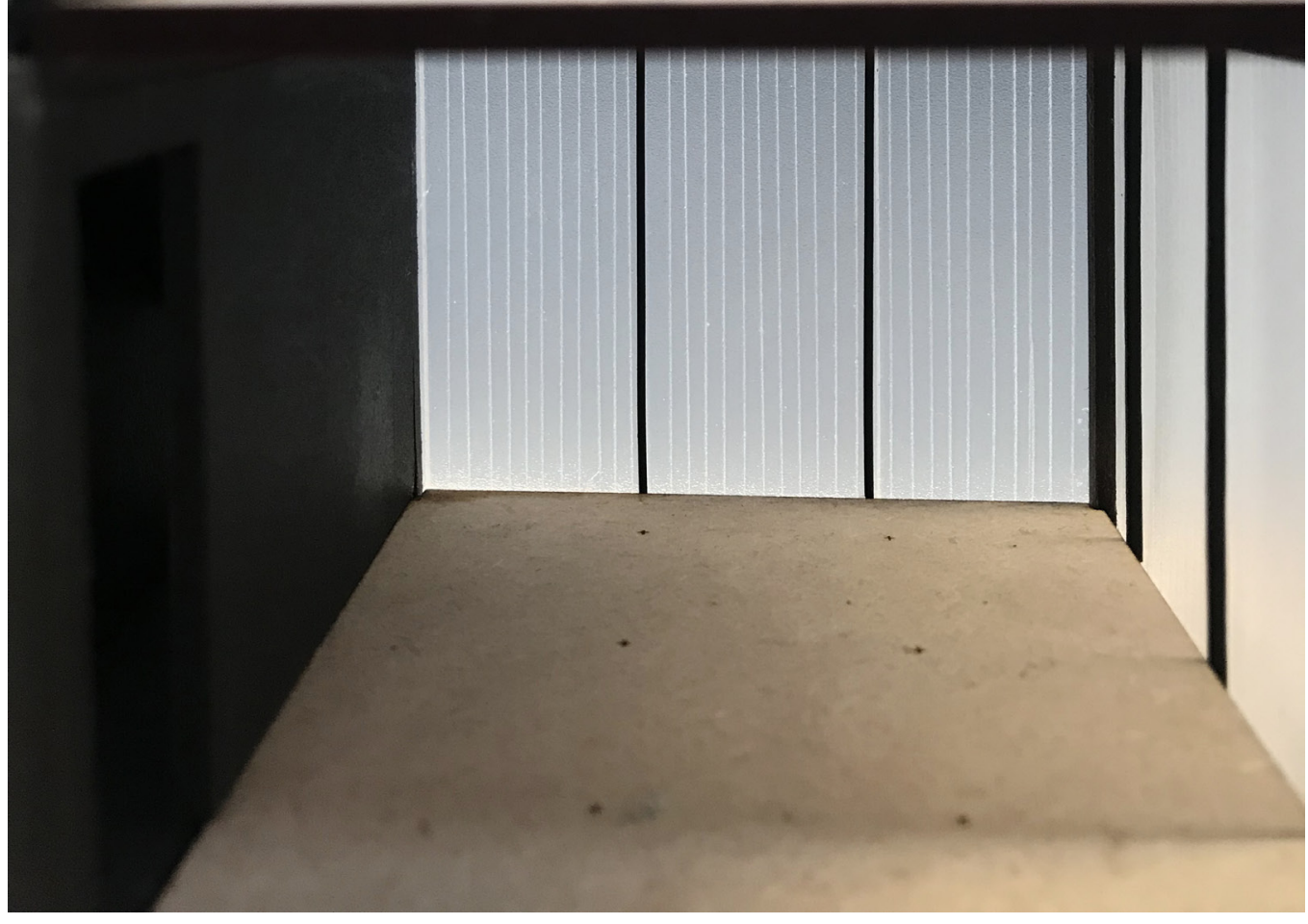

Figure $96 . /$ Photograph of physcial model interiror showing the slack
space ready for SIPs to be added into to create an additional room. 


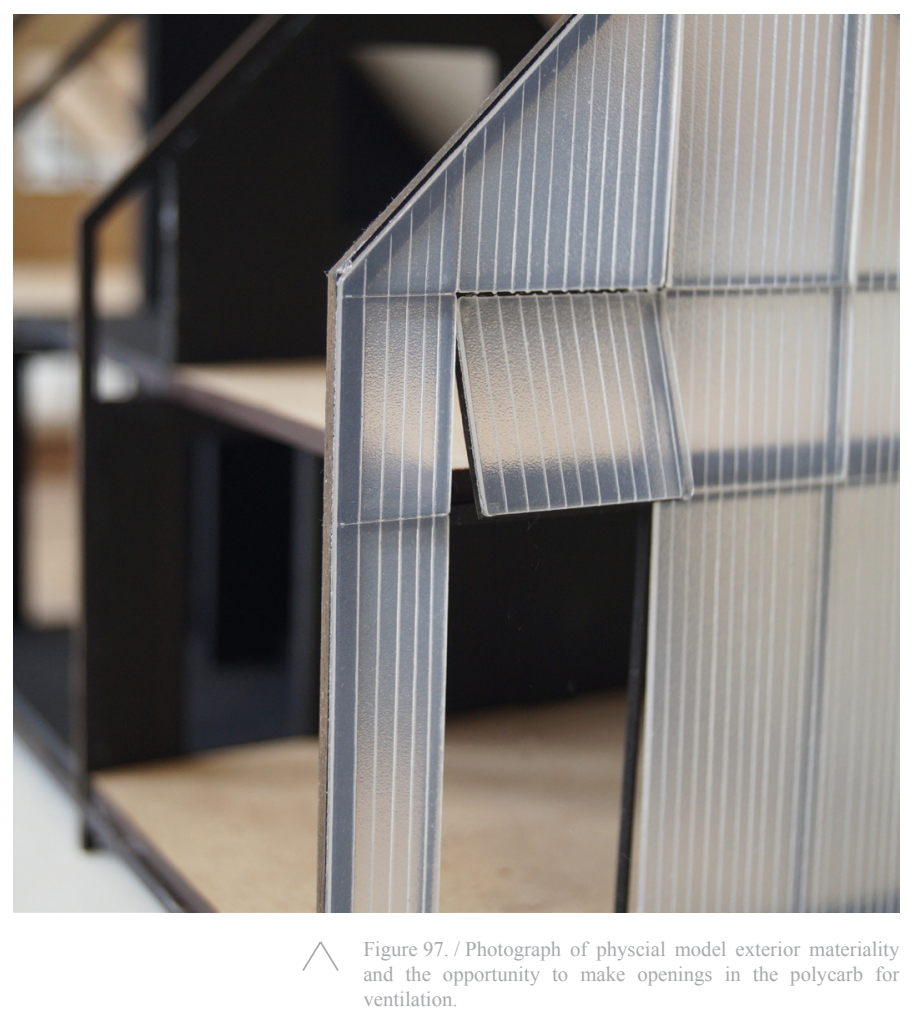

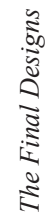




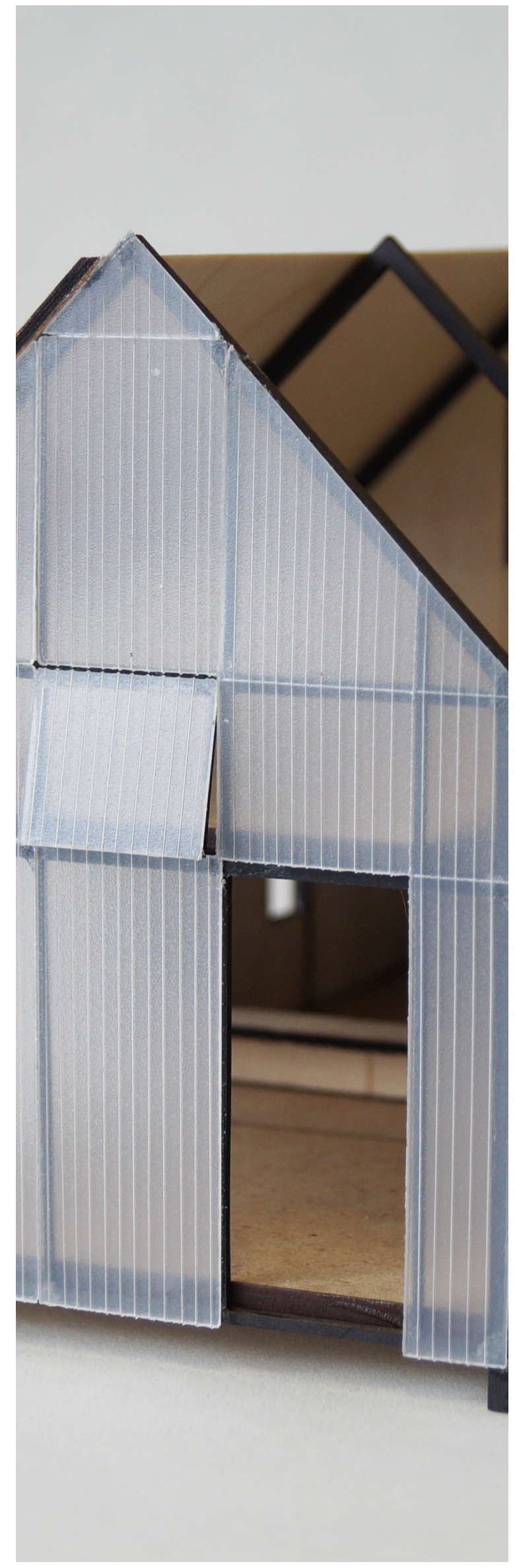

Figure 98./ Photograph of physcial model exterior materiality and the opportunity to make openings in the polycarb for ventilation. 


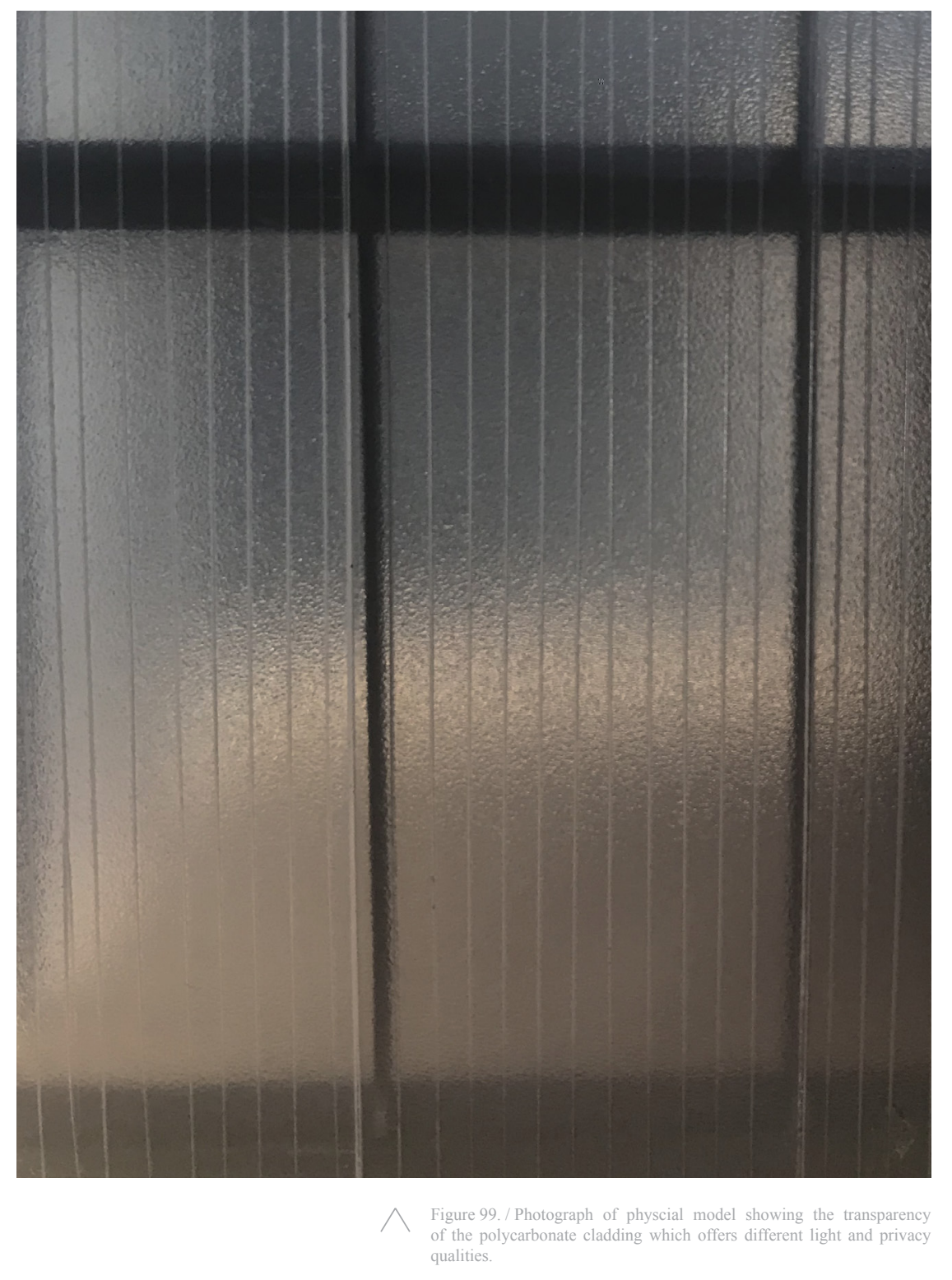

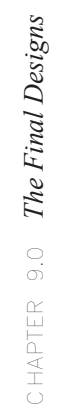




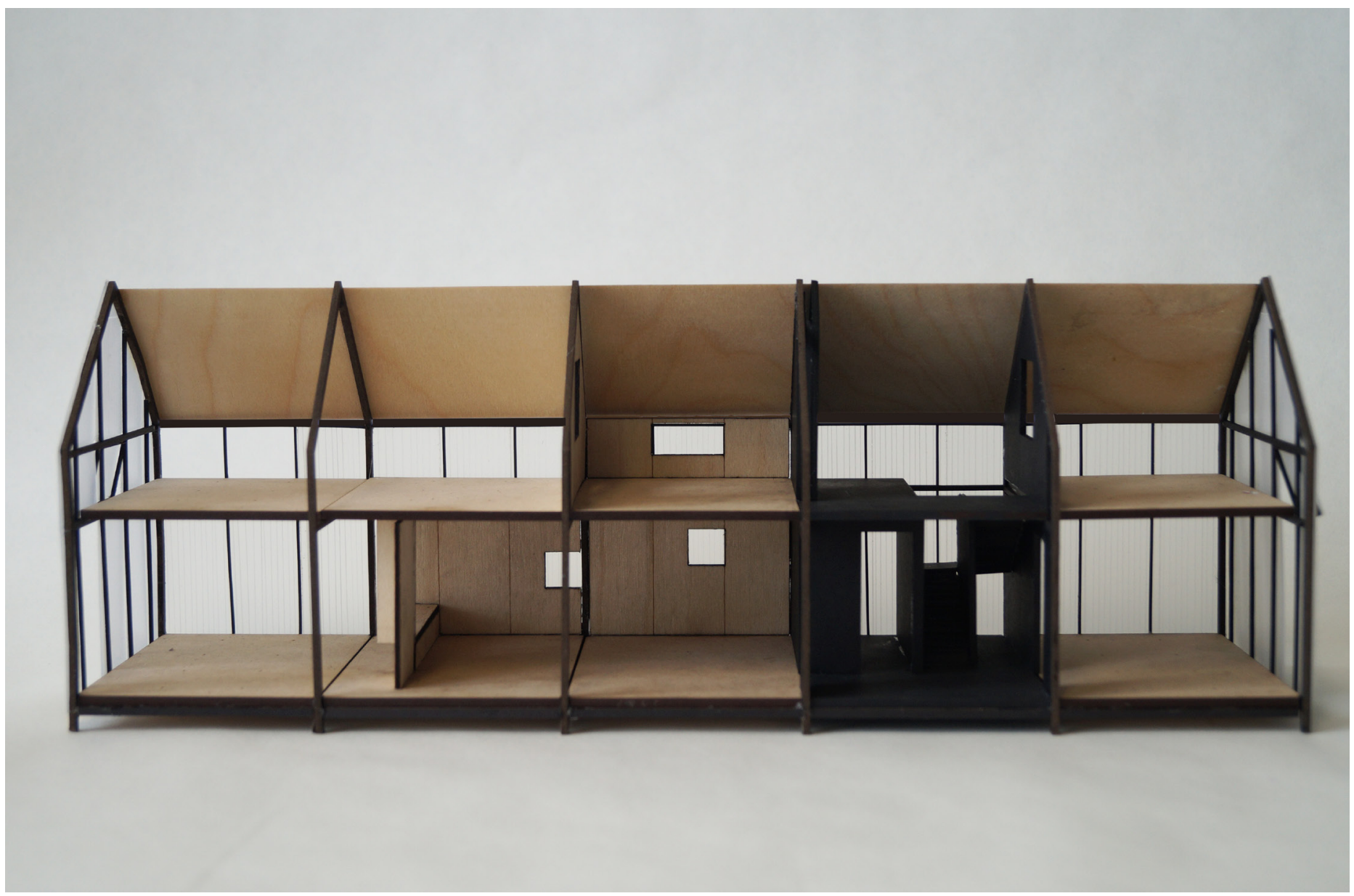
Figure $100 . /$ Photograph of the physical model at stage 1 showing
the 5 bays and the slack space either end for expansion at a later stage. 


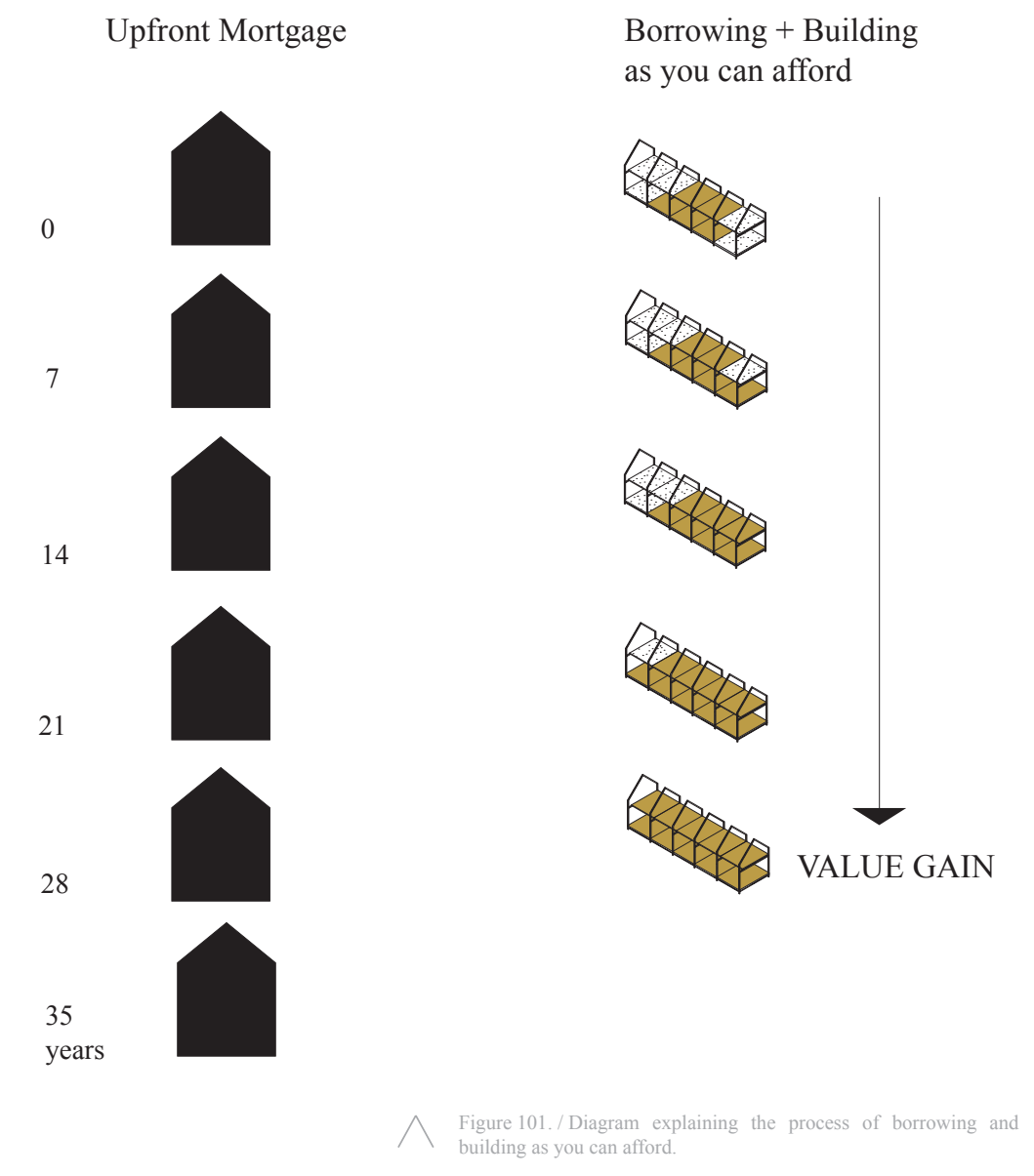

This diagram explains the concept of borrowing and building as you can afford. It shows that by borrowing and building when you have the funds, there is potential to pay off your mortgage quicker. The design and construction of this dwelling allows the users to start small but have the ability and space to add rooms as their needs and finances change. 

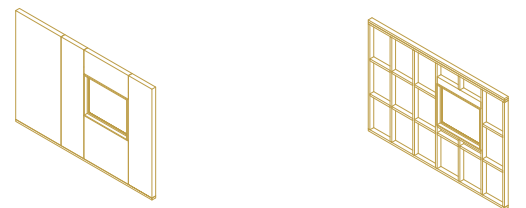

\begin{tabular}{|c|c|c|}
\hline & Alternative Method & Traditional Method \\
\hline \multicolumn{3}{|l|}{ Structure } \\
\hline Frame & 210.86 & 73.22 \\
\hline Roof & 129.42 & 134.02 \\
\hline Walls & 88.92 & 316.36 \\
\hline Floors & 231.89 & 250.62 \\
\hline \multicolumn{3}{|l|}{ Finishes } \\
\hline Floor Finshes & Not required & 102.20 \\
\hline Wall Finishes & Not required & 199.72 \\
\hline Total & 661.09 & 1076.14 \\
\hline
\end{tabular}

To prove this alternative form of construction is an affordable solution that answers the research question, a material cost comparison has been carried out. This comparison provides $\mathrm{m} 2$ costs for materials needed to construct $160 \mathrm{~m} 2$ dwelling. It is important to note this cost comparison only compares material costs that use a different form of material than the standard form of construction. For example, the wall cost has been compared because SIP panels are used rather than the timber frame. Costs are inclusive of labour, and major price differences are the costs for the wall materials. Using the traditional method, the exterior walls would be clad requiring more labour and materials. The alternative method is prefabricated SIPs and the polycarbonate cladding costs to create the waterproof shell are included. This cost is comparative to the exterior cladding used in the traditional method to make the building watertight, and this alternative method proves a considerable amount cheaper than the timber frame. Another area of comparison is the finishes. By using prefabricated SIPs they can be left as is, removing the cost of installing GIB, plaster and paint. The CLT floors can also be left exposed. As mentioned in project Elemental, less money spent on the finishing means more money can be spent in other areas. All other costs such as services, windows etc. haven't been compared because they are assumed to be the same as a traditional build.

Please note:

M2 rates for the traditional method building elements were obtained from Rawlinson's Construction Handbook 2012 (Rawlinsons, 2012). These rates are for a moderate quality two-storey building of similar size so therefore appropriate for comparison. Also note, these prices have added inflation.

M2 rates for the alternative method were gained from suppliers as well as a material cost from Bunnings for the Polycarbonate cladding. 


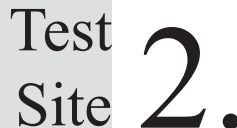

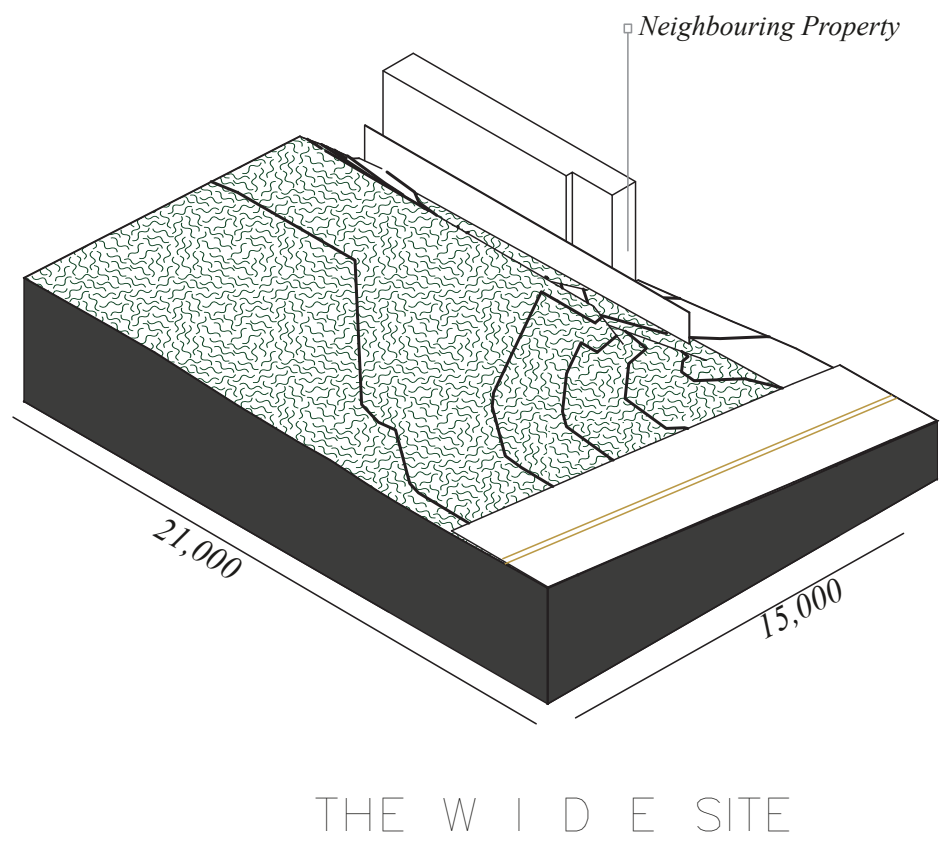

$\wedge$ Figure 102./ Diagram explaining the Wide Site and its characteristics. 


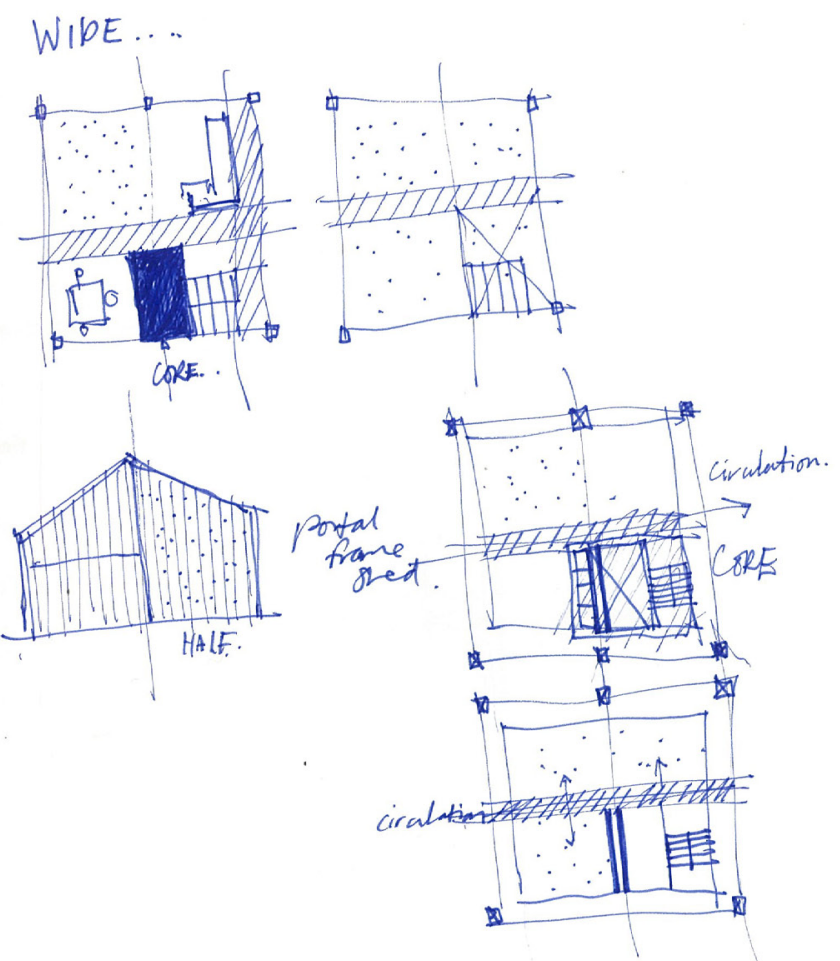

Figure 103./ Sketches explaining the tactics used for the Wide Site. 


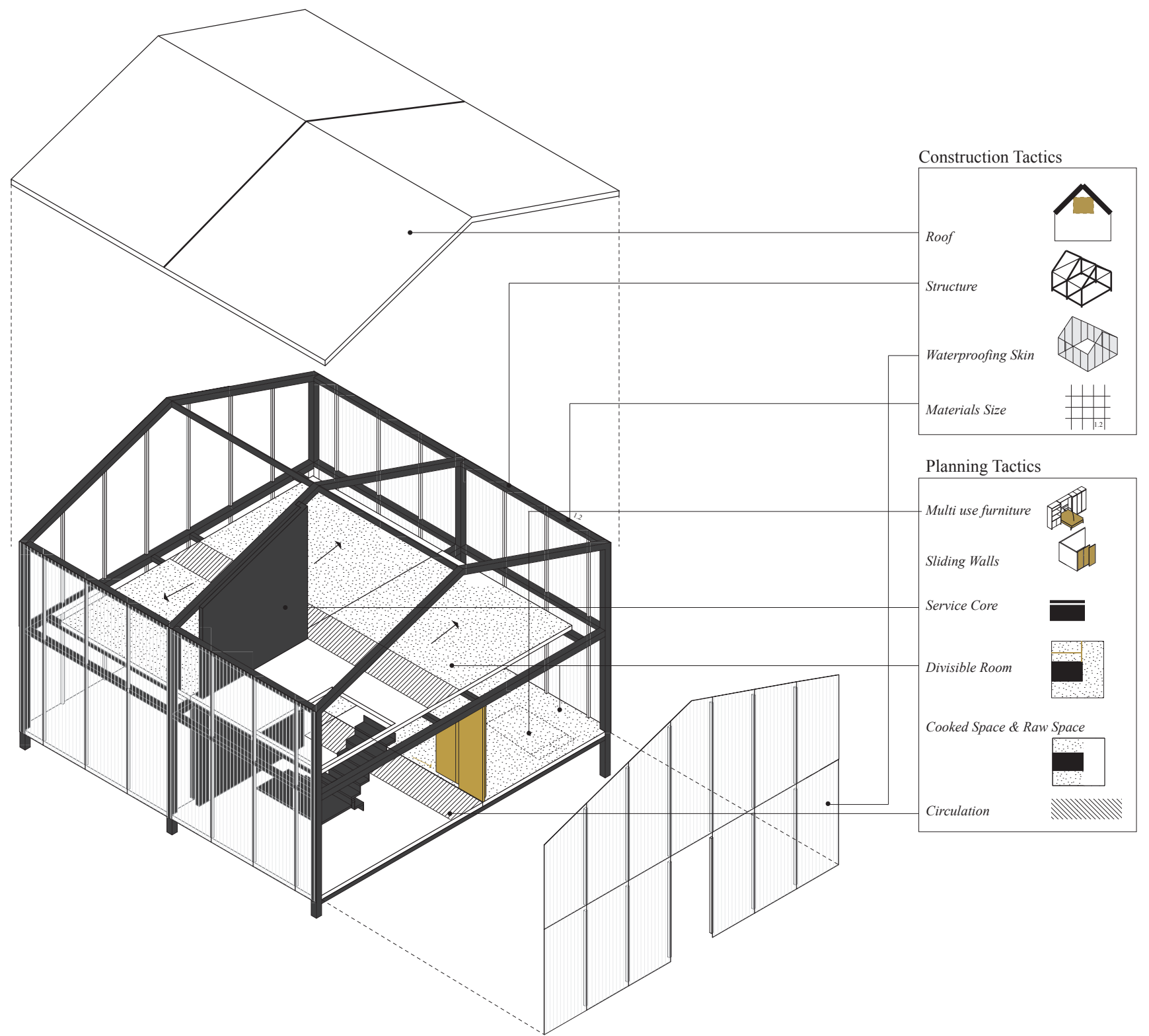

$\bigwedge$ Figure 104. / Flexible design and incremental construction tactics used. 


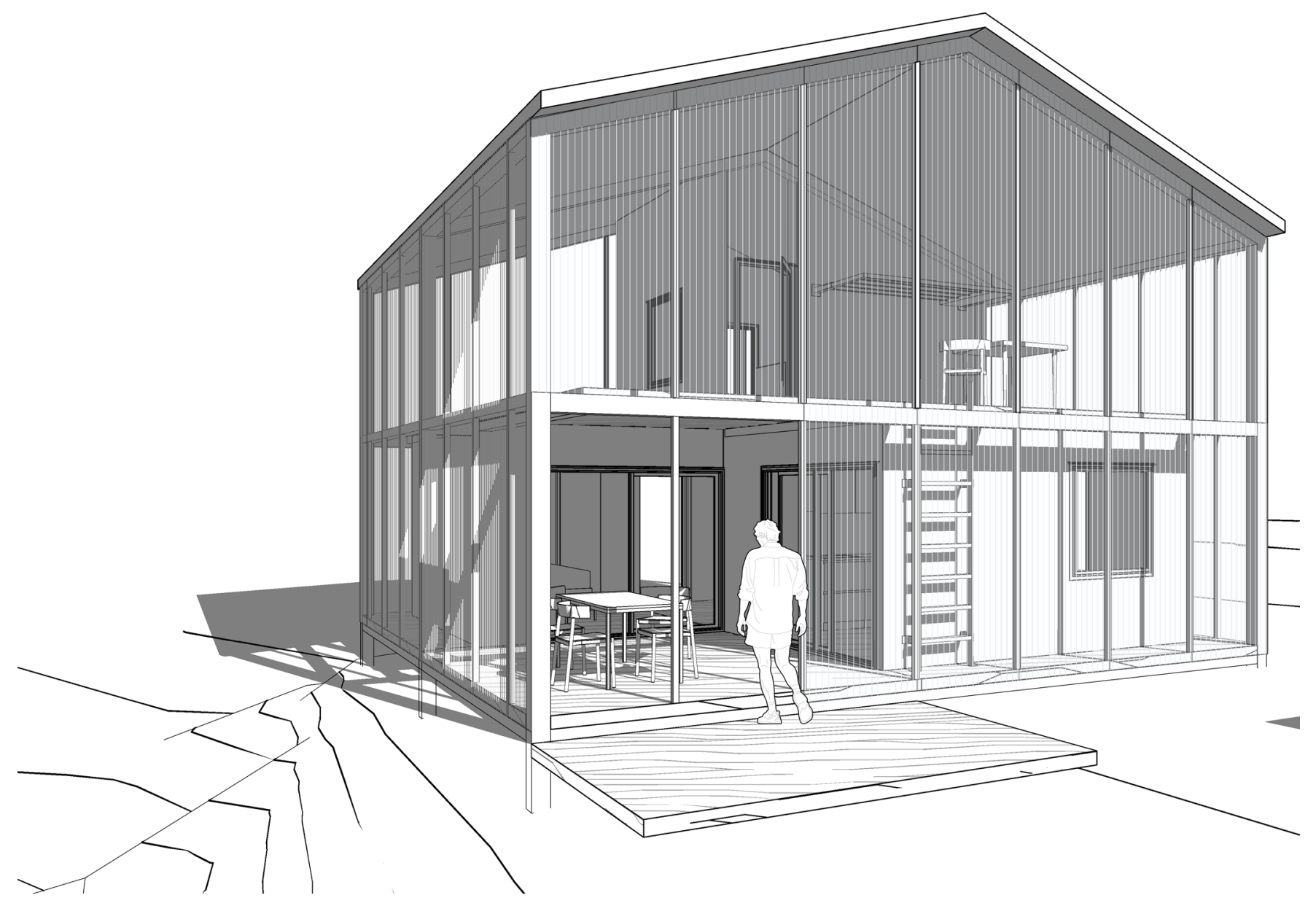




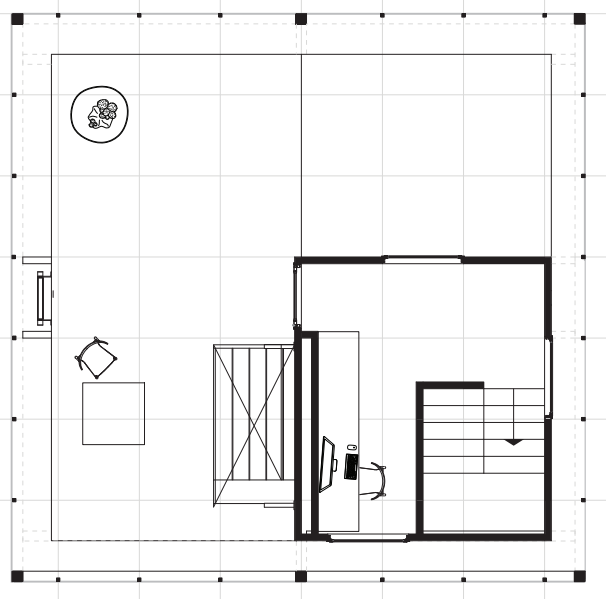

8
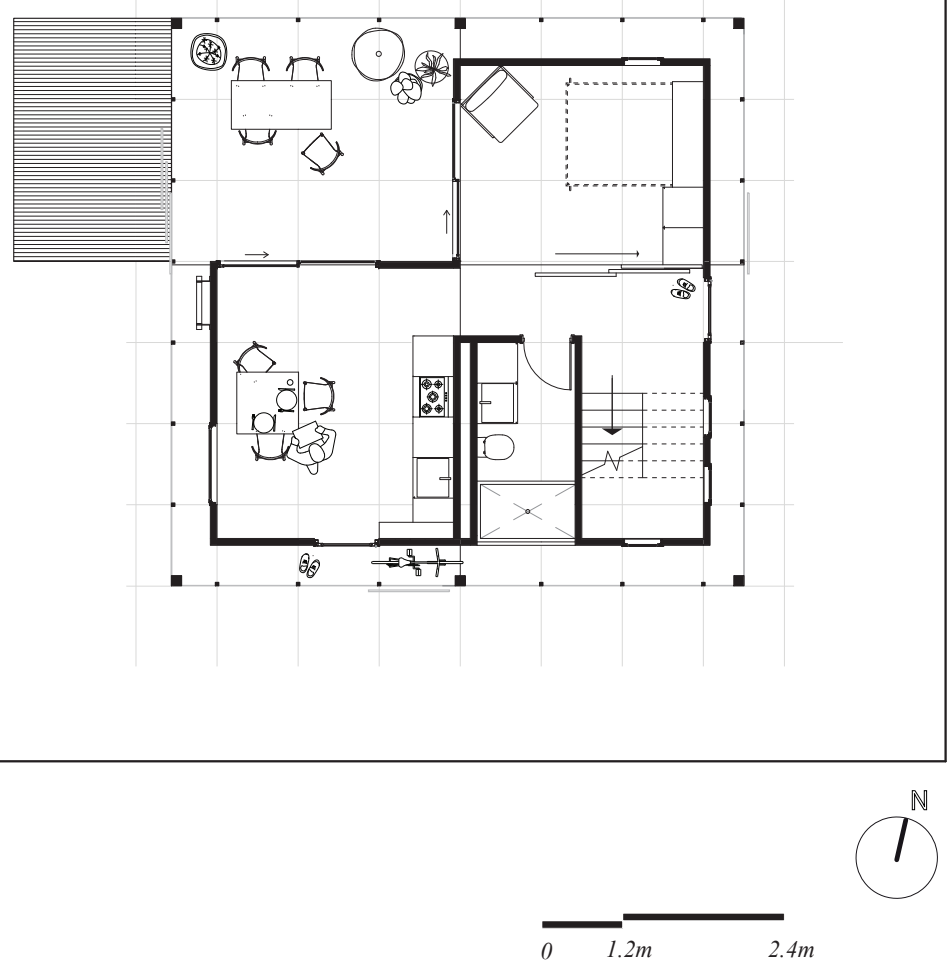


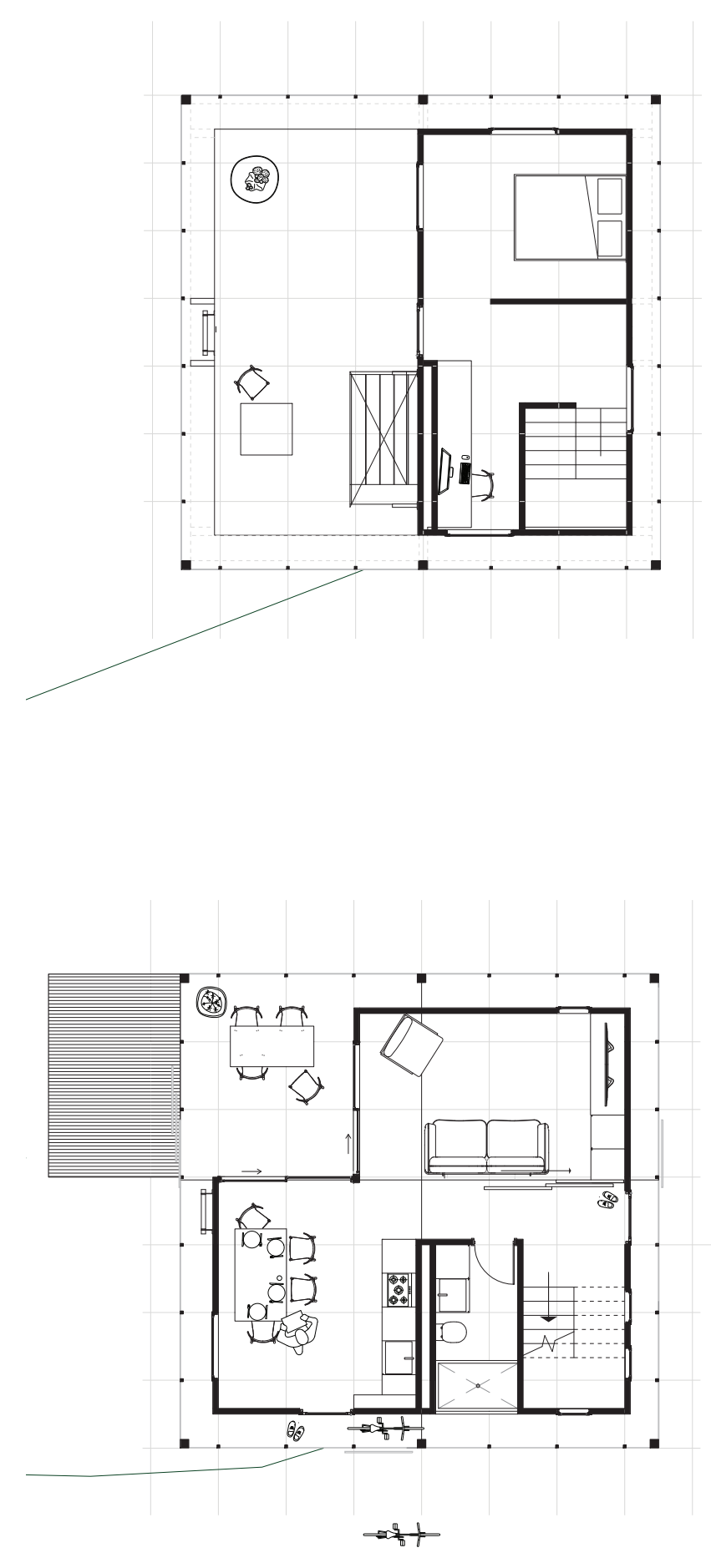

$\wedge$ Figure 107. / Plan Stage 2. 


\section{${ }_{\text {Site }}^{\text {Test }} \& 4$.}
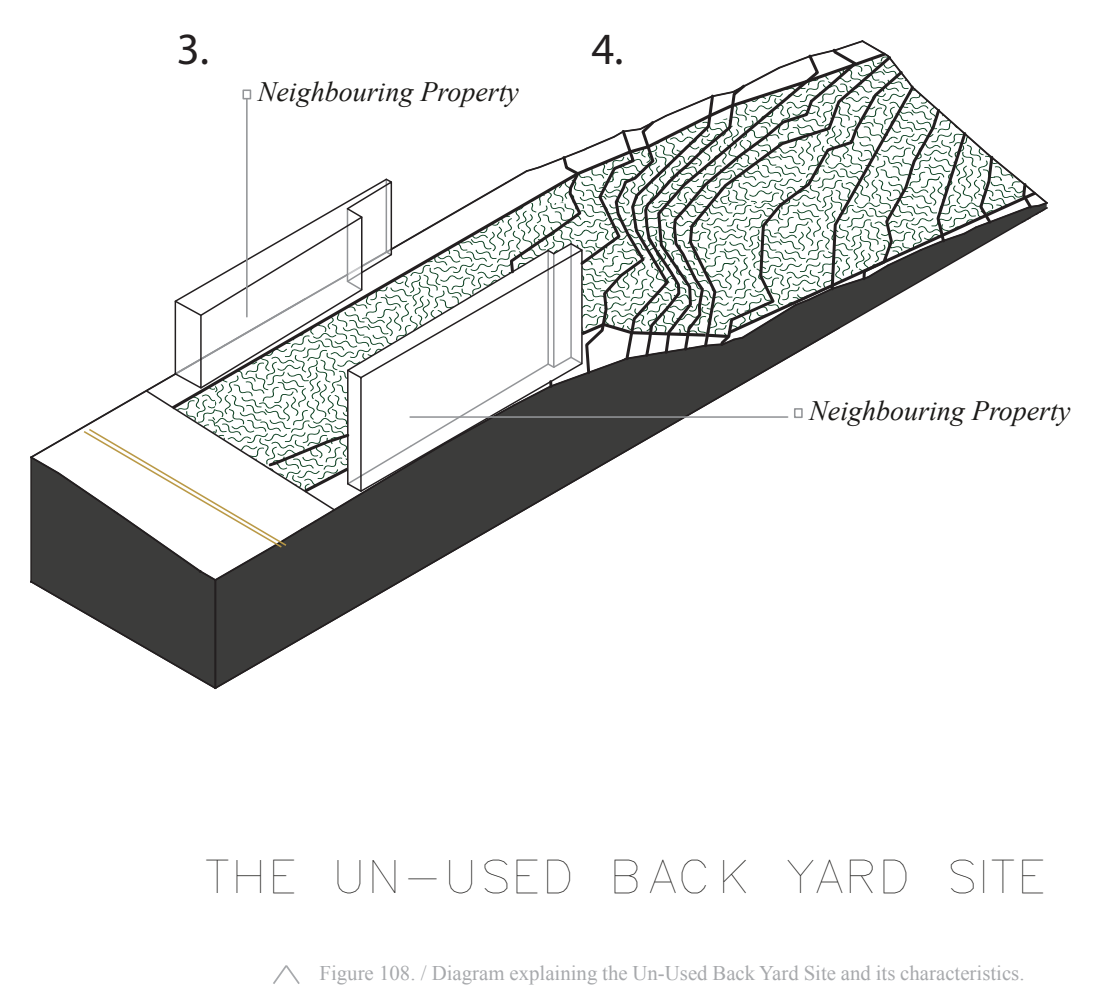


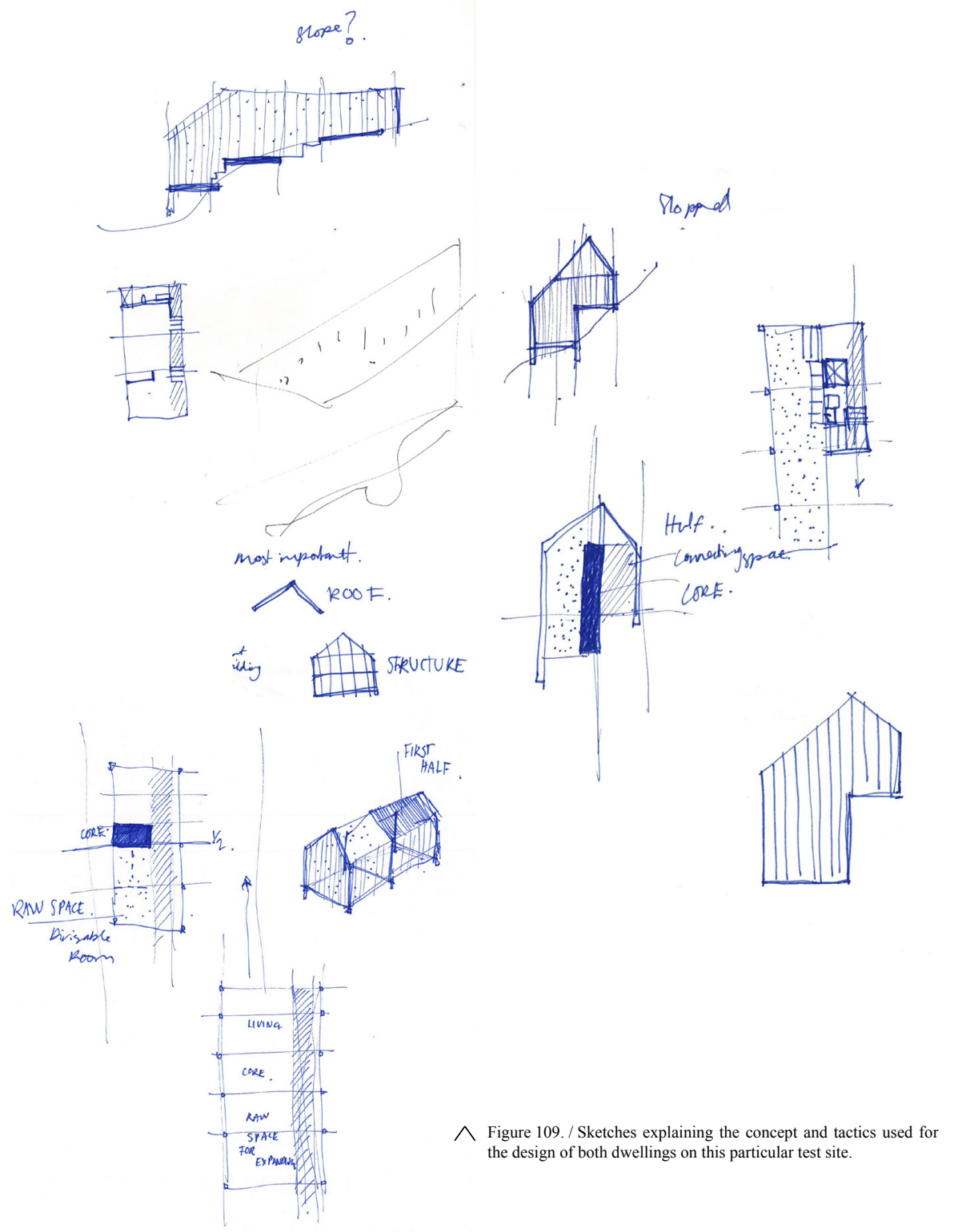




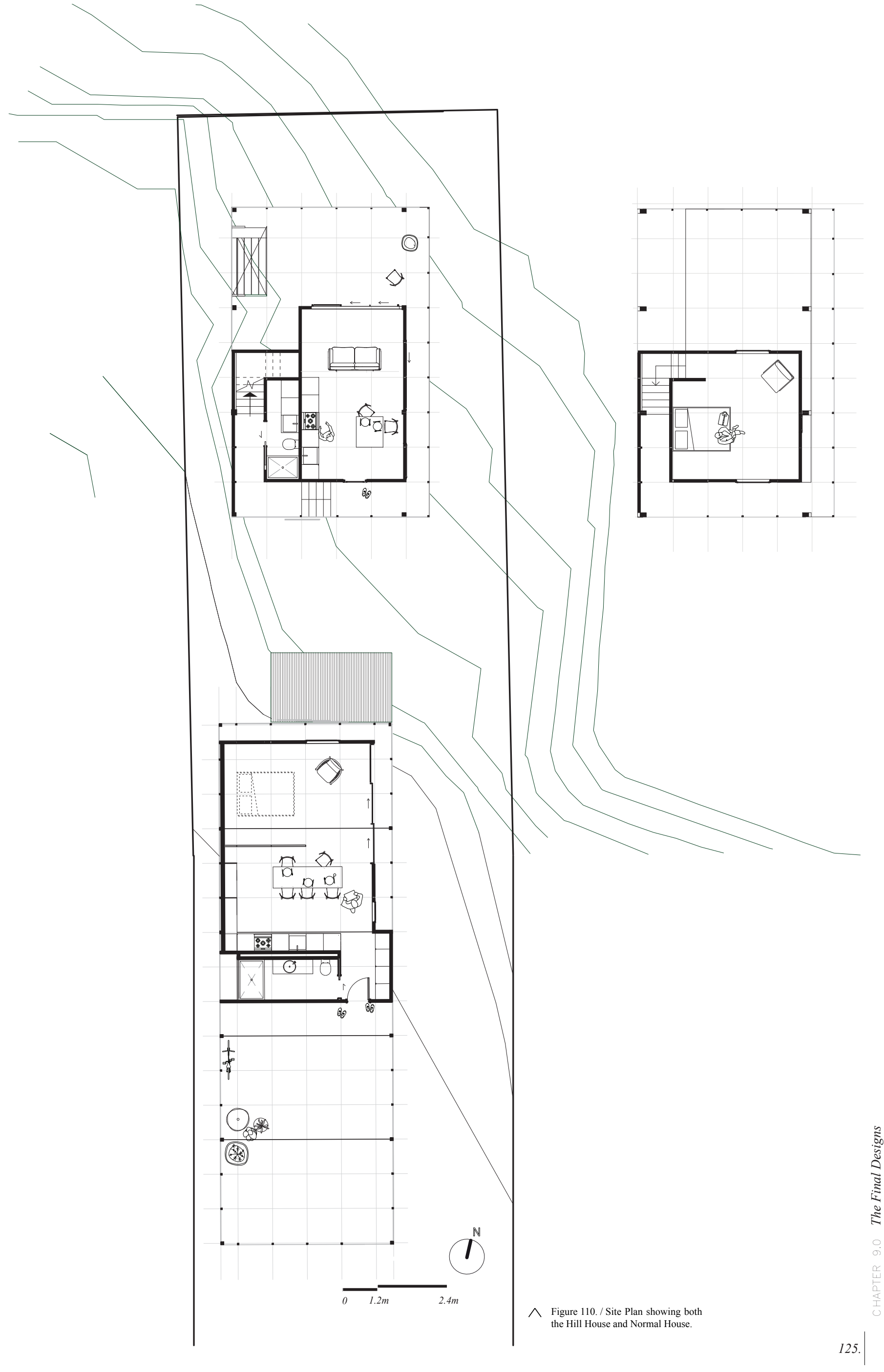




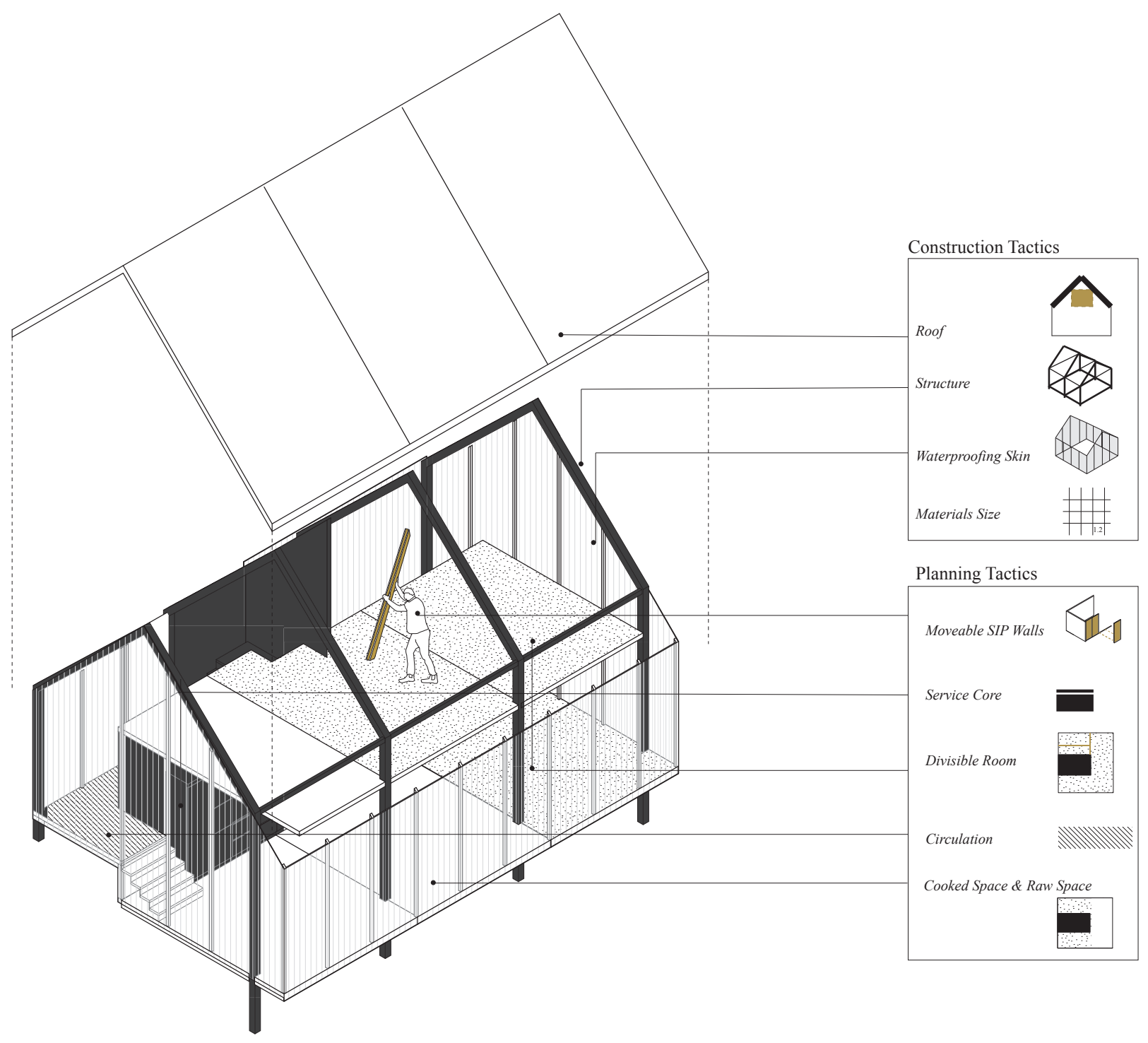




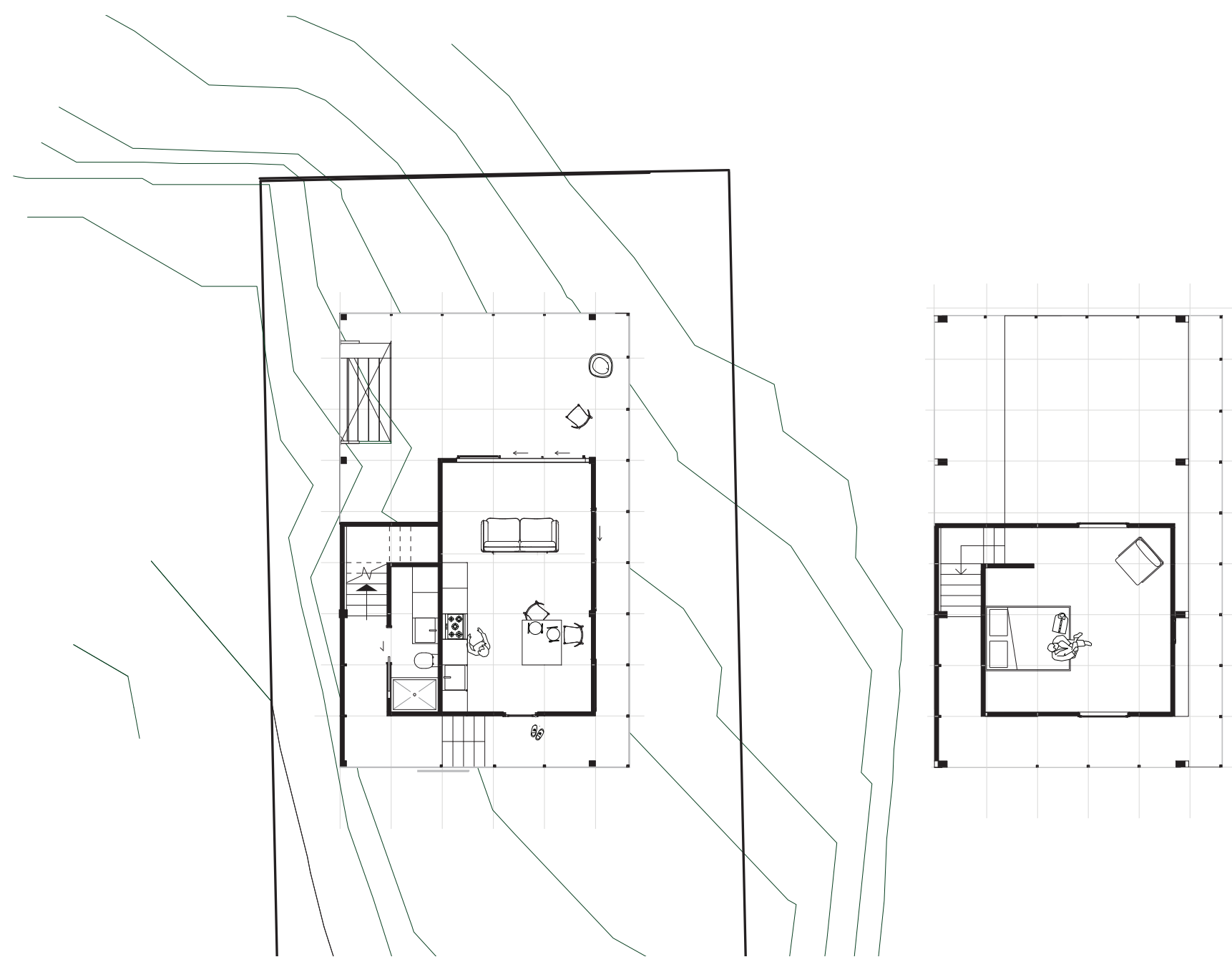

Figure 112. / Hill House Plan. 


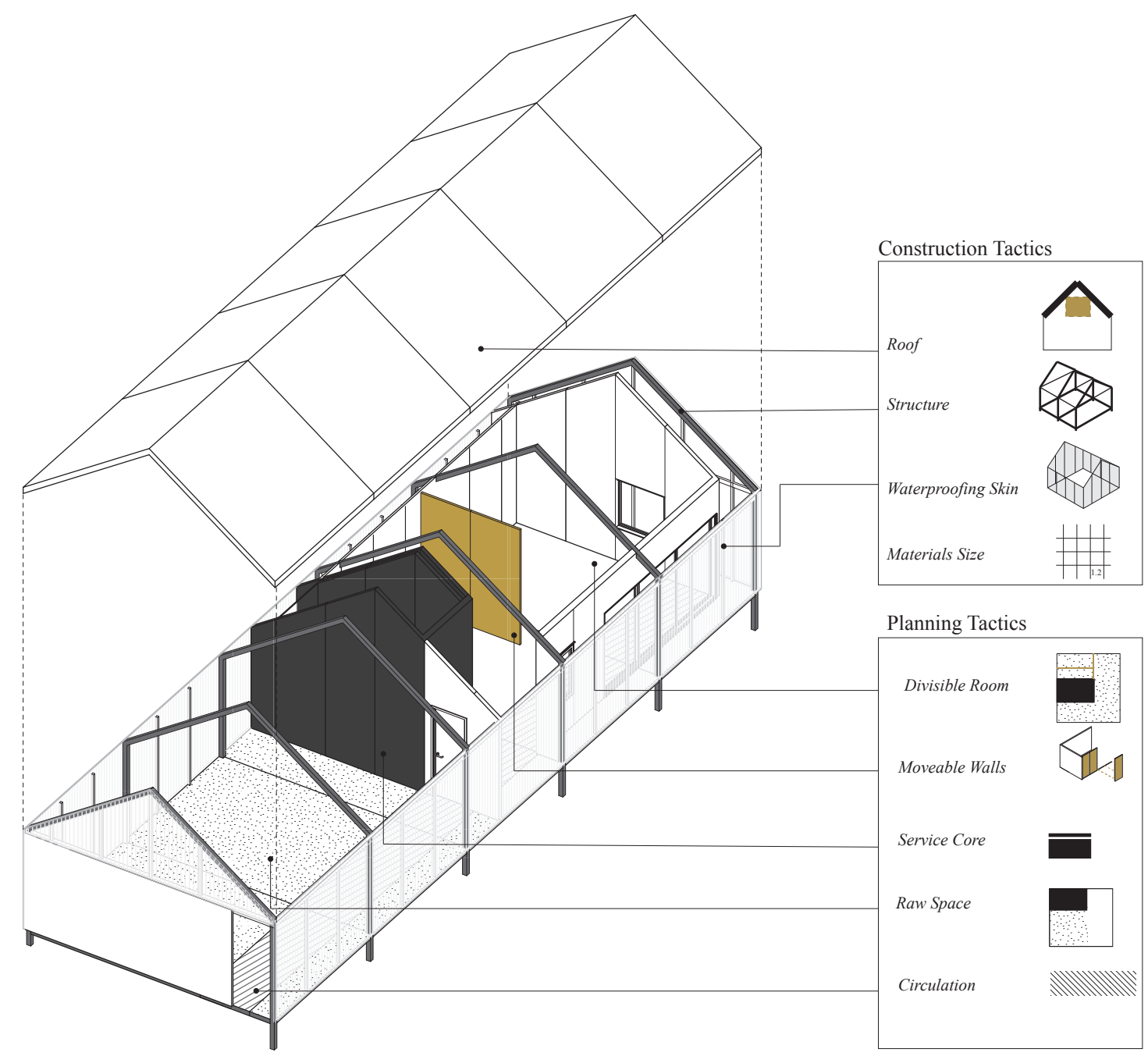

$\bigwedge$ Figure 113. / Flexible design and incremental construction tactics used. 


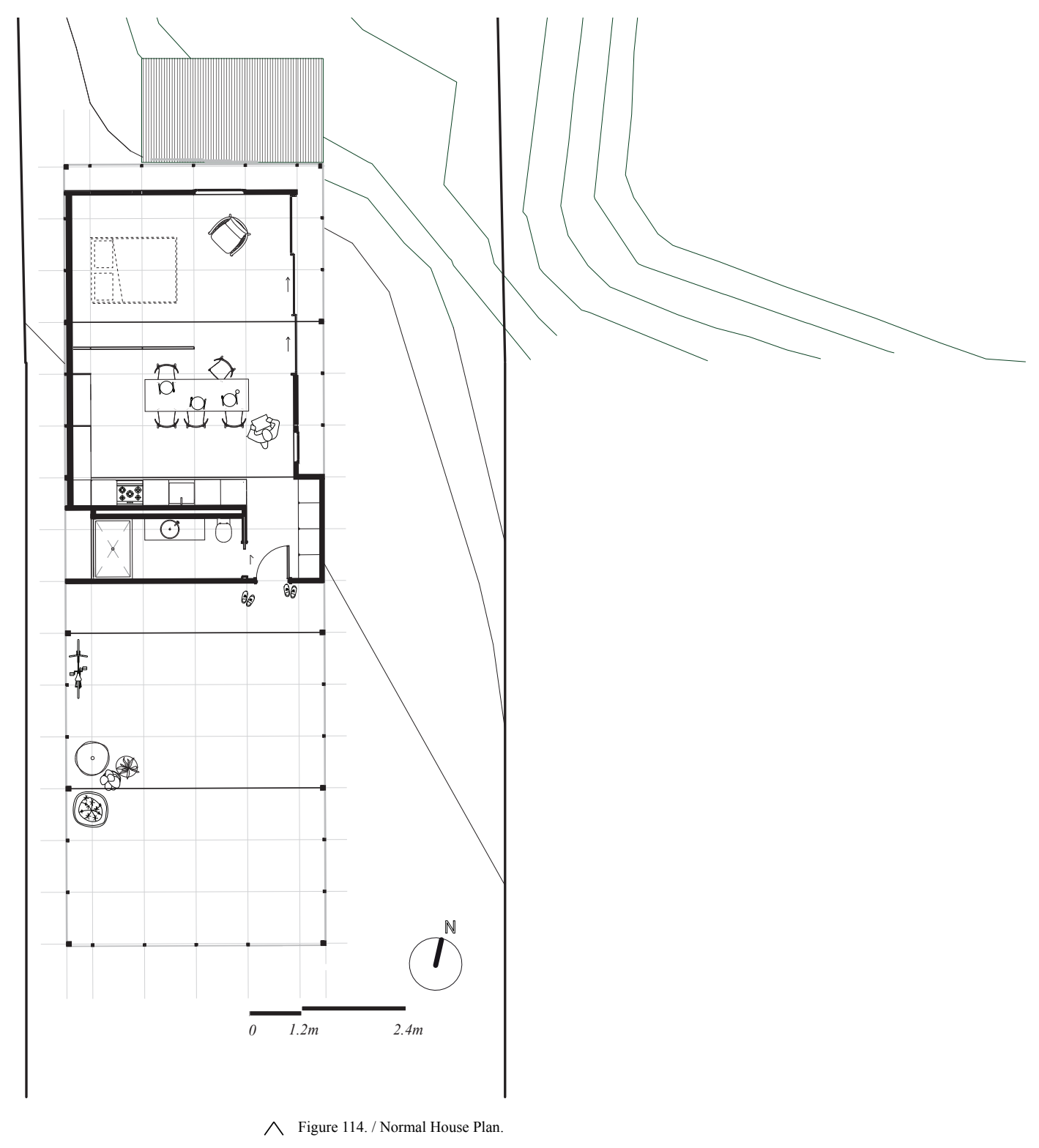




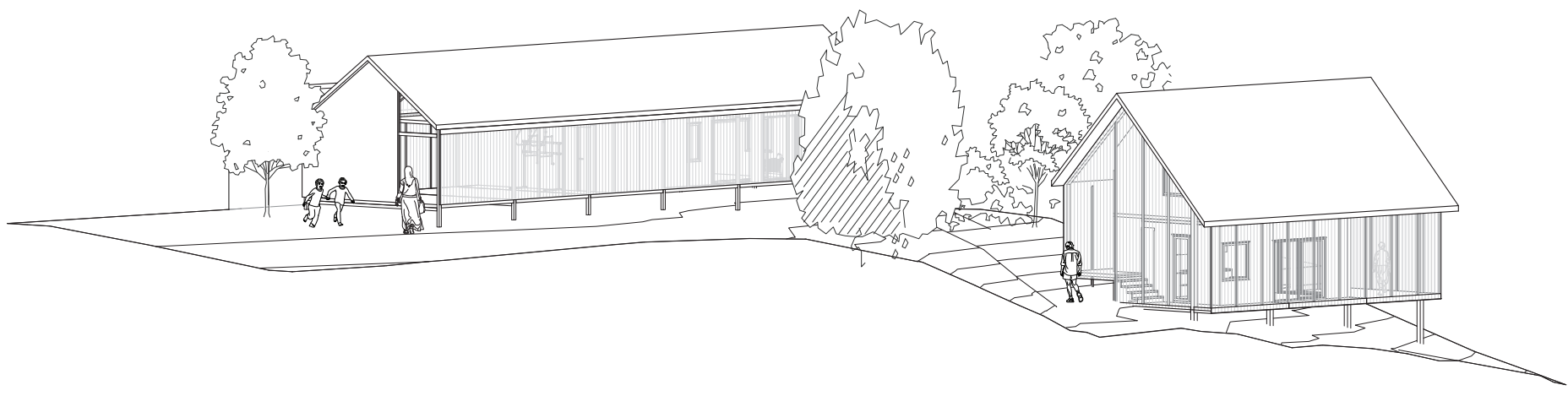

$\wedge$ Figure 115. / Exterior view of the two dwellings 
10.0 CONCLUSION. 
This research portfolio has suggested an alternative housing solution that offers an affordable way for young people seeking homeownership to enter the property market. It is grounded in a research problem, New Zealand's home ownership ideal despite the reality for many young kiwis being priced out and locked out of the current property market. We have a fixation with the idea bigger is better when it comes to housing and people are constantly playing musical houses because houses are static entities and are often unsuitable for our ever-changing needs. The dream of homeownership is further affected by the high price for a place to call home and the cost of building using the traditional timber frame method is ever increasing and continues to produces homes that are static entities irresponsive of change.

These are important uses that need to be resolved through design. The architectural discipline needs to address this problem by revisiting the current methods of construction and look to overseas examples of incremental and flexible housing that can create a more responsive design is accepting of the users' needs and financial circumstances. Architecture needs to address these issues and strive to propose alternative housing strategies so the dream of homeownership becomes obtainable for young people in New Zealand. This research portfolio ultimately addresses these issues and the need for everyone to have access to a decent home at a price they can afford. 
There is no one-fit solution that answers the question this research portfolio is asking. There is not one simple solution as to how flexible design and incremental construction approaches can be applied in the New Zealand context. This is why multiple tactics have been created to answer the research question. The tactics combine design and construction strategies analysed in precedents and literature to present a way of achieving the aims of this research portfolio. They have been developed with the intention of being applied to a range of sites typical to the New Zealand context to provide an alternative housing solution that addresses housing affordability. These approaches needed to be applied to a range of different test sites and each test site presented different ground conditions, orientation and size, therefore, proving the research is applicable to varying situations. As well as be applicable to different sites, the tactics can also work for a range of different scales from the whole dwelling, to just an element or a room.

A house that uses flexible design and incremental construction tactics allows users to add as they can afford. Adding as you can afford could be seen as a way of dealing with housing affordability in New Zealand. A dwelling that has been designed using flexible design and incremental construction tactics creates an opportunity to expand as and when the money and/or materials become available and averts the necessity to move which can be costly in terms of finances and time. A house that uses flexible design and incremental construction techniques is also responsive to the changing needs and financial circumstances of its users.

Separating layers such as the structure, waterproof shell inevitably makes the building more flexible. Normal construction binds layers together so that changing one layer means dealing with all the other layers. This is the reason renovations and changes to existing design end up being costly and difficult in terms of time and money. By creating a house within a shed-like frame and waterproof shell, growth on the inside can easily occur as the users' needs or finances change. Inner partitions which are nonload bearing can easily be changed and rearranged to accommodate new uses while the layers such as the structure and waterproof shell remain unaffected.

If money is invested in prefabricated materials that require less labour and fewer costs associated with finishes then the overall build costs can be less. Creating a polycarbonate shell made from a shed-like frame will also lessen the build cost even more. The cost comparison of materials for this alternative way of building compared to the traditional timber frame proves that this research portfolio provides an alternative housing solution that addresses housing affordability. 
The cost of land hasn't been factored into this research portfolio and could prove to be a major factor affecting the overall project costs. A more thorough cost breakdown which goes beyond material costs and considers things such as labour, permit and consent costs needs to be carried out. Unfortunately, my expertise didn't allow me to obtain these costs but it would be necessary to identify costs that could be further reduced. A full price estimate that goes beyond material costs and starts to factor in elements such as labour, consents and land is the next step in this research and the research would be strengthened if these costs were figured out.

It would also be useful to measure how the costs would vary over a period of time. Build costs would be larger at the beginning but over time, the ongoing costs would be minimal not to mention the cost of making additions would be extremely low because the flexible design and incremental construction of the dwelling would make these changes a lot easier and cheaper.

The mass production of prefabricated building components needs to be more developed in New Zealand to reduce the costs of these components even further. What if Bunnings started selling SIPs? What if companies such as Kiwi Span or Total Span branched out from shed design to creating an affordable housing solution? They mass produce sheds at reasonable prices so why can't they continue to mass produce the shed like frame shown in the design outcome of this research to provide more affordable housing. If larger companies could provide the prefabricated materials, they could become more standardised instead of custom and therefore more accessible for New Zealanders. 

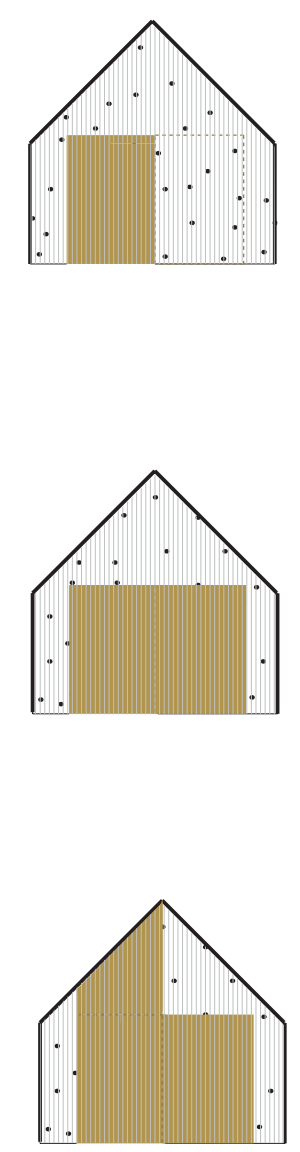

A HOUSE THAT GROWS ON THE INSIDE 
This page is intentionally left blank. 


\subsection{BIBLIOGRAPHY \& FIGURE LIST}


Aravena, A., \& Lacobelli, A. (2012). Elemental. Incremental Housing and Participatory Design Manual. Germany: Hatje Cantz Verlag.

Baracco, M., \& Wright, L. (2017). Robin Boyd: Spatial Continuity (R. Boyd Ed. 1 ed.): Routledge.

Bell, P. (2009). Kiwi Prefab: Prefabricated Housing in New Zealand. (Master of Architecture), Victoria University of Wellington, Wellington.

Bell, P. (2010, June / July). Prefab Housing: Potential for Development. BUILD, 44-45.

Bell, P. (2016). Smart, fast service pods. BUILD, 154.

Bergdoll, B., \& Christensen, P. (2008). Home Delivery. New York: The Museum of Modern Art.

Brand, S. (1994). Shearing Layers How Buildings Learn (pp. 12- 24). London: Phoenix Illustrated.

Cache, B. (1995). Earth Moves: The Furnishing of Territories (A. Boyman, Trans. M. Speaks Ed.). The MIT Press: Cambridge, London.

Cheap start homes with style (2009). Retrieved from http://www.stuff.co.nz/national/ politics/2305522/Cheap-starter-homes-with-style

Downtown, P. (2003). Design Research. Melbourne: RMIT University Press.

Eaqub, S., \& Eaqub, S. (2015). Generation Rent. Wellington: Bridget Williams Books.

Engawa. (n.d.). Retrieved from https://www.definitions.net/definition/engawa

EPSE. (2012). Polycarbonate sheets: Light in weight and light on the environment, heavy on savings. Retrieved from http://www.epse.org/polycarbonate-sheets-light-weight-andlight-environment-heavy-savings

Formance. (N.d.). Why Sips. Retrieved from http://www.formance.co.nz/why-sips/\#top

Greenspan, S. (2016). Half a House. Retrieved from https://99percentinvisible.org/episode/halfa-house/

Habraken, N. J. (1972). Supports : An Alternative to Mass Housing. London: The Architectural Press Ltd.

Hertzberger, H. (2005). Lessons for Students in Architecture. Rotterdam: 010 Publishers.

Hertzberger, H. (2014). Polyvalence: The Competence of Form and Space with Regard to Different Interpretations. Architectural Design, 84(5), 106-113.

Interest New Zealand. (2016). Home loan affordability for first-home buyers - New

Zealand. Retrieved from http://www.interest.co.nz/property/first-home-buyer 
Iskenderoglu, Y. (2009). An Inquiry into the Design Potentials of Le Corbusier's Dom-ino Clusters. (Master of Architecture), Middle East Technical University Turkey.

Jeska, S. (2008). Transparent Plastics. Berlin: Birkahauser Verlag.

Johnson, A., Howden-Chapman, P., \& Eaqub, S. (2018). A Stocktake of New Zealand Housing. Wellington: New Zealand Government.

JYA-rchitects. (2013). Low Cost House / JYA-RCHITECTS. Retrieved from https://www. archdaily.com/440170/low-cost-house-jya-rchitects

Leupen, B. (2005). Towards Time-based Architecture. In B. Leupen, R. Heijne, \& J. v. Zwol (Eds.), Time-based Architecture (pp. 12 - 20). Rotterdam: 010 Publishers.

Leupen, B. (2006). Frame and Generic Space. Rotterdam 010 Publishers.

Marriage, G. (2010). Minimum vs Maximum Paper presented at the 2010 Australasian Housing Researchers' Conference, Sydney.

McGuirk, J. (2014). The perfect architectural symbol for an era obsessed with customisation and participation. Retrieved from Dezeen website: https://www.dezeen.com/2014/03/20/ opinon-justin-mcguirk-le-corbusier-symbol-for-era-obsessed-with-customisation/

Michael Bassett, L. M. (2013). Priced Out. Retrieved from Auckland Council Research and Evaluation Unit website: http://knowledgeauckland.org.nz/publication/ show $/ 931 /$ ?mergedTopics $=40 . \& s=50$

Miller, C. (2017). Home ownership rates lowest in 66 years according to Statistics NZ. Auckland: NZ Herald.

Mullens, M. A., \& Arif, M. (2006). Structural Insulated Panels: Impact on the Residential Construction Process. Journal of Construction Engineering and Management, 132(7), 786-794.

New Zealand Productivity Commission. (2012). Housing Affordability Inquiry. Retrieved from New Zealand: http://www.productivity.govt.nz/sites/default/files/Final\%20 Housing\%20Affordability\%20Report_0_0.pdf

Page, I. (2008). New House Price Modelling. Retrieved from Wellington:

Quintal, B. (2014). A Selection of Shigeru Ban's Best Work. Retrieved from https://www. archdaily.com/489222/a-selection-of-shigeru-ban-s-best-work\}

Rawlinsons. (2012). Elemental Costs of Buildings Rawlinsons New Zealand Construction Handbook (pp. 58). Auckland: Rawlinsons Media Limited.

Redman, S. (2016, May 2016). The House That Isn't There. Retrieved from https://www.houzz. co.nz/ideabooks/60912671/list/the-house-that-isnt-there 
Schneider, T., \& Till, J. (2005). Flexible housing: Opportunities and limits. Architectural Research Quarterly, 9(2), 155-167.

Schneider, T., \& Till, J. (2007). Flexible Housing. Oxford: Elsevier Inc.

Schrader, B. (2012). Housing and government - A property-owning democracy. Retrieved from Te Ara website: http://www.TeAra.govt.nz/en/zoomify/32429/encouraging-home-ownership

Starter Homes. (2009). Retrieved from http://architecture.org.nz/2009/04/14/starter-homes/

Statistics NZ. (2007). Reasons for moving within and between regions. Retrieved from Wellington:

Statistics NZ. (2016). National family and household projections. Retrieved from Population projections overview website: http://archive.stats.govt.nz/browse_for_stats/population/ estimates_and_projections/projections-overview/nat-family-hhold-proj.aspx

Statistics NZ. (2017). Dwelling and household trends: 1991-2017. Wellington: Statistics New Zealand Retrieved from http://archive.stats.govt.nz/browse_for_stats/population/ estimates_and_projections/dwellings-household-trends-1991-2017.aspx\#dwelling.

Villa Verde Housing / ELEMENTAL. (2013). Retrieved from https://www.archdaily.com/447381/ villa-verde-housing-elemental 
All figures not attributed are author's own.

Figure 7 State Advances Corporation. (1950), Home Ownership. Retrieved from Te Ara website: http://www.TeAra.govt.nz/en/zoomify/32429/

encouraging-home-ownership

Figure 8 GJ Gardner Homes. (2017), Affordable Wellsford. Retrieved from GJ Gardner Website: https://www.gjgardner.co.nz/english/listings/affordablewellsford

Figure 9 Stuff NZ. (2018), Online Poll Results. Retrieved from Stuff website: https:// www.stuff.co.nz/life-style/homed/latest/96755666/housing-crisis-documentarypulls-no-punches-on-eve-of-election

Figure 12 First Light Studio. (2016), UNIpod. Retrieved from Prefab NZ website: http:// www.prefabnz.com/Projects/Detail/unipod

Figure 32 Shigeru Ban Architects. (2000), SBA Naked House. Retrieved from Shigeru Ban Architects website: http://www.shigerubanarchitects.com/works/2000_nakedhouse/index.html

Figure 35 Oskar Leo Kaufmann. (2008), System 3. New York. Retrieved from Olkaufmann website: http://www.olkaufmann.com/work/08-system3-new-york/

Figure 38 Chia, S. (Photographer). (2013), Villa Verde Housing / ELEMENTAL. [Digitial Image]. Retrieved from Arch Daily website: https://www.archdaily.com/447381/ villa-verde-housing-elemental

Figure 41 HMA. (2009), Starter Homes Design Competition Module 1.2. Retrieved from http://architecture.org.nz/2009/04/14/starter-homes/

Figure 44 Hyochel, H. (Photographer). (2013), Low Cost House / JYA-RCHITECTS. [Digital Image]. Retrieved from Arch Daily: https://www.archdaily.com/440170/ low-cost-house-jya-rchitects

Figure 47 Attali, E. (Photographer). (2016). Baracco + Wright Architects Garden House. [Digital Image]. Retrieved from DIVISARE: https://divisare.com/ projects/325654-baracco-wright-architects-erieta-attali-garden-house

Figure 62 Ibid

Figure 63 [Untitled photo of SIP installation]. (n.d.) Retrieved from Premier SIPS NZ website: http://www.premiersips.co.nz/ 
